NASA/TM-2012-217632

Structural Analysis and Optimization of a Composite Fan Blade for Future Aircraft Engine

Rula M. Coroneos

Glenn Research Center, Cleveland, Ohio 


\section{NASA STI Program . . . in Profile}

Since its founding, NASA has been dedicated to the advancement of aeronautics and space science. The NASA Scientific and Technical Information (STI) program plays a key part in helping NASA maintain this important role.

The NASA STI Program operates under the auspices of the Agency Chief Information Officer. It collects, organizes, provides for archiving, and disseminates NASA's STI. The NASA STI program provides access to the NASA Aeronautics and Space Database and its public interface, the NASA Technical Reports Server, thus providing one of the largest collections of aeronautical and space science STI in the world. Results are published in both non-NASA channels and by NASA in the NASA STI Report Series, which includes the following report types:

- TECHNICAL PUBLICATION. Reports of completed research or a major significant phase of research that present the results of NASA programs and include extensive data or theoretical analysis. Includes compilations of significant scientific and technical data and information deemed to be of continuing reference value. NASA counterpart of peer-reviewed formal professional papers but has less stringent limitations on manuscript length and extent of graphic presentations.

- TECHNICAL MEMORANDUM. Scientific and technical findings that are preliminary or of specialized interest, e.g., quick release reports, working papers, and bibliographies that contain minimal annotation. Does not contain extensive analysis.

- CONTRACTOR REPORT. Scientific and technical findings by NASA-sponsored contractors and grantees.
- CONFERENCE PUBLICATION. Collected papers from scientific and technical conferences, symposia, seminars, or other meetings sponsored or cosponsored by NASA.

- SPECIAL PUBLICATION. Scientific, technical, or historical information from NASA programs, projects, and missions, often concerned with subjects having substantial public interest.

- TECHNICAL TRANSLATION. Englishlanguage translations of foreign scientific and technical material pertinent to NASA's mission.

Specialized services also include creating custom thesauri, building customized databases, organizing and publishing research results.

For more information about the NASA STI program, see the following:

- Access the NASA STI program home page at http://www.sti.nasa.gov

- E-mail your question to help@sti.nasa.gov

- Fax your question to the NASA STI Information Desk at 443-757-5803

- Phone the NASA STI Information Desk at 443-757-5802

- Write to: STI Information Desk NASA Center for AeroSpace Information 7115 Standard Drive Hanover, MD 21076-1320 
NASA/TM-2012-217632

\section{Structural Analysis and Optimization of a Composite Fan Blade for Future Aircraft Engine}

Rula M. Coroneos

Glenn Research Center, Cleveland, Ohio

National Aeronautics and

Space Administration

Glenn Research Center

Cleveland, Ohio 44135 


\section{Acknowledgments}

This work is supported by the Subsonic Fixed Wing project under NASA's Fundamental Aeronautics Program. The author expresses her sincere appreciation and gratitude to her advisor Dr. Rama S.R. Gorla, Professor at Cleveland State University, for his guidance and valuable suggestions during the research and writing of this project.

This report contains preliminary findings, subject to revision as analysis proceeds.

Trade names and trademarks are used in this report for identification only. Their usage does not constitute an official endorsement, either expressed or implied, by the National Aeronautics and Space Administration.

This work was sponsored by the Fundamental Aeronautics Program at the NASA Glenn Research Center.

Level of Review: This material has been technically reviewed by technical management.

Available from

NASA Center for Aerospace Information 7115 Standard Drive

Hanover, MD 21076-1320
National Technical Information Service 5301 Shawnee Road Alexandria, VA 22312 


\title{
Structural Analysis and Optimization of a Composite Fan Blade for Future Aircraft Engine
}

\author{
Rula M. Coroneos \\ National Aeronautics and Space Administration \\ Glenn Research Center \\ Cleveland, Ohio 44135
}

\begin{abstract}
This report addresses the structural analysis and optimization of a composite fan blade sized for a large aircraft engine. An existing baseline solid metallic fan blade was used as a starting point to develop a hybrid honeycomb sandwich construction with a polymer matrix composite face sheet and honeycomb aluminum core replacing the original baseline solid metallic fan model made of titanium. The focus of this work is to design the sandwich composite blade with the optimum number of plies for the face sheet that will withstand the combined pressure and centrifugal loads while the constraints are satisfied and the baseline aerodynamic and geometric parameters are maintained. To satisfy the requirements, a sandwich construction for the blade is proposed with composite face sheets and a weak core made of honeycomb aluminum material. For aerodynamic considerations, the thickness of the core is optimized whereas the overall blade thickness is held fixed so as to not alter the original airfoil geometry. Weight is taken as the objective function to be minimized by varying the core thickness of the blade within specified upper and lower bounds. Constraints are imposed on radial displacement limitations and ply failure strength. From the optimum design, the minimum number of plies, which will not fail, is back-calculated. The ply lay-up of the blade is adjusted from the calculated number of plies and final structural analysis is performed. Analyses were carried out by utilizing the OpenMDAO Framework, developed at NASA Glenn Research Center combining optimization with structural assessment.
\end{abstract}

\subsection{Introduction}

Advanced composites are becoming the material of choice for aircraft engine components. Using composite materials in aircraft engines enables manufacturers to reduce weight, and improve performance. Advanced composite materials are made with either polymer-, metal- or ceramic matrix and high strength fibers. Polymer matrix composites (PMC) are attractive due to their low weight, high strength and low cost for manufacturing complex shaped components. Since 1975, PMCs have been used in jet engines starting with simple components in the fan and bypass duct. A milestone in PMCtechnology was set by series production of fan blades for the GE90 engine. Their service temperature however was restricted to a maximum of $150^{\circ} \mathrm{C}$, which is not a limitation for a commercial aircraft engine fan blade. Ceramic matrix composites can withstand much higher temperatures and are thus targeted for use in the hot turbine section of the engine, for parts such as guide vanes, turbine blades and shrouds, to allow increase in-service temperatures and reduce cooling requirements.

Fibrous composite properties are ideal for structural applications such as high-performance aircraft engine blades where high strength-to-weight and stiffness-to-weight ratios are needed. These factors, along with the flexibility to select a composite ply lay-up and fiber orientation to minimize the deformation and the stress under high rotational speeds of future aircraft engines, make a sandwich blade construction attractive.

The objective of this project is to perform structural analysis, design and optimization of a sandwich construction of a given NASA baseline metallic fan blade comparable to a future large aircraft engine fan blade. Polymer matrix composite (PMC) face sheet with aluminum core replaces the metallic blade made of titanium where the fiber material is graphite and the matrix is made from intermediate modulus high strength epoxy-resin. Loads applied include combined centrifugal and pressure. Nonlinear optimization 
techniques are used to minimize the overall mass while displacement limitations and ply failure criteria are satisfied. The minimum number of plies for the face sheet is back-calculated using the optimization results. To finalize the task, a final structural analysis is performed to verify the optimized design.

The computer software utilized for analysis and optimization is entitled OpenMDAO (Multi Disciplinary Analysis and Optimization) (Ref. 1) developed at NASA Glenn Research Center (GRC). OpenMDAO is an open-source framework written in Python, providing a number of solvers and optimizers that users can leverage to build their analysis and optimization methods quickly and efficiently. For this project, the structural analysis was performed using MSC/Nastran (Ref. 2) along with two OpenMDAO optimizers NEWSUMT (Ref. 3) and NLPQ (Ref. 4). The content of the report is outlined next.

Description of the baseline finite element model is presented in section 2.0 along with static and dynamic analyses results. In section 3.0, the following topics are described: Formulation of the composite blade design; Grouping of structural elements; Initial ply lay-up configuration; Ply build-up during manufacturing process; Ply failure analysis, and static and dynamic analyses results of the initial composite design. Section 4.0 describes the ply lay-up tailoring using optimization methods, along with the mathematical optimization problem formulation. Optimization results of the composite blade design are presented in section 5.0, including static and dynamic results. Section 6.0 describes the discrete optimization process to obtain the number of plies. Final analysis results and discussion of the optimized composite blade are presented in section 7.0 along with comparison of the initial and final ply lay-up shapes. Final static and dynamic analyses results are also presented in this section. Conclusions are summarized in section 8.0 followed by references.

\subsection{Description of the Baseline Finite Element Blade}

The baseline finite element model adopted for structural analysis and optimization of a composite design is a NASA fan blade sized for large aircraft engine, as shown in Figure 1. There are 18 fan blades in the metallic baseline design, each with a total mass excluding the hub of $101 \mathrm{lb}$. The blade span length is $48.5 \mathrm{in}$., the rotating speed is roughly $1536 \mathrm{rpm}$, and the design pressure ratio is 1.35 with a bypass ratio of 16.2. A summary of its geometric and aerodynamic parameters is provided below:

Geometric parameters:

Blade span length $=48.5$ in.

Blade tip chord $=28.8$ in.

Blade base chord $=20.07$ in.

Inner radius $=23$ in.

Outer radius $=71.5$ in.

Aerodynamic parameters:

Revolutions Per Minute $(\mathrm{RPM})=1536$

Tip speed $=1050 \mathrm{ft} / \mathrm{sec}$

Leading Edge (L.E.) tip Mach no. $=1.17$

Design pressure ratio $=1.35$

Bypass ratio $=16.2$

The material of the baseline solid blades is a titanium alloy, Ti-6Al-4V, with elastic modulus, $\mathrm{E}=1.60 \mathrm{E}+7$ psi, Poisson's ratio, $v=0.3$, shear modulus $\mathrm{G}=6.15 \mathrm{E}+6 \mathrm{psi}$, mass density, $\rho=0.16 \mathrm{lb} / \mathrm{in}^{3}$, and yield strength $=1.5 \mathrm{E}+5$ psi. The fan tip diameter is $143 \mathrm{in}$. and the rotation speed is $1536 \mathrm{rpm}$, rotating about the $\mathrm{x}$-axis. The $\mathrm{z}$-axis is aligned with the blade span axis and the $\mathrm{y}$-axis is perpendicular to the $x-z$ plane. The geometry for one blade is meshed with 9,782 8-nodal hexahedral elements with 15,096 nodes, as shown in Figure 2. 


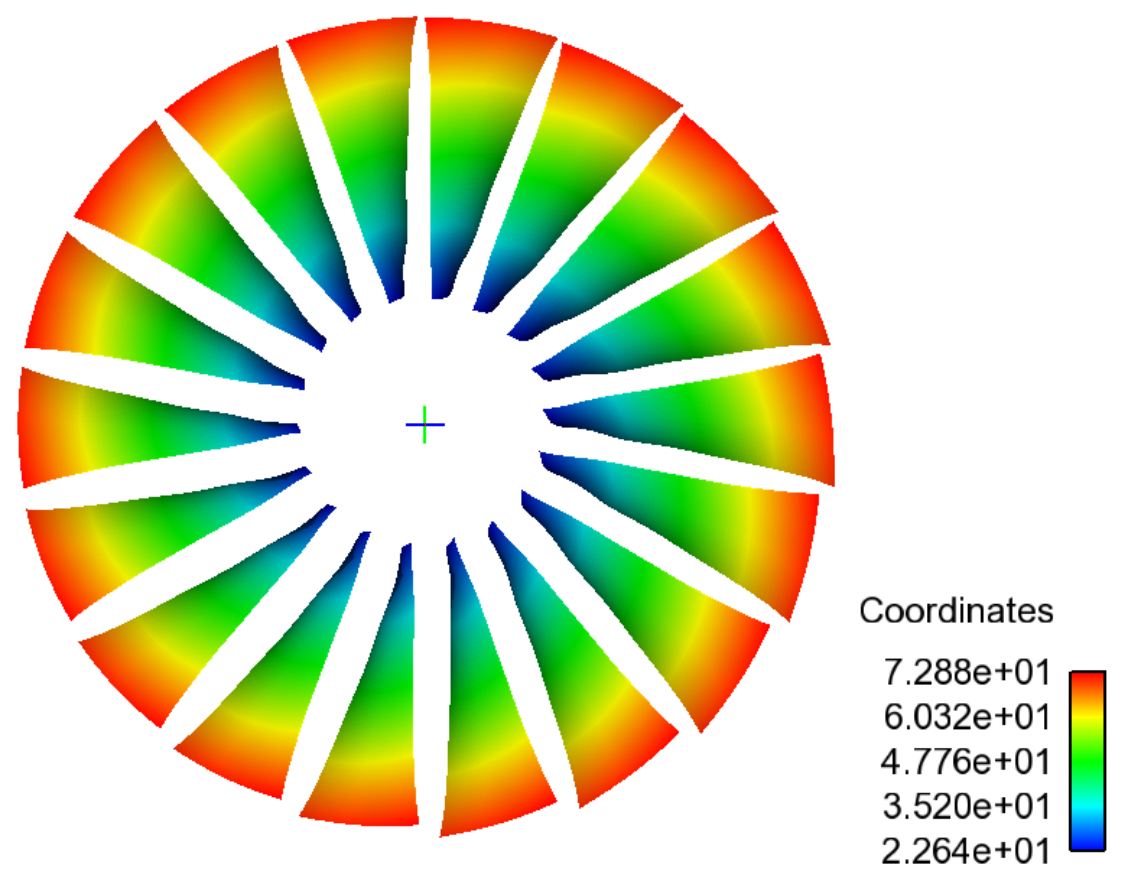

Figure 1.-Baseline model depicting diameter in inches (front view).

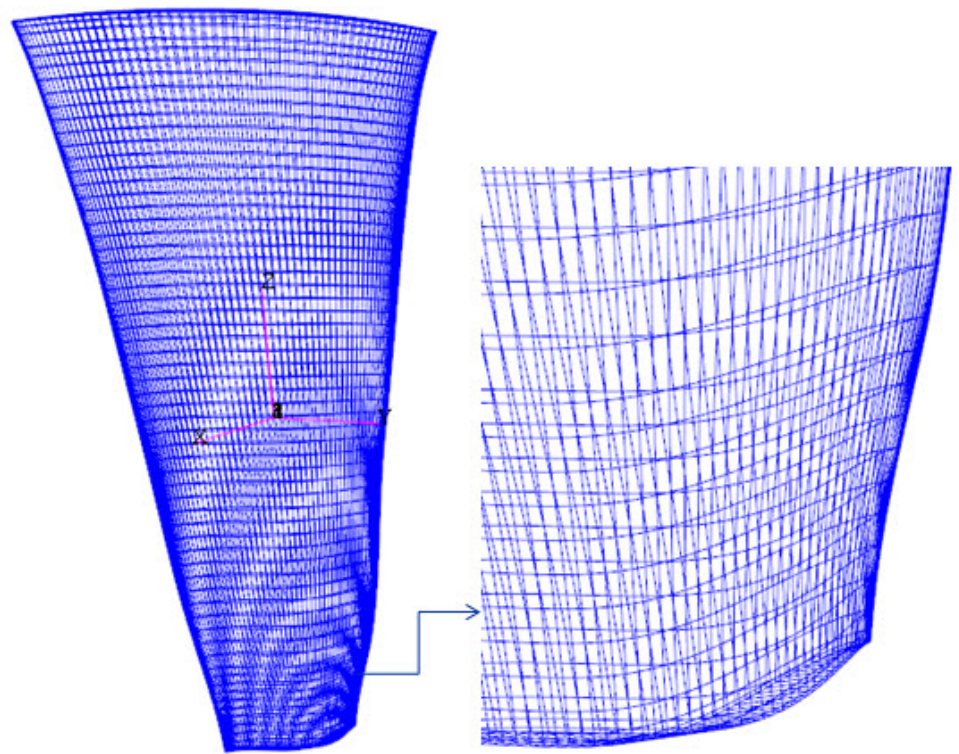

Figure 2.-Finite element model of the baseline fan blade with close up section. 


\subsection{Static Analysis Results of the Baseline Metallic Blade}

Due to symmetry of the geometry and the loading, only a single finite element blade model is used in the analysis and optimization of the solid hexahedral model. The blades are acted upon by pressure loads and centrifugal loads. The design pressure ratio is given at 1.35, with a rotational speed of 1,536 rpm along the $\mathrm{x}$-axis. The pressure load, applied on the top surface of the blade, is calculated by subtracting the outflow pressure from the inflow pressure considering 1 atmospheric pressure, 1 ATM $=14.6959$ psi:

Outflow pressure $=1.35 * 14.6959=19.8395$ psi

Inflow pressure $=14.6959 \mathrm{psi}$

Pressure load $=$ outflow - inflow $=19.8395-14.6959=5.1436 \mathrm{psi}$

Boundary conditions are fixed on all six degrees of freedom (i.e., rotations and translations) at all nodes at the root of the blade. The blade is analyzed using the MSC/Nastran software, a general purpose finite element solver (Ref. 2). From the MSC/Nastran linear static analysis results, SOL 101, the maximum principal stress is found at node 12 at the root section of the blade at 70,299 psi. The maximum shear stress is at 29,131 psi and the displacement resultant is $4.34 \mathrm{in}$. at the tip of the blade. The displacement value in z-direction is $0.819 \mathrm{in}$. The weight of the metallic blade is $100.5 \mathrm{lb}$. The static analysis results of the baseline metallic blade are summarized in Table 1. Post processing is performed utilizing the MSC/Patran (Ref. 5) software. Plots of the stresses and deformations results are depicted in Figures 3 and 4.

\subsection{Dynamic Analysis Results of the Baseline Metallic Blade}

Dynamic analysis (or modal analysis) of the metallic blade is performed to determine its structural natural frequencies and mode shapes with damping neglected. The natural frequencies of a structure are the frequencies at which the structure naturally tends to vibrate if it is subjected to excitation. The deformed shape of the structure at a specific natural frequency of vibration is termed its normal mode of vibration.

From the theory of vibration the natural frequency $\omega$ of 1 DOF oscillator is:

$$
\omega=\sqrt{\frac{k}{m}}
$$

where $\omega$ is the radian frequency, $k$ is the stiffness of the component and $m$ is the mass. From the radian frequency, the natural frequency in $\mathrm{Hertz},(\mathrm{Hz}), f_{n}$, can be found by simply dividing $\omega$ by $2 \pi$ :

$$
f_{n}=\frac{1}{2 \pi} \sqrt{\frac{k}{m}}
$$

TABLE 1.-STATIC ANALYSIS RESULTS FOR THE METALLIC BLADE AND CORRESPONDING WEIGHT

\begin{tabular}{|l|r|}
\hline \multicolumn{1}{|c|}{ Static analysis results } & \multicolumn{1}{|c|}{$\begin{array}{c}\text { Titanium Alloy } \\
\text { Ti-6Al-4V }\end{array}$} \\
\hline Max principal stress, psi & 70299.5 \\
\hline Max shear stress, psi & 29131.0 \\
\hline & \\
\hline Displacement, resultant, in. & 4.34 \\
\hline Displacement, z-direction, in. & 0.819 \\
\hline & 100.528 \\
\hline Weight (lb) & \\
\hline
\end{tabular}




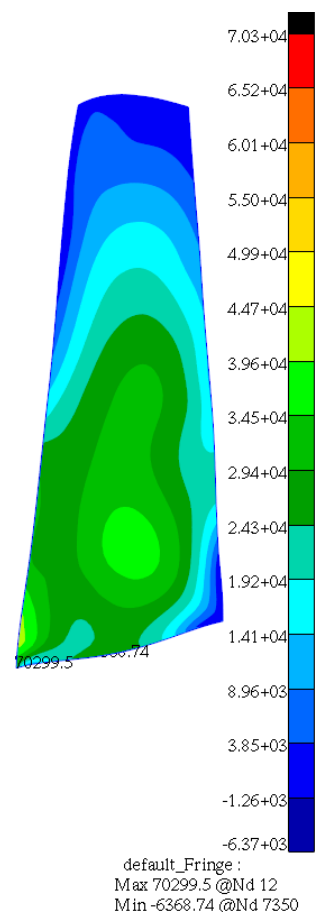

(a) Titanium:

Max Principal Stress $=70,299.5 \mathrm{psi}$

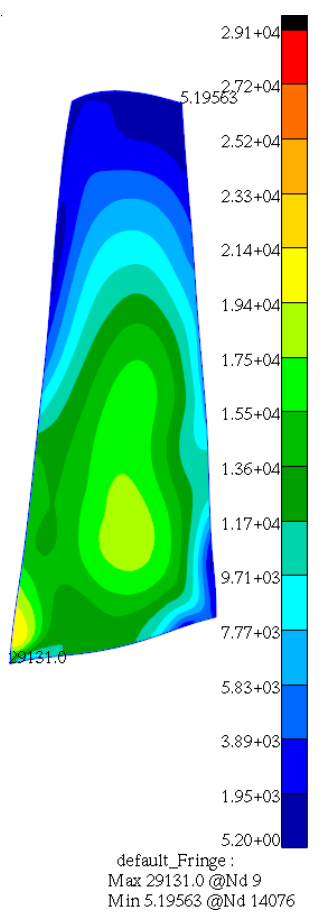

(b) Titanium:

Max Shear Stress $=29,131.0 \mathrm{psi}$

Figure 3.-Stress analysis of the metallic blade (a) maximum principal stress, (b) maximum shear stress.

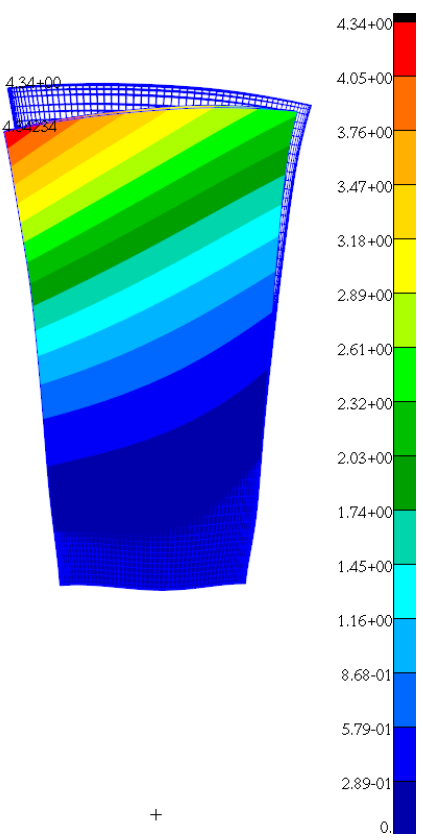

(a) Titanium:

Displacement Resultant $=4.34$ in .

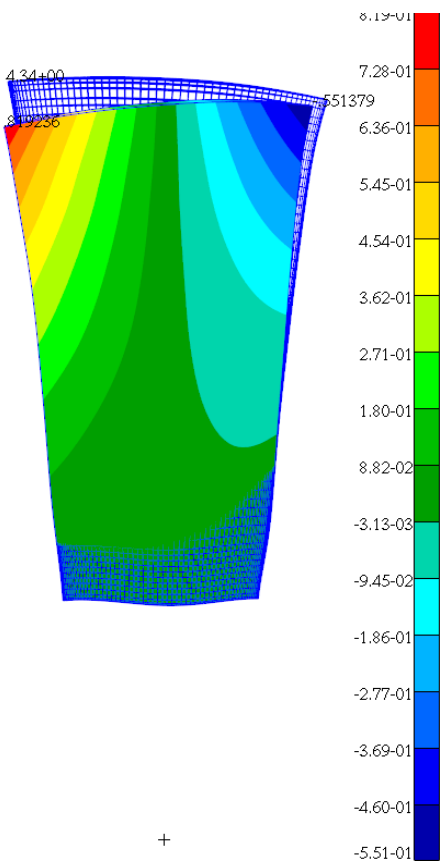

(b) Titanium:

Displacement z-direction $=0.819$ in .

Figure 4.-Deformation results of the metallic blade (a) Displacement resultant,

(b) Maximum displacement in z-direction. 
For the titanium blade:

$$
f_{n}=\frac{1}{2 \pi} \sqrt{\frac{1.2625 E+4}{1}}=17.883
$$

where the $k$ and $m$ are the calculated generalized stiffness and generalized mass values, respectively.

Results of the first six natural modes from the MSC/Nastran dynamic calculations are summarized in Table 2. All six modes are evenly distributed in the frequency domain. The increment of frequency is 40 to $64 \mathrm{~Hz}$. Fringe plots of the first six natural modes are depicted in Figures 5 and 6 . The modes depicted in the figures can be divided into bending modes $\left(1^{\text {st }}, 2^{\text {nd }}, 4^{\text {th }}\right.$, and $6^{\text {th }}$ modes $)$ and torsion modes $\left(3^{\text {rd }}\right.$ and $5^{\text {th }}$ modes $)$.

TABLE 2.-NATURAL FREQUENCIES FOR THE METALLIC NASA FAN BLADE

\begin{tabular}{|c|c|}
\hline Mode number & $\begin{array}{c}\text { Frequency, } \\
\mathrm{Hz}\end{array}$ \\
\hline Mode 1 & 17.883 \\
\hline Mode 2 & 59.339 \\
\hline Mode 3 & 110.762 \\
\hline Mode 4 & 151.209 \\
\hline Mode 5 & 215.544 \\
\hline Mode 6 & 257.562 \\
\hline
\end{tabular}

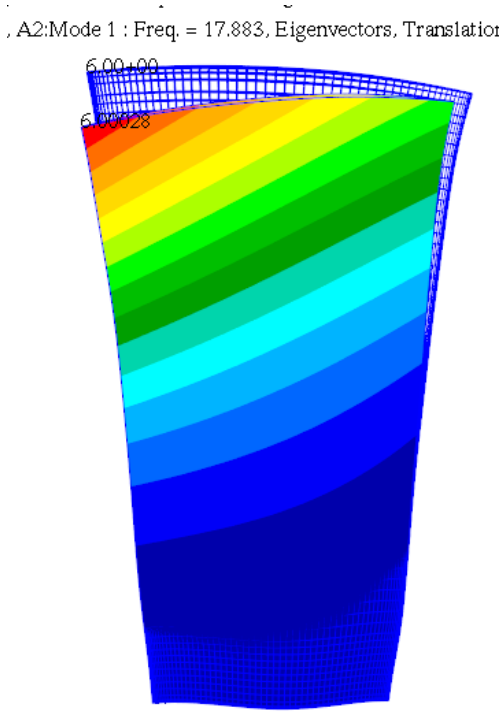

(a) Titanium Mode 1: Frequency $=17.883 \mathrm{~Hz}$
A2:Mode $2:$ Freq. $=59.239$, Eigenvectors, Translational,

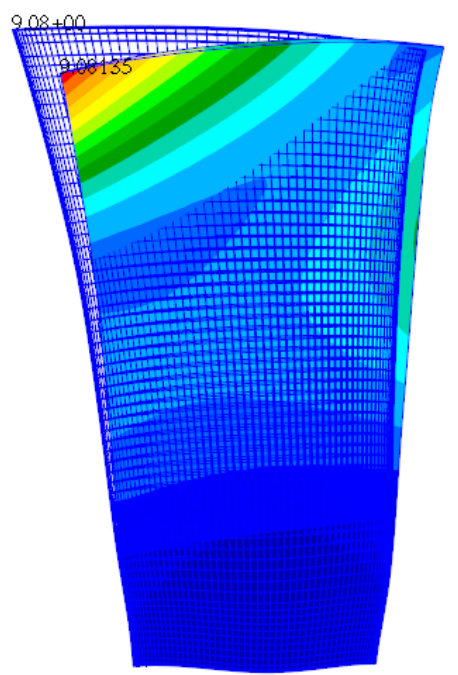

(b) Titanium Mode 2: Frequency $=59.339 \mathrm{~Hz}$
A2: Mode $3:$ Freq. $=110.76$, Eigenvectors, Translatio:

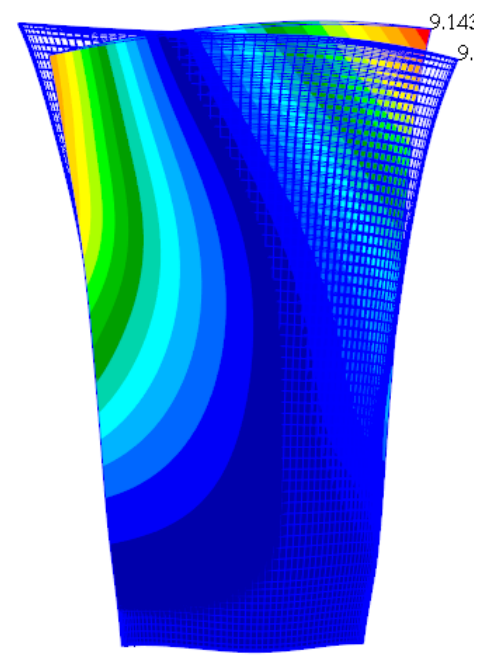

(c) Titanium Mode 3: Frequency $=110.762 \mathrm{~Hz}$

Figure 5.-Mode shapes for the metallic blade: (a) mode 1, (b) mode 2, (c) mode 3. 


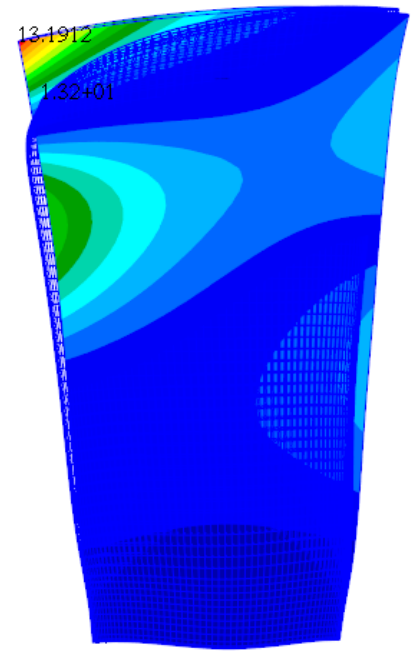

(a) Titanium Mode 4: Frequency $=151.209 \mathrm{~Hz}$

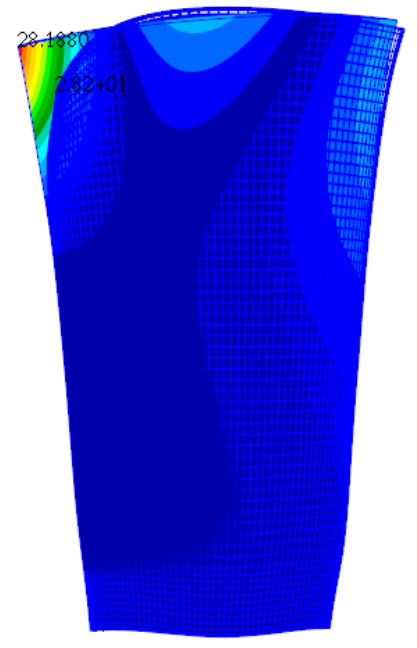

(b) Titanium Mode 5: Frequency $=215.544 \mathrm{~Hz}$

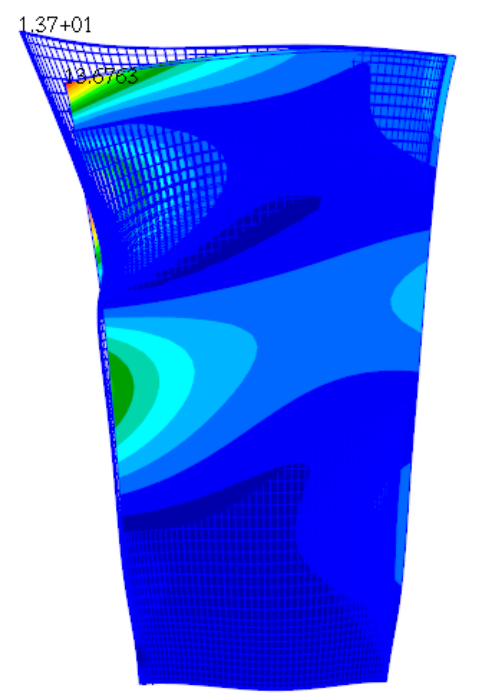

(c) Titanium Mode 6: Frequency $=257.562 \mathrm{~Hz}$

Figure 6.-Mode shapes for the metallic blade: (a) mode 4, (b) mode 5, (c) mode 6.

\subsection{Formulation of the Composite Blade Design}

The baseline solid metallic model was converted into an equivalent two-dimensional shell model and is shown in Figure 7. The conversion to the two-dimensional shell model was required so that the composite laminates could be defined using the layered quadrilateral, CQUAD4 elements with PCOMP (Layered Composite Element Property) in MSC/Nastran (Ref. 2).

The original thickness of each of the elements was maintained by calculating the distance of the coordinate points at the top and bottom surface of the solid model while the middle layer was taken as the face sheet for the two-dimensional shell model. The model conversion was accomplished by using the MSC/Patran (Ref. 5) finite element modeling tool and Fortran programming.

The initial conversion to the two-dimensional quadrilateral mesh created quite a few elements that were out of range, in terms of element aspect ratio and skewness. These elements were all located along the trailing edge and leading edge of the blade as well as at the root and tip of the blade. These caused singularity errors in the static analysis. Therefore, a process was designed to correct the elements and create a new mesh by merging a dozen or more elements at leading and trailing edges including the bottom and top rows at the root and tip of the blade. This process generated a new mesh where the high aspect ratio and skew were eliminated and an aspect ratio of $<5.0$ was achieved. Merging the elements, rather than eliminating them, ensured that the geometric parameters of the blade remained intact. Figure 7 depicts the updated mesh.

The updated shell model is considered for the sandwich composite ply lay-up design, analysis and optimization. This model consists of 3,162 quadrilateral elements (CQUAD4) and 3,277 nodes, as shown in Figure 7. The blade face sheets are modeled with fiber-reinforced advanced polymer composite materials composed of graphite/epoxy tape fibers and intermediate modulus high strength matrix (Ref. 6). Fixed boundary conditions are applied at the root of the blade in all translations and rotations degrees of freedom. The total remaining number of degrees of freedom are 16,120. Since the geometry and loading of the titanium model is maintained for the composite model, and symmetry is assumed, a single blade is used for the composite analysis and optimization. The same pressure loads and rotation force are imposed upon the blade as the metallic model, i.e., pressure load is $5 \mathrm{psi}$, and the rotation is $1,536 \mathrm{rpm}$ along the $\mathrm{x}$-axis. 


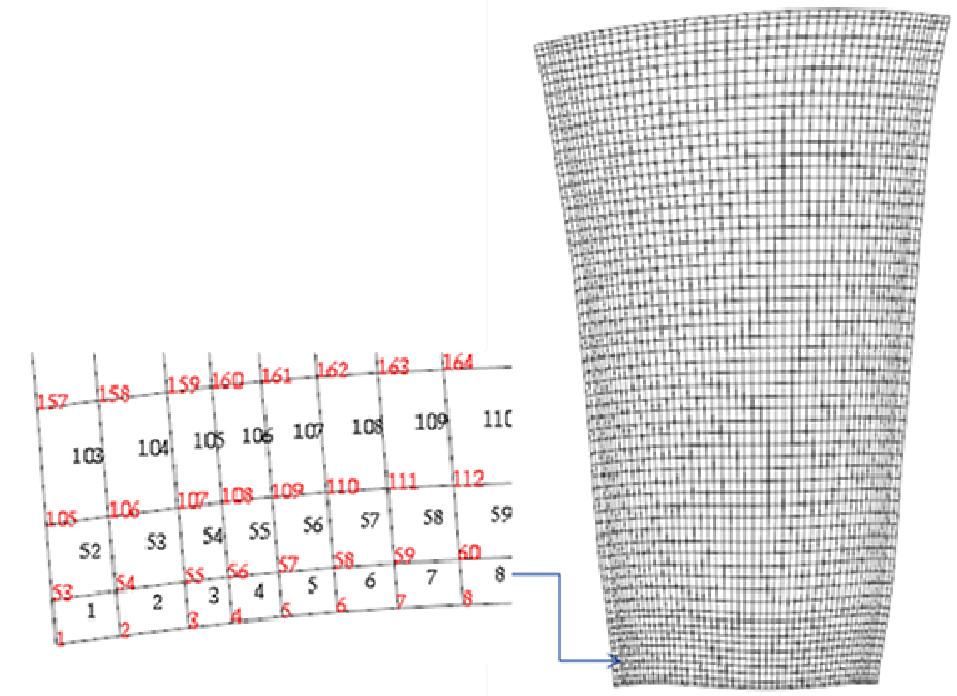

Figure 7.-Finite element model of the equivalent shell model with close-up section (node numbers in red, element numbers in black).

\begin{tabular}{|c|c|c|c|}
\hline Elastic constants & Values & Allowable stresses & $\begin{array}{c}\text { Values, } \\
\text { psi }\end{array}$ \\
\hline $\begin{array}{l}\text { Elastic modulus in longitudinal } \\
\text { direction, psi } \\
\text { (fiber } 0^{\circ} \text { angle) }\end{array}$ & $\mathrm{E} 11=1.94 \mathrm{E}+7 \mathrm{psi}$ & $\begin{array}{l}\text { Allowable tension stress in } \\
\text { longitudinal direction } \\
\text { Allowable compression stress in } \\
\text { longitudinal direction }\end{array}$ & $\begin{array}{l}\mathrm{Xt}=242,500 \\
\mathrm{Xc}=146,904\end{array}$ \\
\hline $\begin{array}{l}\text { Elastic modulus in lateral } \\
\text { direction, psi } \\
\text { (matrix } 90^{\circ} \text { angle) }\end{array}$ & $\mathrm{E} 22=1.19 \mathrm{E}+6 \mathrm{psi}$ & $\begin{array}{l}\text { Allowable tension stress in lateral } \\
\text { direction } \\
\text { Allowable compression stress in } \\
\text { lateral direction }\end{array}$ & $\begin{array}{l}\mathrm{Yt}=13,036 \\
\mathrm{Yc}=30,417\end{array}$ \\
\hline Shear modulus, psi & $\mathrm{G} 12=6.32 \mathrm{E}+5 \mathrm{psi}$ & Allowable stress for in-plane shear & $\mathrm{S}=10,940$ \\
\hline Poisson ratio & NU12 $=0.26$ & --- & --- \\
\hline Mass density, lb/in. ${ }^{3}$ & 0.0554 & --- & --- \\
\hline
\end{tabular}

Unidirectional laminate properties of the graphite/epoxy tape are considered for this model with a fiber volume fraction of 0.6. These are represented using an orthotropic material model for shell elements (MAT8) in MSC/Nastran (Ref. 2). The PMC material properties considered are given in Table 3. The fibers carry most of the applied load. It is important to note that the strength of PMC in the fiber orientation is somewhat greater than the titanium material. On the other hand, the Young's modulus, perpendicular to the fiber orientation, is much smaller.

A sandwich construction for the blade is proposed for this fan blade with composite face sheets and a weak core made of honeycomb material, which is qualified to Boeing BMS 8-124 material specification (Ref. 7). The density of the honeycomb hexagonal cell is small, has weak in-plane stiffness properties and acts as empty space to separate the face sheet and hence, increase the bending stiffness without increasing weight. In addition, it offers significant weight savings, and low manufacturing cost.

Once the material properties have been specified, the next step in the composite analysis is to properly define the fiber orientation. Material property orientation is an important consideration when using composite materials because fiber orientation can greatly influence the deformations since the fibers carry most of the applied load. For the fan blade, the $0^{\circ}$ fibers are oriented along the span of the blade (E11), hence the weak orientation is in the transverse direction (E22), perpendicular to the fiber direction. The material orientation is depicted as coordinate axis label 100 in Figure 8. 


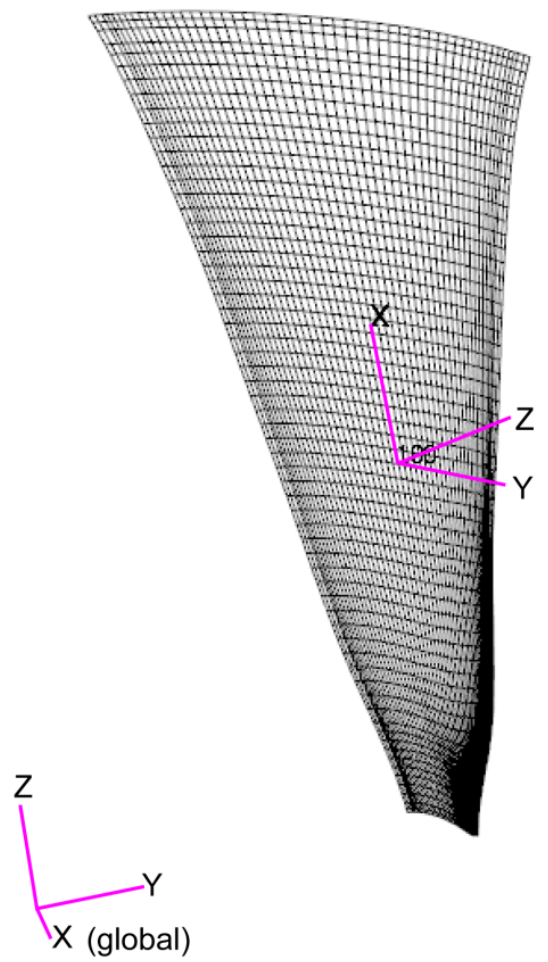

Figure 8.-PMC Material coordinate system (Label 100) with respect to global coordinate system.

\subsection{Grouping of Structural Elements}

When the number of elements in the structure is large, the complexity and computational cost of the overall analysis process increases. For these large structures, the number of design variables is reduced by a technique called design variable linking or element grouping, and is followed for the composite blade. The thickness of each of the elements is essentially the design variable for the optimization. The ply layup is also determined from the element grouping and thickness of the elements. The grouping of the 3,162 elements and the thickness of the baseline metallic blade was adopted in formulating the grouping of the CQUAD4 elements and generating the initial design for the composite blade. The grouping process supports and ensures that each group of elements defines a continuous region and that the predefined boundary shapes are retained. Each group of elements references the same property identification number, in the MSC/Nastran analysis.

The blade model was descritized into fifteen groups, which become the design variables (DV) in the optimization problem. The descritization was accomplished by sorting the thickness from thinner to thicker and forming the groups in ascending order. An initial constant ply thickness of 0.025 in. is assumed. The minimum, maximum and average number of plies are based on the thickness of the metallic blade and are calculated as follows:

$\operatorname{Min}=($ min_thickness_metal/0.025);

Max $=($ max_thickness_metal $/ 0.025)$;

Average number of plies $=$ ROUND $(\operatorname{Min}+\operatorname{Max}) / 2$ 
The element grouping and number of plies for each design group is depicted in Table 4. As shown in the table, design variable 1 consists of 124 elements, with a thickness range of 0.0596 to 0.09128 in. These elements are on the leading and trailing edges of the blade as shown in dark blue in Figure 9(a). Similarly, design variable 2 consists of 342 elements, with a thickness range of 0.11231 to 0.19979 in. These elements are adjacent to the elements in the previous group, as shown in dark red in Figure 9(b). The individual groups of the elements for design variables 1 to 15 are shown in Table 4 and Figures 9(a) to (c) through Figure 13(a) to (c). The complete assembly of the fan blade element grouping is shown in Figure 14.

The average number of plies was adjusted to accommodate the requirement of a symmetric lay-up, as shown in the last column of Table 4. For aerodynamic considerations, the thickness of the core is varied where as the overall blade thickness is held fixed in order to keep the airfoil geometry and the original model unchanged.

TABLE 4.-ELEMENT GROUPING, THICKNESS RANGE AND NUMBER OF PLIES

\begin{tabular}{|c|c|c|c|c|c|c|c|}
\hline \multirow[t]{2}{*}{$\begin{array}{c}\text { Design } \\
\text { variable }\end{array}$} & \multirow[t]{2}{*}{$\begin{array}{l}\text { Number of } \\
\text { elements }\end{array}$} & \multicolumn{2}{|c|}{$\begin{array}{l}\text { Thickness range } \\
\text { for metal }\end{array}$} & \multicolumn{2}{|c|}{ Number of plies } & \multirow{2}{*}{$\begin{array}{c}\text { Average } \\
\text { number of } \\
\text { plies } \\
\text { (rounded) }\end{array}$} & \multirow{2}{*}{$\begin{array}{c}\text { Adjust for } \\
\text { symmetrical } \\
\text { laminate }\end{array}$} \\
\hline & & Min & Max & Min & Max & & \\
\hline 1 & 124 & 0.0596 & 0.09128 & 2.384 & 3.6512 & 3 & 4 \\
\hline 2 & 342 & 0.11231 & 0.19979 & 4.4924 & 7.9916 & 6 & 8 \\
\hline 3 & 363 & 0.20008 & 0.29955 & 8.0032 & 11.982 & 10 & 12 \\
\hline 4 & 334 & 0.30018 & 0.39997 & 12.0072 & 15.9988 & 14 & 16 \\
\hline 5 & 345 & 0.40057 & 0.49992 & 16.0228 & 19.9968 & 18 & 20 \\
\hline 6 & 418 & 0.50021 & 0.59996 & 20.0084 & 23.9984 & 22 & 24 \\
\hline 7 & 333 & 0.60045 & 0.69968 & 24.018 & 27.9872 & 26 & 28 \\
\hline 8 & 241 & 0.70015 & 0.79972 & 28.006 & 31.9888 & 30 & 32 \\
\hline 9 & 173 & 0.80014 & 0.89999 & 32.0056 & 35.9996 & 34 & 36 \\
\hline 10 & 126 & 0.90032 & 0.99905 & 36.0128 & 39.962 & 38 & 40 \\
\hline 11 & 98 & 1.00013 & 1.09997 & 40.0052 & 43.9988 & 42 & 44 \\
\hline 12 & 79 & 1.1042 & 1.19811 & 44.168 & 47.9244 & 46 & 48 \\
\hline 13 & 72 & 1.20064 & 1.29819 & 48.0256 & 51.9276 & 50 & 52 \\
\hline 14 & 62 & 1.30013 & 1.39589 & 52.0052 & 55.8356 & 54 & 56 \\
\hline 15 & 52 & 1.40059 & 1.51687 & 56.0236 & 60.6748 & 58 & 60 \\
\hline Total & 3162 & --- & --- & --- & --- & --- & --- \\
\hline
\end{tabular}




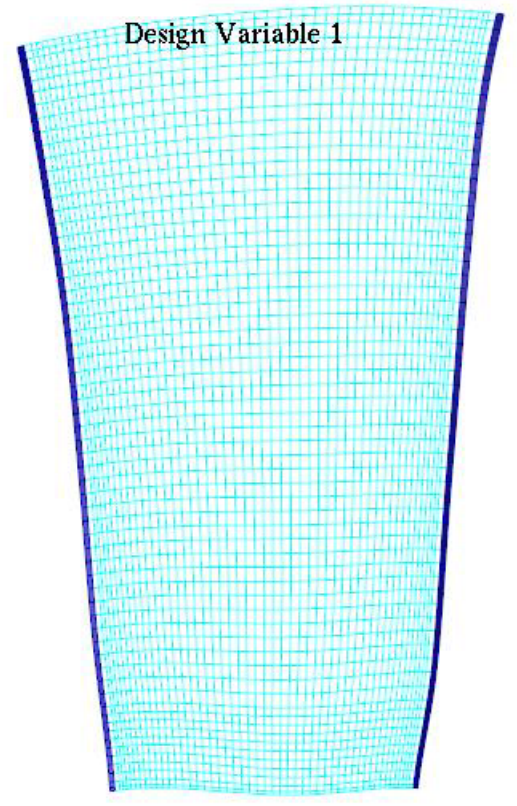

(a) DV1: Number of elements $=124$

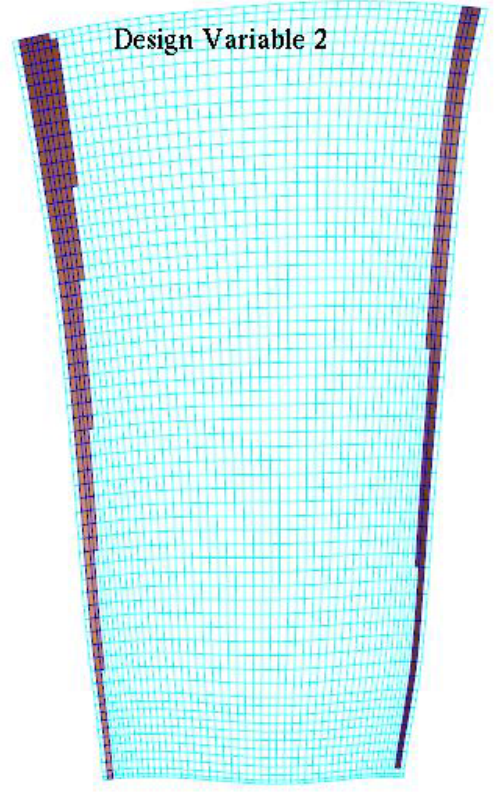

(b) DV2: Number of elements $=342$
Design Variable 3

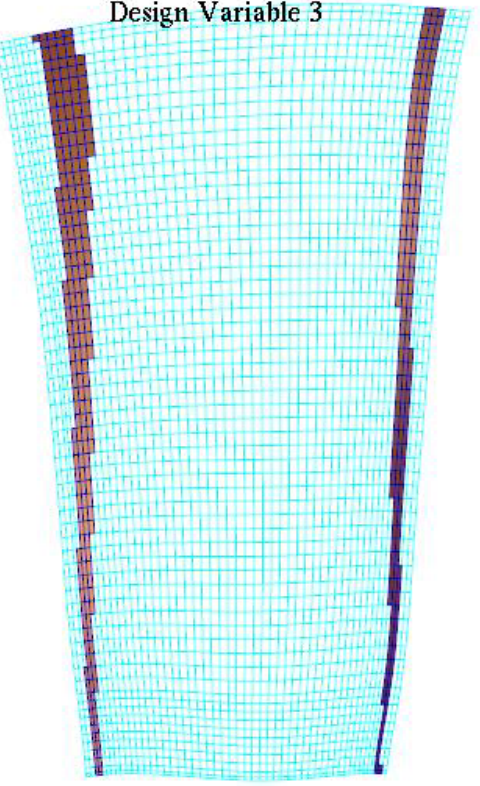

(c) DV3: Number of elements $=363$

Figure 9.-Design variable (DV) groups in dark colors (a) DV1, (b) DV2, (c) DV3.

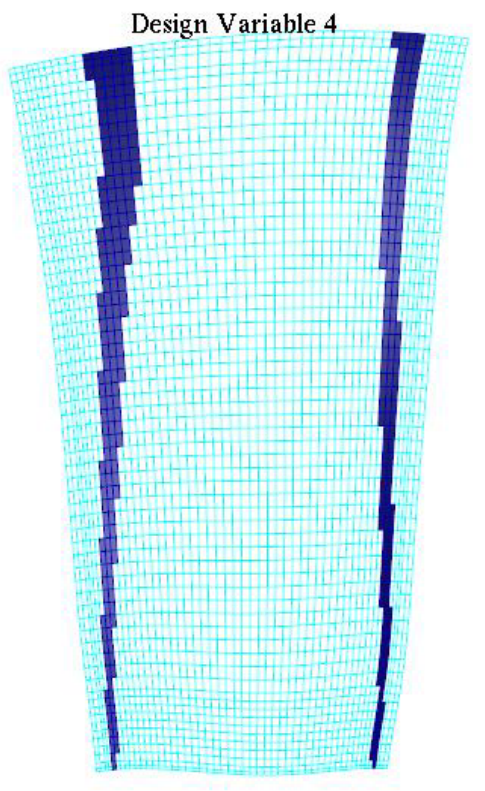

(a) DV4: Number of elements $=334$

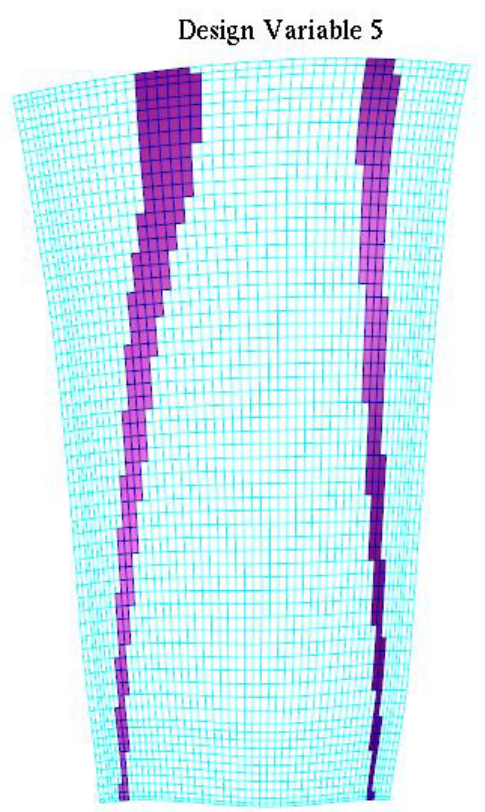

(b) DV5: Number of elements $=345$
Design Variable 6

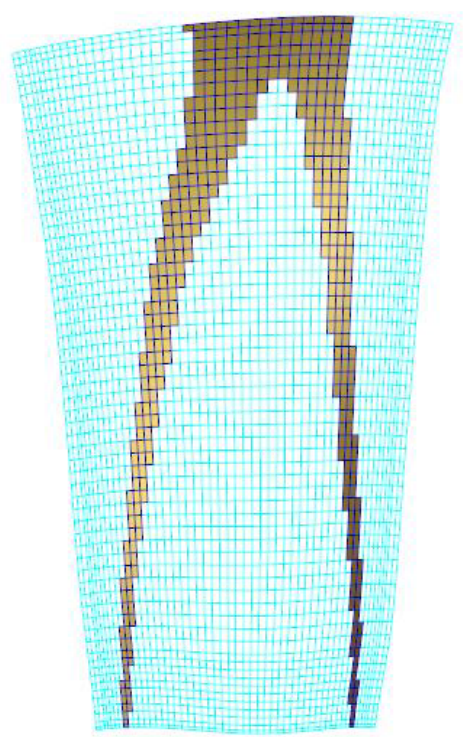

(c) DV6: Number of elements $=418$

Figure 10.-Design variable (DV) groups in dark colors (a) DV4, (b) DV5, (c) DV6.

NASA/TM-2012-217632

11 
Design Variable 7

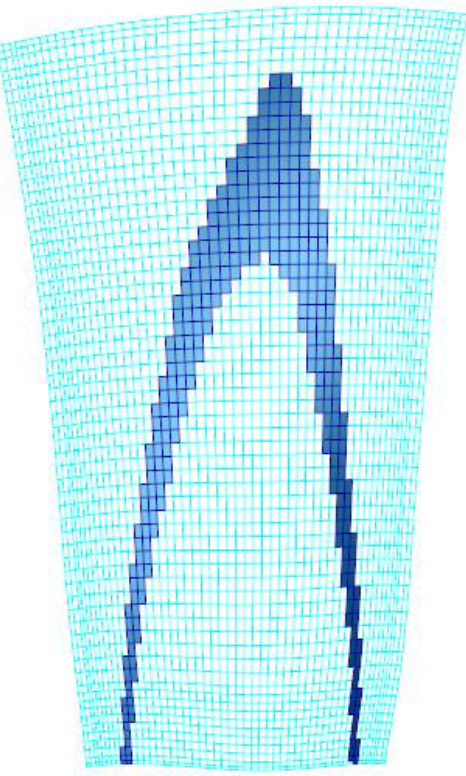

(a) DV7: Number of elements $=333$
Design Variable 8

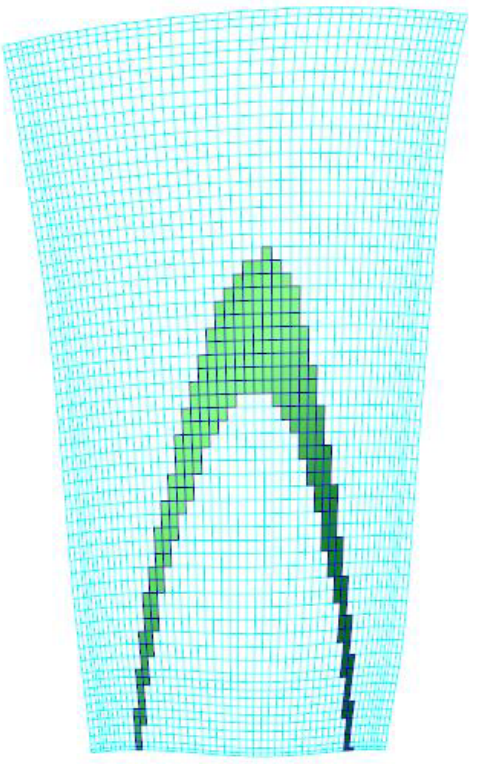

(b) DV8: Number of elements $=241$
Design Variable 9

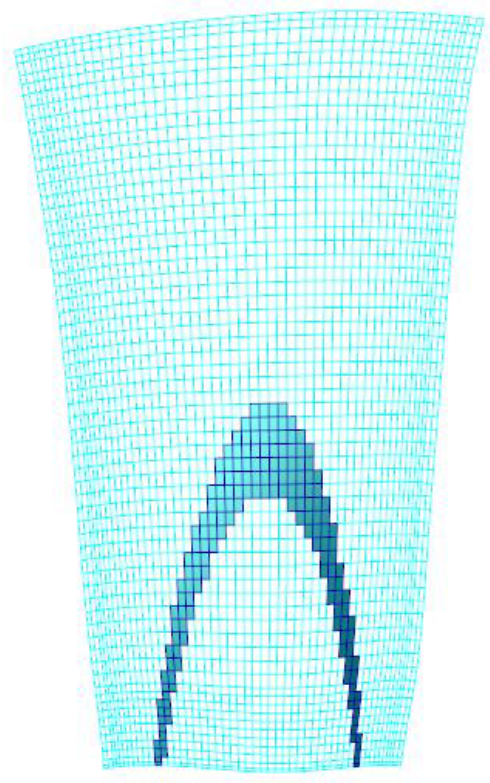

(c) DV9: Number of elements $=173$

Figure 11.-Design variable (DV) groups in dark colors (a) DV7, (b) DV8, (c) DV9.

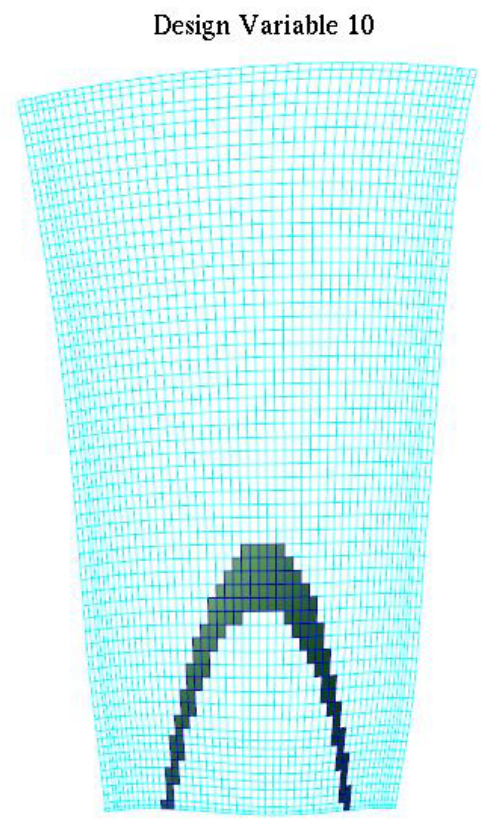

(a) DV10: Number of elements $=126$
Design Variable 11

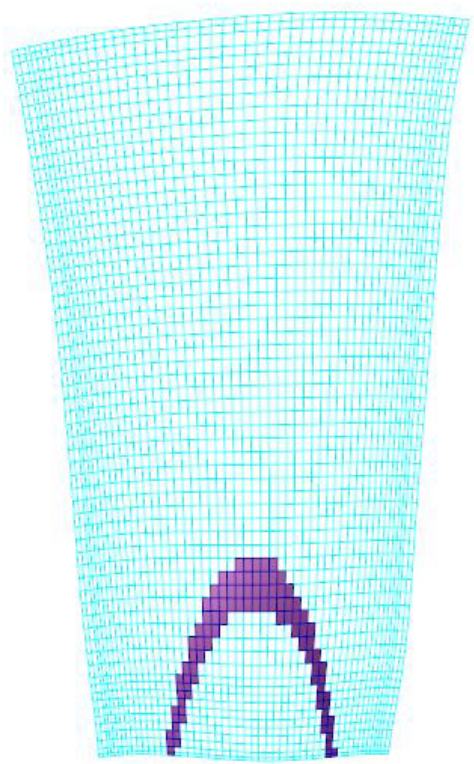

(b) DV11: Number of Elements $=98$
Design Variable 12

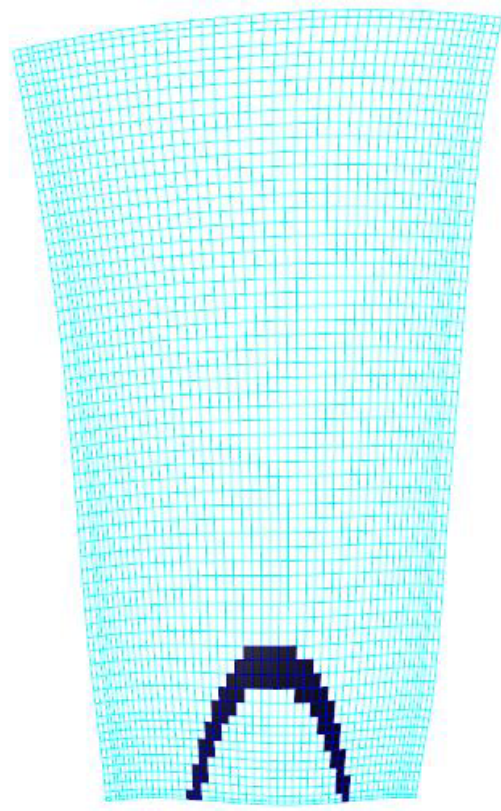

(c) DV12: Number of Elements $=79$

Figure 12.-Design variable (DV) groups in dark colors (a) DV10, (b) DV11, (c) DV12. 


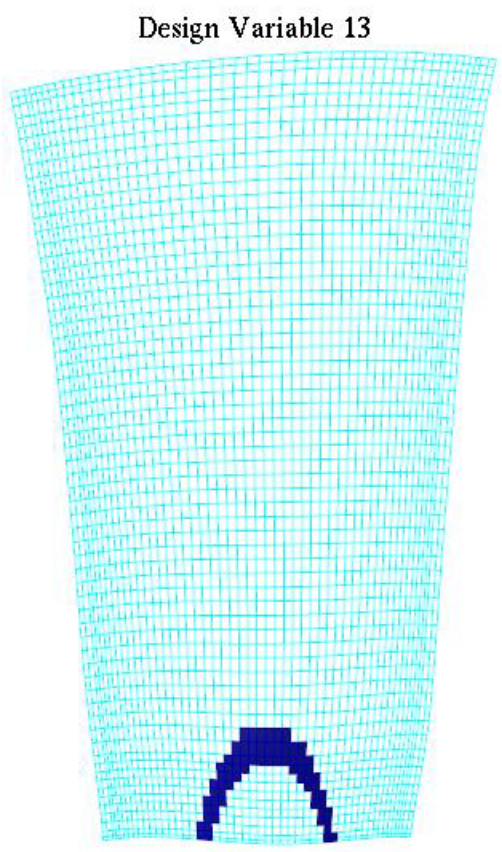

(a) DV13: Number of Elements $=72$

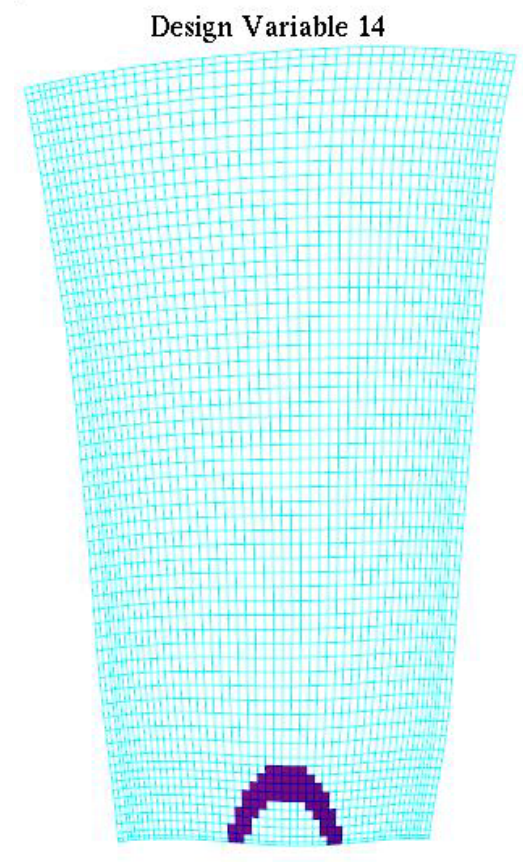

(b) DV14: Number of Elements $=62$

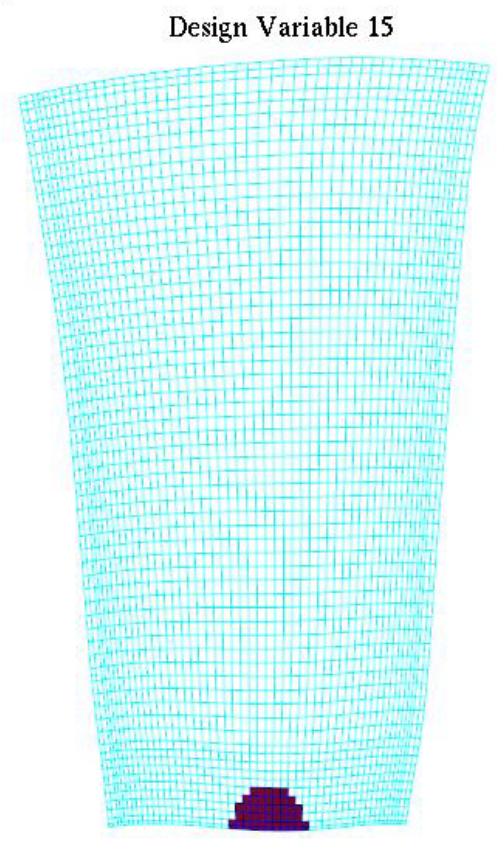

(c) DV15: Number of Elements $=52$

Figure 13.-Design variable (DV) groups in dark colors (a) DV13, (b) DV14, (c) DV15.

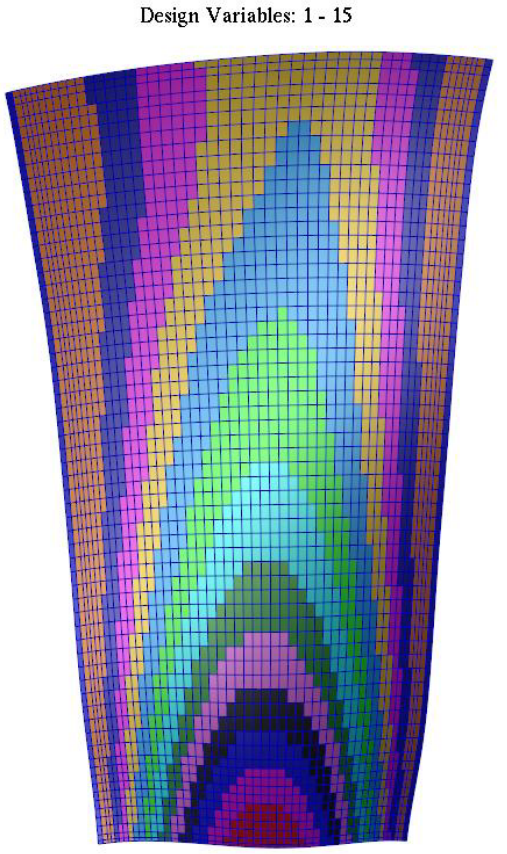

Design Variables: (1-15)

Figure 14.-Complete assembly of design variable groups (1-15). 


\subsection{Initial Ply Lay-Up Configuration}

A typical symmetric ply lay-up sequence is assumed at ply orientation angles of [0/90/+45/-45] degrees. The composite face sheets of group numbers 7 to 15 include the Boeing BMS 8-124 honeycomb material core ply of $0.5 \mathrm{in}$. thick. The honeycomb core ply is oriented at $0^{\circ}$. The fiber orientations and ply lay-ups were defined on the PCOMP card in MSC/Nastran with an initial thickness of 0.025-in. assuming symmetry. The 'SYM' option is defined on the PCOMP card (Ref. 2) to make the behavior of the laminate symmetric where only plies on one side of the element centerline are specified. The plies are numbered starting with 1 on the bottom layer. Examples of symmetrical laminates are shown in Figure 15.

The composite fan blade initially is designed with about 55 percent of $\left[0^{\circ} / 90^{\circ}\right]$ plies and 45 percent of $\left[ \pm 45^{\circ}\right]$ plies. The initial ply lay-up for each of the 15 groups is shown in Table 5 . The honeycomb core ply of 0.5 in. thick for the composite face sheets, group numbers 7 to 15 , defined as 0.25 in. symmetric in the MSC/Nastran PCOMP card, is denoted with an asterisk in Table 5. Initially, the composite fan blade is designed with ten ply lay-up shapes, as shown on the last row of Table 5, and described in the next section.
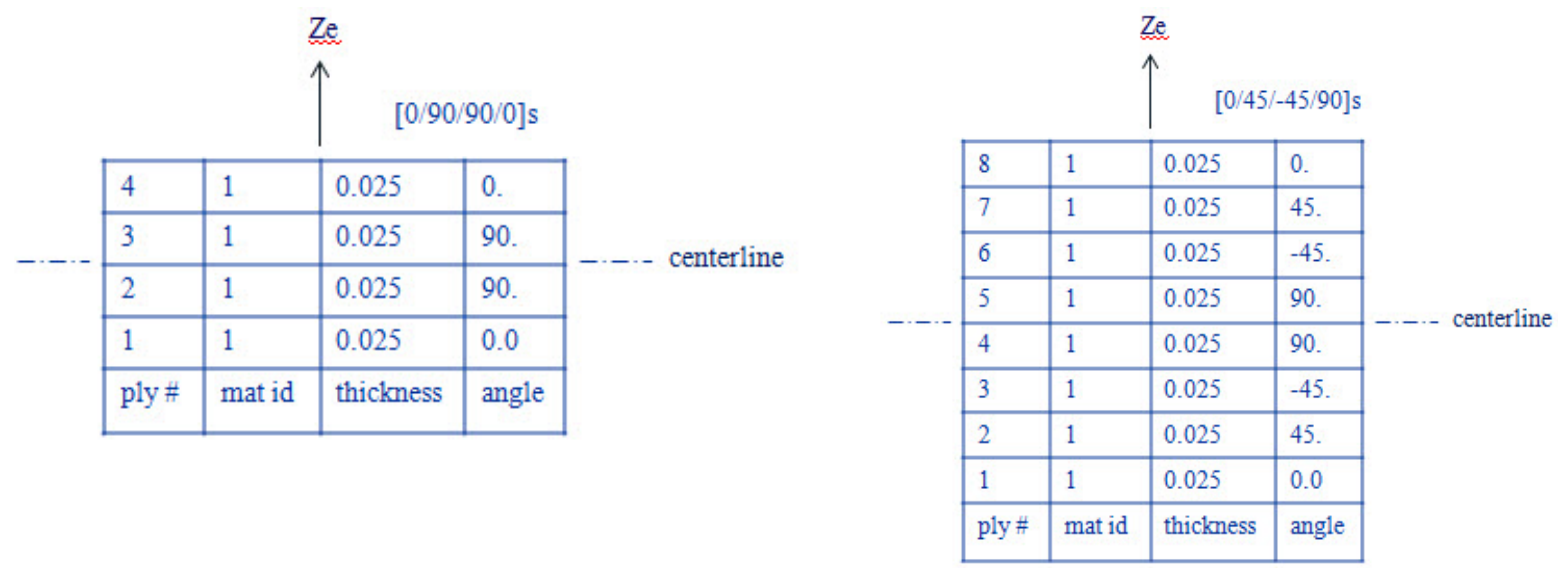

Figure 15.-Ply lay-up in a laminate consisting of symmetrical plies.

TABLE 5.-SYMMETRIC PLY LAY-UP IN THE BLADE LAMINATE, CORE PLY DENOTED WITH AN ASTERISK*

\begin{tabular}{|c|c|c|}
\hline $\begin{array}{l}\text { Group } \\
\text { number }\end{array}$ & Number of plies & Ply angles, Symmetric (S) Ply lay-up \\
\hline 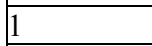 & 4 & {$[0 / 90]_{\mathrm{S}}$} \\
\hline 2 & 8 & {$[0 / 90 / 45 /-45]_{\mathrm{s}}$} \\
\hline 3 & 12 & {$[0 / 90 / 45 /-45 / 90 / 0]_{\mathrm{S}}$} \\
\hline 4 & 16 & {$[0 / 90 / 45 /-45 / 90 / 0 /-45 / 45]_{\mathrm{S}}$} \\
\hline 5 & 20 & {$[0 / 90 / 45 /-45 / 90 / 0 /-45 / 45 / 0 / 90]_{\mathrm{S}}$} \\
\hline 6 & 24 & {$[0 / 90 / 45 /-45 / 90 / 0 /-45 / 45 / 0 / 90 / 45 /-45]_{\mathrm{S}}$} \\
\hline 7 & 8 & {$[0 / 90 / 45 /-45 / *]_{\mathrm{S}}$} \\
\hline 8 & 12 & {$[0 / 90 / 45 /-45 / 90 / 0 / *]_{\mathrm{S}}$} \\
\hline 9 & 16 & {$[0 / 90 / 45 /-45 / 90 / 0 /-45 / 45 / *]_{\mathrm{S}}$} \\
\hline 10 & 20 & {$[0 / 90 / 45 /-45 / 90 / 0 /-45 / 45 / 0 / 90 / *]_{\mathrm{S}}$} \\
\hline 11 & 24 & {$[0 / 90 / 45 /-45 / 90 / 0 /-45 / 45 / 0 / 90 / 45 /-45 / *]_{\mathrm{S}}$} \\
\hline 12 & 28 & {$[0 / 90 / 45 /-45 / 90 / 0 /-45 / 45 / 0 / 90 / 45 /-45 / 90 / 0 / *]_{\mathrm{S}}$} \\
\hline 13 & 32 & {$[0 / 90 / 45 /-45 / 90 / 0 /-45 / 45 / 0 / 90 / 45 /-45 / 90 / 0 /-45 / 45 / *]_{\mathrm{S}}$} \\
\hline 14 & 36 & {$[0 / 90 / 45 /-45 / 90 / 0 /-45 / 45 / 0 / 90 / 45 /-45 / 90 / 0 /-45 / 45 / 0 / 90 / *]_{\mathrm{S}}$} \\
\hline 15 & 40 & {$[0 / 90 / 45 /-45 / 90 / 0 /-45 / 45 / 0 / 90 / 45 /-45 / 90 / 0 /-45 / 45 / 0 / 90 / 45 /-45 / *]_{\mathrm{S}}$} \\
\hline \multicolumn{2}{|c|}{ Ply Shapes: } & $\begin{array}{llllllllll}1 & 2 & 3 & 4 & 5 & 6 & 7 & 8 & 9 & 10\end{array}$ \\
\hline
\end{tabular}




\subsection{Ply Build-Up During Manufacturing Process}

Advanced composite structures can be manufactured using a wide variety of processes. Each of the fabrication processes has characteristics that define the type of products to be produced. To select the most efficient manufacturing process, the manufacturing team considers several factors such as performance requirements, size of the product, surface complexity, materials, production rate, etc. Common production processes for polymer matrix composites are resin transfer molding (RTM) process and autoclave curing process (Ref. 8). RTM is a low pressure, closed molding process which offers a dimensionally accurate and high quality surface finish composite molding, using liquid thermoset polymers reinforced with various forms of fiber reinforcements. Autoclave curing is typically referring to the process of bonding multiple materials into a single material with the use of an autoclave. Autoclaves are controlled by setting the desired temperature and pressure.

The blade was designed with 15 design groups where each group was specified to have plies oriented at $[0 / 90 /+45 /-45]$ degrees including a honeycomb core ply for design groups ( 7 to 15$)$. During manufacturing process, the plies are built-up by adding the layers on top of each other. Ten layers or ply shapes in total are required to build the complete blade to form its desired shape, as shown in the last row of Table 5 .

The blade is designed initially with a ten ply lay-up shapes or designs as shown in Figures: 16(a) to (c), 17(a) to (c), 18(a) to (c) and Figure 19. For structural integrity, it is very important that some of the plies be continued across the border of the adjacent element groups. Therefore, plies of several element groups share the same orientation. For example, the first ply lay-up shape is made of fibers oriented at [0/90] degrees, which are stacked together to form the laminate over the entire face sheet of the blade, see Figure 16(a). The second ply shape is made of fibers oriented at $[+45 /-45]$ degrees stacked together to form the laminate over the face sheet of the blade excluding the elements at the edges of the blade having thickness in the range of (0.0596 to 0.09128 in.) or essentially the plies of [0/90] degrees of element group 1, see Figure 16(b). Similarly, the third ply lay-up shape is made of plies oriented at [90/0] degrees and is layered over element groups (3 to 6) and (8 to 15), Figure 16(c). The shape of the fourth ply of the lay-up is identified by considering plies oriented at [-45/45] degrees and covers element groups (4 to 6) and (9 to 15), shown in Figure 17(a). The fifth ply-layup shape is made of plies oriented at [0/90] degrees of elements groups $(5,6)$ and (10 to 15), see Figure 17(b). The sixth shape is made of fibers oriented at [ $+45 /-45]$ degrees and encompasses all elements in groups (6 and 11 to 15), Figure 17(c). The seventh ply lay-up is made of [90/0] degree plies and encompasses element groups (12 to 15), shown in Figure 18(a). The eighth ply shape lay-up is made of [-45/45] degree plies and covers element groups (13 to 15), Figure 18(b). The ninth ply lay-up shape is made of fibers oriented at [0/90] degrees and encompasses element groups 14 and 15, shown in Figure 18(c). The tenth and final ply shape lay-up is made of fiber orientations at [45/-45] degrees and covers element group 15, shown in Figure 19. The build-up of the honeycomb core ply is also set in place for ply shapes 3 to 10 , as shown in Table 5, denoted with an asterisk. 


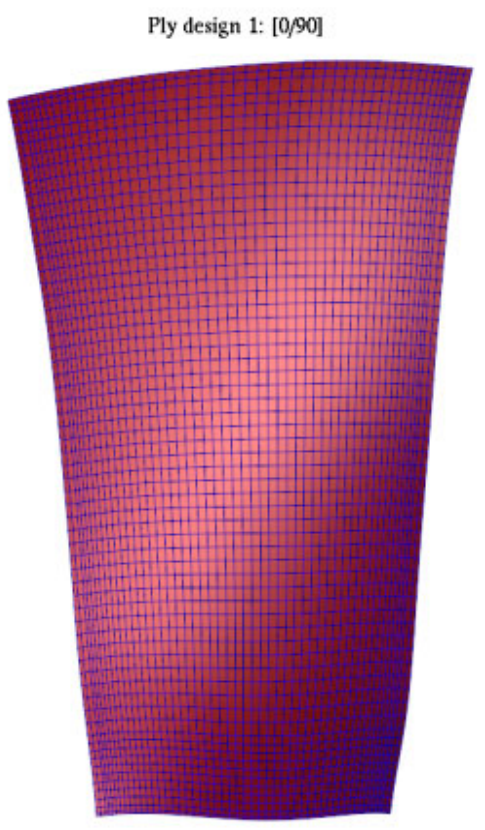

(a) Ply shape 1:[0/90]

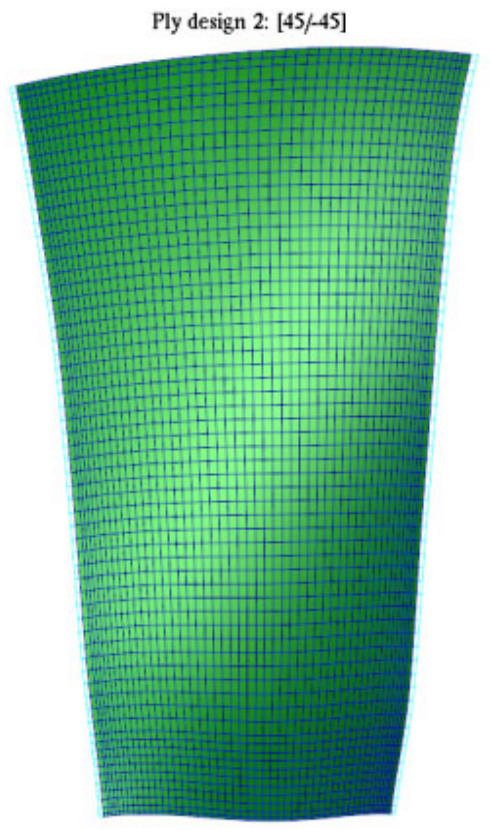

(b) Ply shape 2:[45/-45]

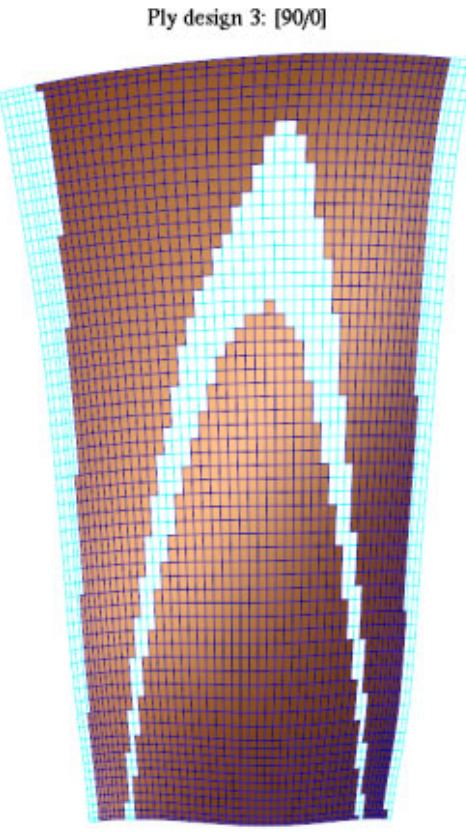

(c) Ply shape 3:[90/0]

Figure 16._Ply build-up shapes: (a) shape 1, (b) shape 2, (c) shape 3.

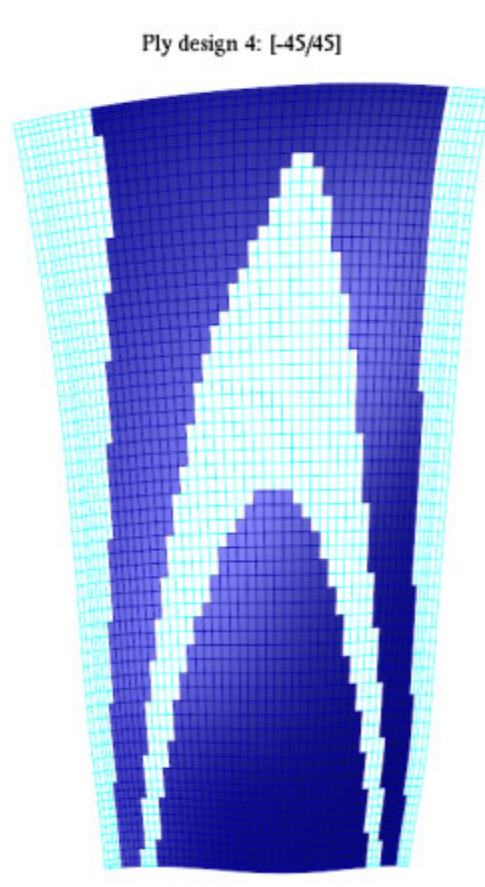

(a) Ply shape 4:[-45/45]

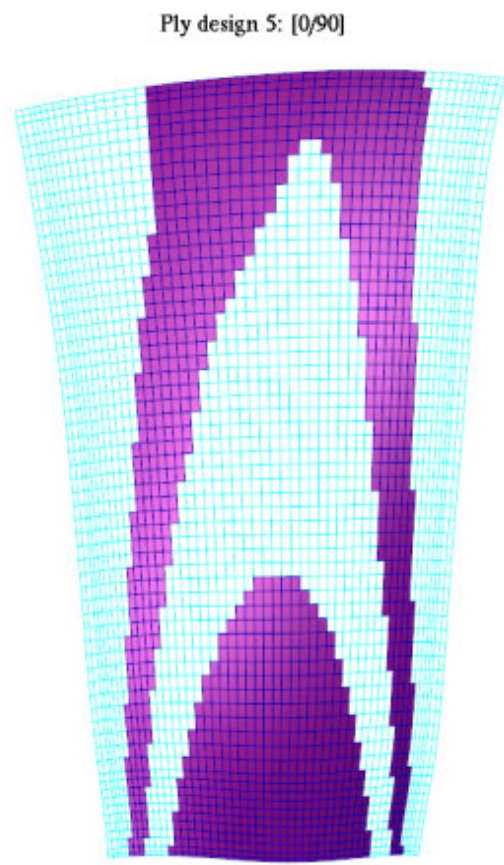

(b) Ply shape 5:[0/90]

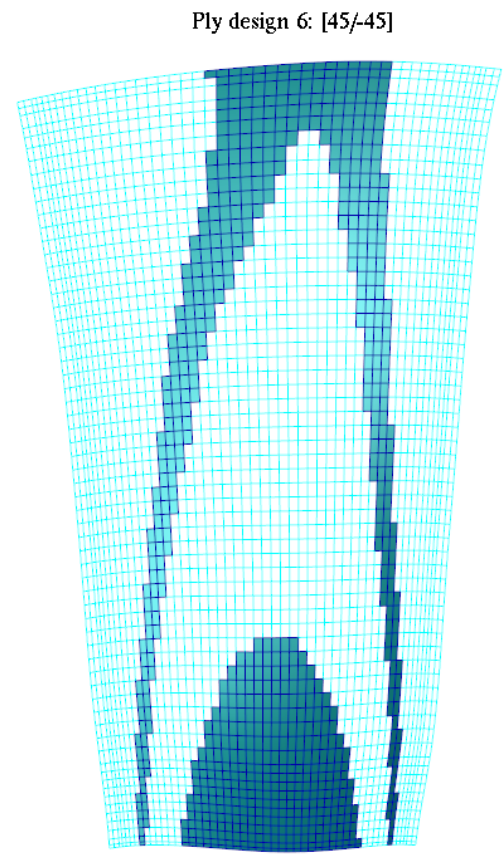

(c) Ply shape 6:[45/-45]

Figure 17.-Ply build-up shapes: (a) shape 4, (b) shape 5, (c) shape 6. 


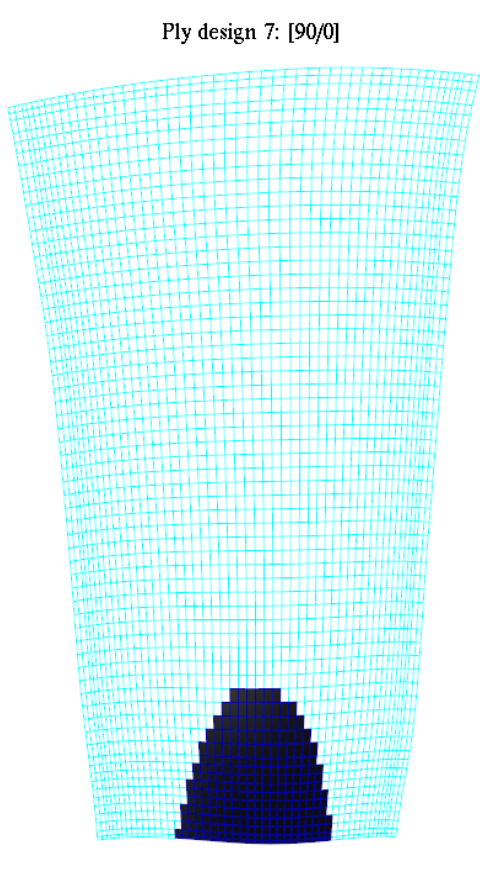

(a) Ply shape 7:[90/0]

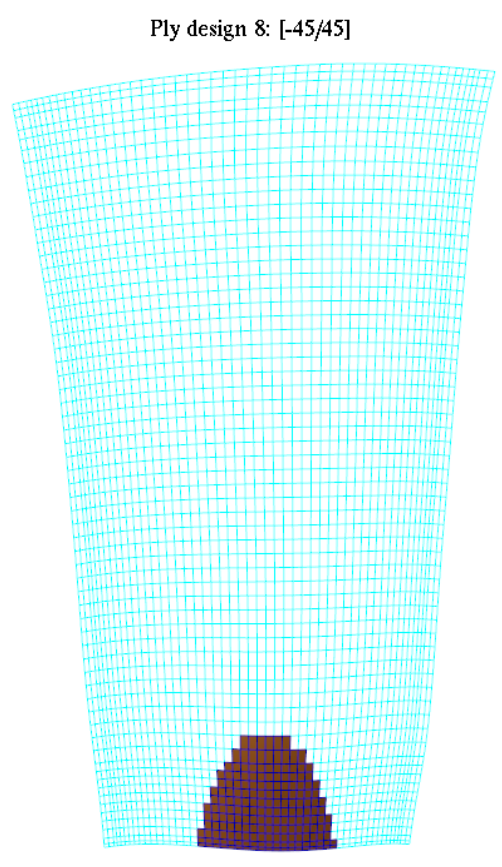

(b) Ply shape $8:[-45 / 45]$

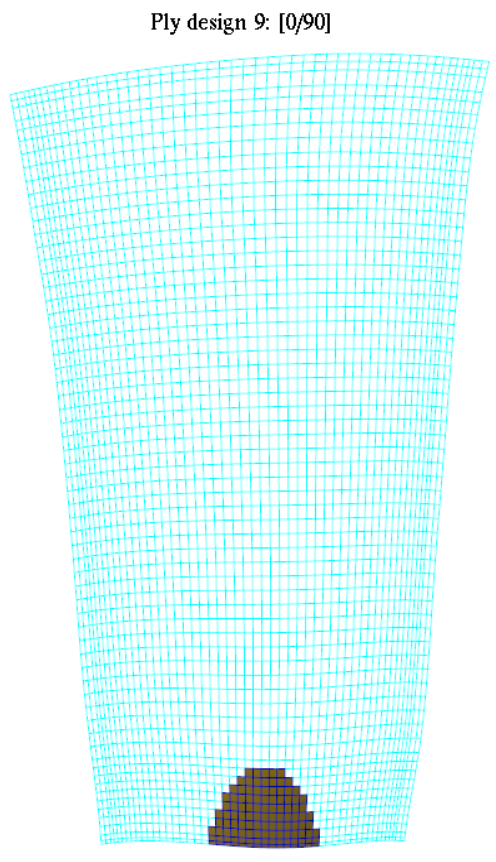

(c) Ply shape 9: [0/90]

Figure 18._Ply build-up shapes: (a) shape 7, (b) shape (8), (c) shape 9.

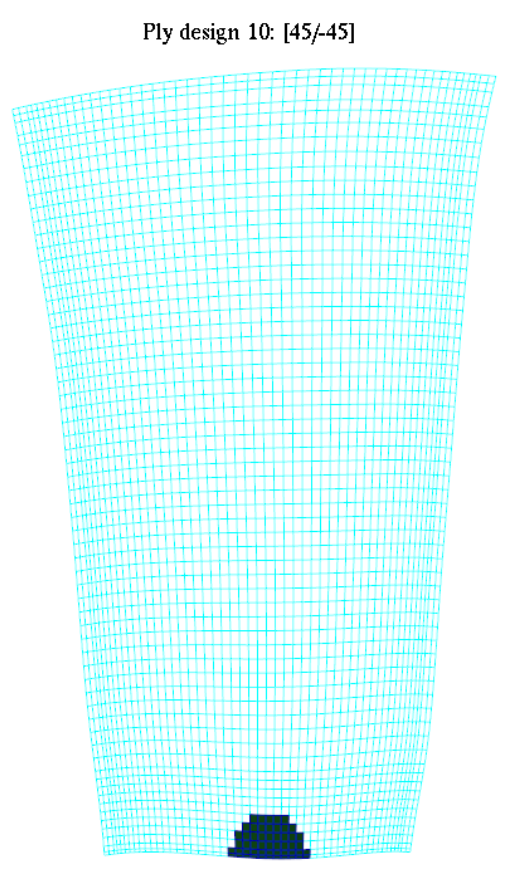

Ply shape 10: [45/-45]

Figure 19.-Ply build-up shape 10. 


\subsection{Ply Failure Analysis}

Ply failure analysis is useful to calculate stress failure for any ply lay-up. Ply failure theories have been implemented in MSC/Nastran (Ref. 2) for calculation of residual strength or ultimate load analysis. Failure indices (FI) and strength ratios are used as a linear measure of residual strength. A brief outline on failure index and Strength ratio as implemented in MSC/Nastran is provided next.

\subsubsection{Failure Index}

Three types of failure theories have been implemented in MSC/Nastran for calculation of failure indices (FI) in the lamina. The theories are: (1) Hill's theory, Hoffman's theory and Tsai-Wu (Tensor Polynomial) theory. Tsai-Wu failure theory is considered for the NASA composite blade analysis, given as:

$$
F I=\left(\frac{1}{X t}-\frac{1}{X c}\right) \sigma_{1}+\left(\frac{1}{Y t}-\frac{1}{Y c}\right) \sigma_{2}+\frac{\sigma_{1}^{2}}{X t X c}+\frac{\sigma_{2}^{2}}{Y t Y C}+2 F_{12} \sigma_{1} \sigma_{2}+\frac{\tau_{12}^{2}}{S^{2}}
$$

where $\sigma_{1}, \sigma_{2}$, and $\tau_{12}$ are the lamina direct and shear stresses along the principal directions and $X_{T}, X_{C}, Y_{T}$, $Y_{C}$ are the allowable tension and compression stresses along principal directions and $S$ is the allowable shear stress. Typical values for $F_{12}$ are:

$$
F_{12}= \pm 0.5 \sqrt{\frac{1}{X_{t} X_{c} Y_{t} Y_{C}}}
$$

For the composite blade $F_{12}=2.43 \mathrm{E}-12$. The ply is assumed safe if the value of the failure index is less than 1 and to have failed if the failure index value exceeds 1 .

\subsubsection{Strength Ratio}

First-ply strength ratio (SR) failure concept is implemented in MSC/Nastran (Ref. 2). Strength ratio is a better indicator than failure indices (FI) because it shows how far a ply is to failure and is similar to margin of safety. Failure indices do not show this since they are usually nonlinear functions. For the composite fan blade, the strength ratios are formulated as the constraints in the optimization problem. Strength ratio is calculated in MSC/Nastran using the Tsai-WU failure criteria as follows:

$$
\frac{\sigma_{1}^{2}}{X t X c}+\frac{\sigma_{2}^{2}}{Y t Y c}+2 F_{12} \sigma_{1} \sigma_{2}+\frac{\tau_{12}^{2}}{S^{2}}+\sigma_{1}\left(\frac{1}{X t}-\frac{1}{X c}\right)+\sigma_{2}\left(\frac{1}{Y t}-\frac{1}{Y c}\right)=F I
$$

where $\sigma_{1}, \sigma_{2}, \tau_{12}$ are the actual stresses, $X t, X c, Y t, Y c$ are the stress allowable in tension and compression and FI is the failure index, set to 1.0 .

Multiplying the actual stresses with the strength ratio (SR) and setting FI $=1.0$ the equation becomes:

$$
\frac{\left(\mathrm{SR} * \sigma_{1}\right)^{2}}{X t X C}+\frac{\left(\mathrm{SR} * \sigma_{2}\right)^{2}}{Y t Y C}+2 F_{12} \sigma_{1} \sigma_{2}(\mathrm{SR})^{2}+\frac{\tau_{12}^{2}(\mathrm{SR})^{2}}{S^{2}}+\sigma_{1} \mathrm{SR}\left(\frac{1}{X t}-\frac{1}{X c}\right)+\sigma_{2} \mathrm{SR}\left(\frac{1}{Y t}-\frac{1}{Y_{C}}\right)=1.0
$$


Rewriting as:

$$
(\mathrm{SR})^{2}\left[\frac{\sigma_{1}^{2}}{X t X c}+\frac{\sigma_{2}^{2}}{Y t Y C}+2 F_{12} \sigma_{1} \sigma_{2}+\frac{\tau_{12}^{2}}{S^{2}}\right]+\operatorname{SR}\left[\sigma_{1}\left(\frac{1}{X t}-\frac{1}{X C}\right)+\sigma_{2}\left(\frac{1}{Y t}-\frac{1}{Y c}\right)\right]-1=0.0
$$

Solving for the roots (SRs) in the quadratic equation the loads can be linearly scaled based on SR to yield failure index $(\mathrm{FI})=1.0$. Strength ratio $(\mathrm{SR})$ of less than 1.0 indicates a failed ply.

\subsection{Static Analysis Results for the Initial Composite Design}

Linear static stress analysis was performed using the finite element software, MSC/Nastran which has been interfaced in the OpenMDAO Framework (Ref. 1). MSC/Patran software is used for pre and post processing of the results (Ref. 5). The intra-lamina 'Tsai-Wu' failure criterion is used to find the ply failures. Static analysis results for the initial design of the composite blade are presented in Table 6 . The maximum principal stress is at 117,943 psi and the maximum shear stress is at 59,768 psi. Both maximum principal stress and maximum shear stress are higher than the titanium model but they are below their allowable values. The higher stresses are probably due to the reduced thickness of the composite and the inclusion of the honeycomb core. Stress distribution is shown in Figure 20. The displacement magnitude is 9.38 in. with 1.4 in. displacement in the z-direction. The deformed blade shape is shown in Figure 21. For the initial analysis of the composite blade, none of the plies exhibit any failure, since the maximum failure index $=0.6776$ or $<1.0$ and minimum strength ratio for all plies $(\mathrm{SR}=2.38)$ or greater than 1.0 , see Figure 22. The weight savings for the composite blade compared with the titanium model is 75 percent or 25.5 versus $100.5 \mathrm{lb}$, much lighter as expected.

\subsection{Dynamic Analysis Results for the Initial Composite Design}

Dynamic analysis results for the initial design of the sandwich composite blade were calculated using MSC/Nastran SOL 103 modal analysis solver (Ref. 2). Results of the first six natural modes from the MSC/Nastran dynamic calculations are summarized in Table 7. Similar to titanium results, all six modes are evenly distributed in the frequency domain. Eigenvalue plots of the first six natural modes are depicted in Figures 23(a) to (c) and 24(a) to (c). The modes depicted in the figures can be divided into bending modes $\left(1^{\text {st }}, 2^{\text {nd }}, 4^{\text {th }}\right.$, and $6^{\text {th }}$ modes $)$ and torsion modes $\left(3^{\text {rd }}\right.$ and $5^{\text {th }}$ modes $)$.

TABLE 6.-STATIC ANALYSIS RESULTS OF THE INITIAL COMPOSITE DESIGN AND CORRESPONDING WEIGHT

\begin{tabular}{|l|c|}
\hline \multicolumn{1}{|c|}{ Static analysis results } & $\begin{array}{c}\text { Composite PMC with } \\
\text { honeycomb core }\end{array}$ \\
\hline Max principal stress, psi & 117943.0 \\
\hline Max shear stress, psi & 59768.47 \\
\hline & \\
\hline Displacement, resultant, in. & 9.38 \\
\hline Displacement, z-direction, in. & 1.40 \\
\hline & \\
\hline Weight (lb) & 25.557 \\
\hline
\end{tabular}




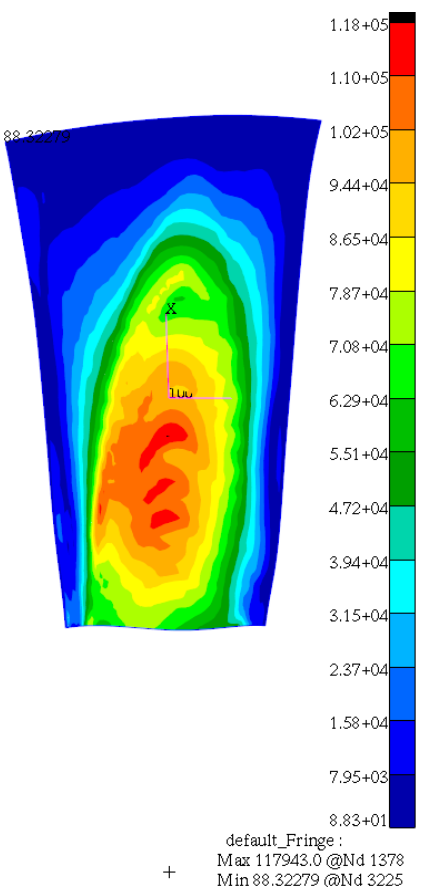

(a) Initial design:

Max Principal Stress $=117,943 \mathrm{psi}$

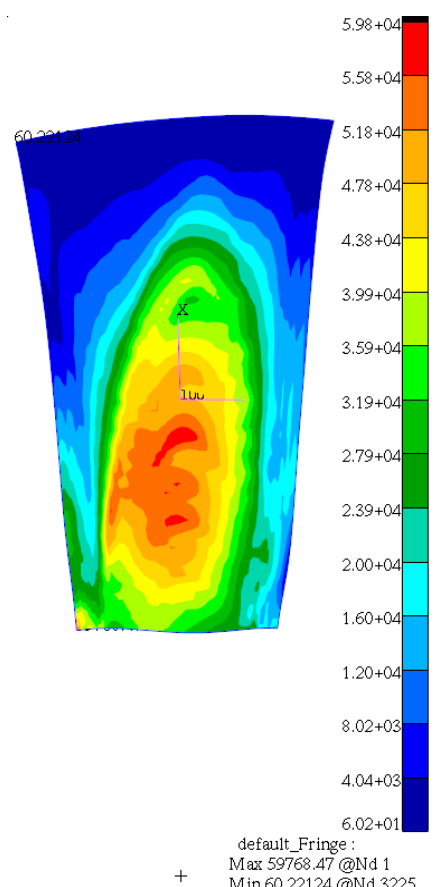

(b) Initial design:

Max Shear Stress $=59,768 \mathrm{psi}$

Figure 20.-Stress distribution results for the composite initial design (a) maximum principal stress, (b) maximum shear stress.

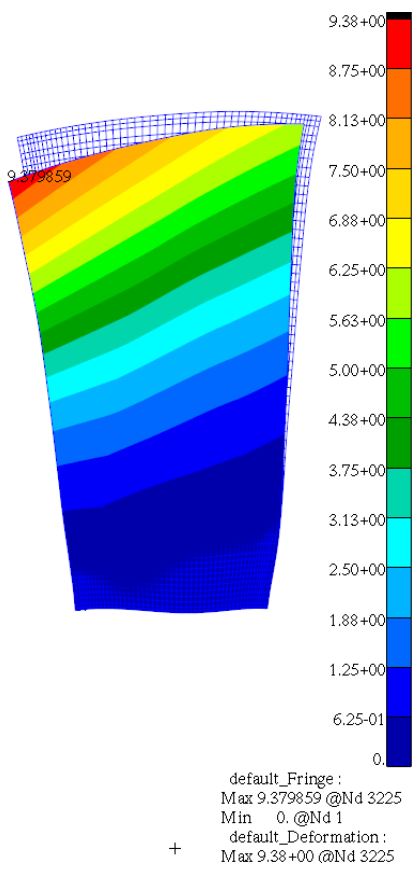

(a) Initial design:

Displacement resultant $=9.38$ in .

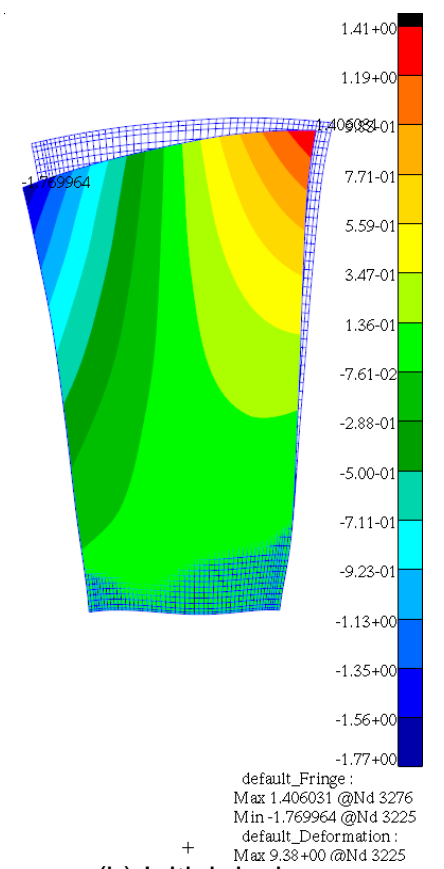

(b) Initial design:

Displacement $\mathrm{z}$-direction $=1.40$ in.

Figure 21.-Deformation results for the composite initial design (a) displacement resultant, (b) displacement in z-direction. 


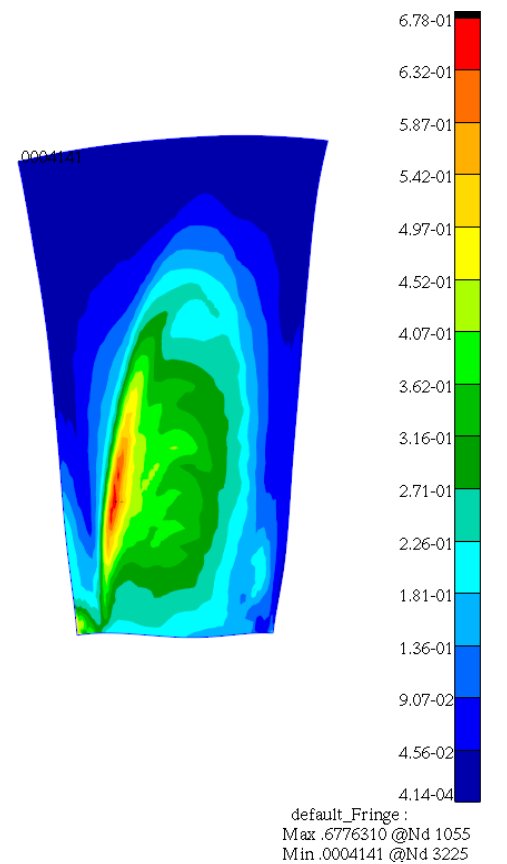

(a) Max failure index $(\mathrm{FI})<0.677$

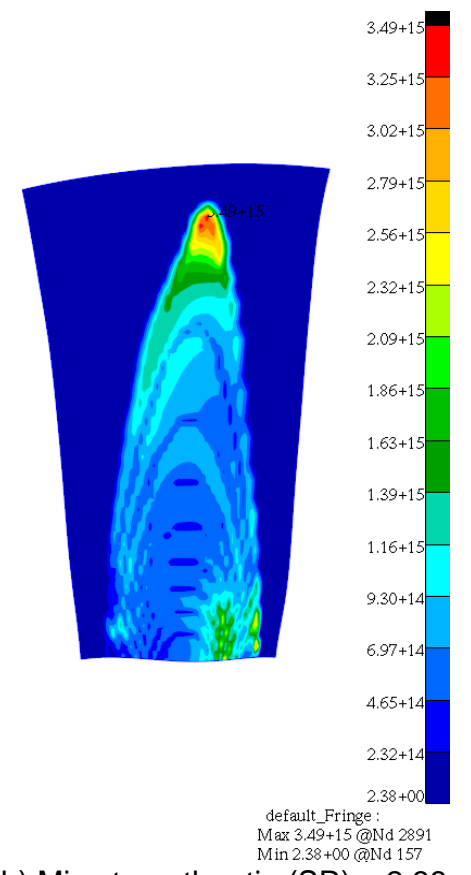

(b) Min strength ratio $(\mathrm{SR})>2.38$

Figure 22.-Ply failure analysis results for the composite initial design (a) failure index, (b) and strength ratio.

TABLE 7.-NATURAL FREQUENCIES FOR

THE INITIAL COMPOSITE DESIGN

\begin{tabular}{|l|c|}
\hline Mode number & $\begin{array}{c}\text { Frequency, } \\
\mathrm{Hz}\end{array}$ \\
\hline Mode 1 & 19.473 \\
\hline Mode 2 & 58.792 \\
\hline Mode 3 & 110.320 \\
\hline Mode 4 & 150.936 \\
\hline Mode 5 & 248.470 \\
\hline Mode 6 & 263.912 \\
\hline
\end{tabular}


:DEFAULT, A1:Mode $1:$ Freq. $=19.473$, Eigenvectors, 'DEFAULT, A1:Mode $2:$ Freq. $=58.792$, Eigenvectors, :DEFAULT, A1:Mode $3:$ Freq. $=110.32$, Eigenvectors, ${ }^{\prime}$

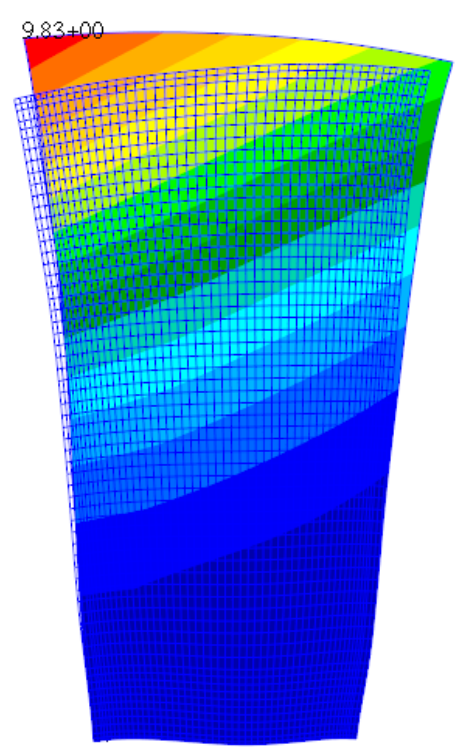

(a) Initial design

Mode 1: Frequency $=19.473 \mathrm{~Hz}$

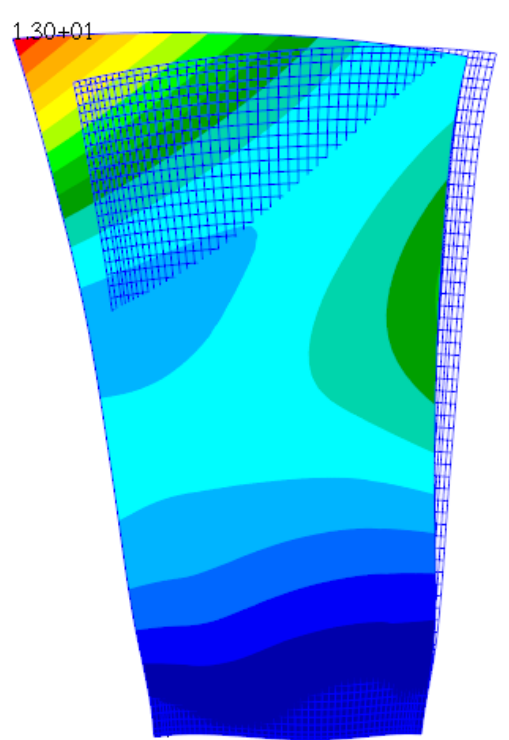

(b) Initial design

Mode 2: Frequency $=58.792 \mathrm{~Hz}$

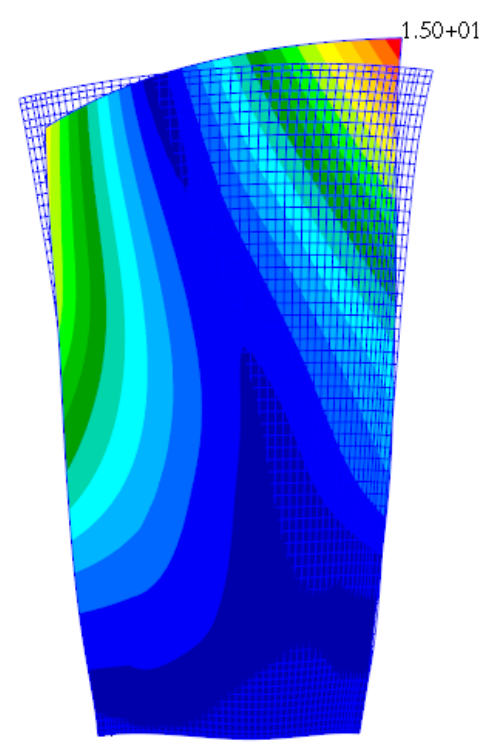

(c) Initial design Mode 3: Frequency $=110.32 \mathrm{~Hz}$

Figure 23. - Fringe plots of mode shapes for the composite initial design (a) mode 1, (b) mode 2, (c) mode 3.

:DEFAULT, A1:Mode $4:$ Freq. = 150.94, Eigenvectors, T DEFAULT, A1:Mode $5:$ Freq. $=248,47$, Eigenvectors, Tra: DEFAULT, A1:Mode 6: Freq. $=263.91$, Eigenvectors, ${ }^{\circ}$

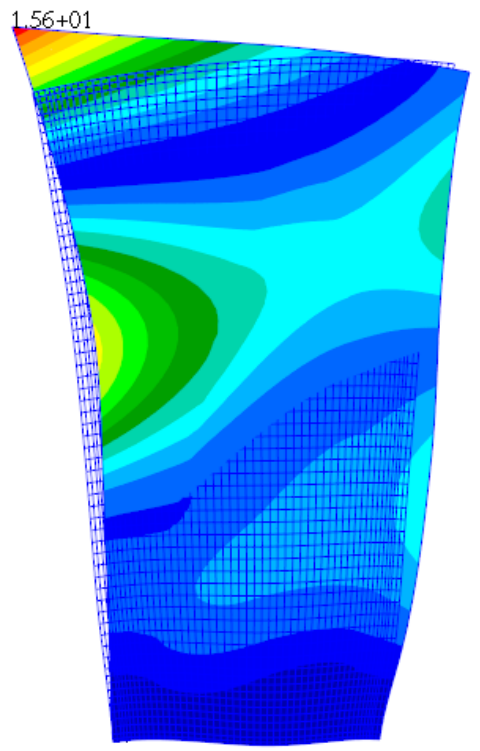

(a) Initial design

Mode 4: Frequency $=150.94 \mathrm{~Hz}$

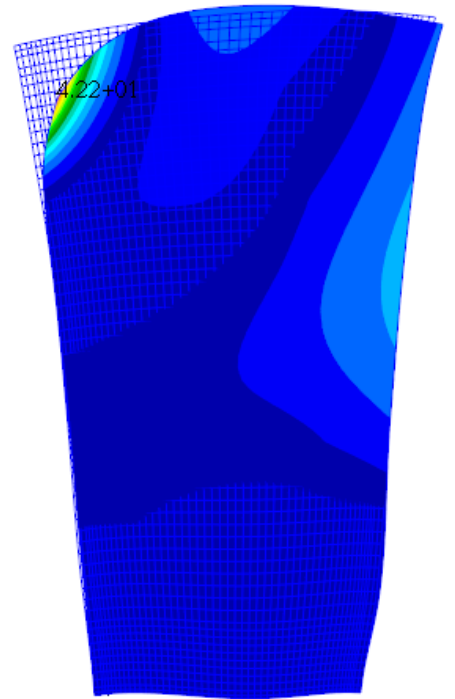

(b) Initial design Mode 5: Frequency $=248.47 \mathrm{~Hz}$

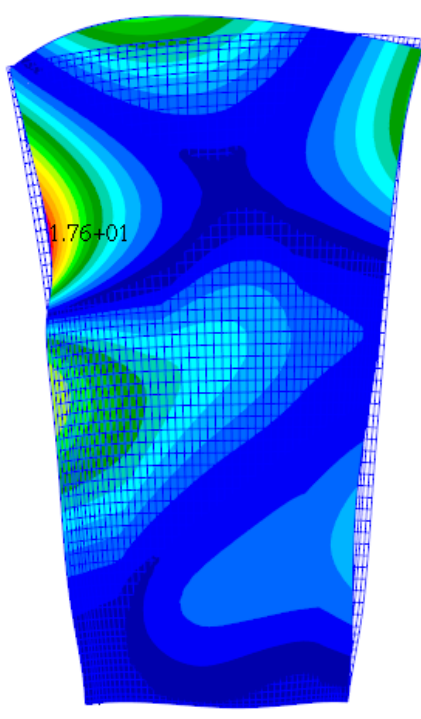

(c) Initial design Mode 6: Frequency $=263.91 \mathrm{~Hz}$

Figure 24.-Fringe plots of mode shapes for the composite initial design (a) mode 4, (b) mode 5, (c) mode 6. 


\subsection{Ply Lay-Up Tailoring Using Optimization Methods}

This step in composite optimization process is to make use of the methods of nonlinear programming to solve the optimization problem utilizing the design concepts of the composite structure while the constraints imposed on radial displacement limitations and ply failure strength ratio criteria are satisfied and the baseline aerodynamic and geometric parameters are maintained.

Weight reduction is taken as the objective function by varying the core thicknesses of the blade within specified upper and lower bounds as the design variables. Constraints are imposed on radial displacements limitation at the two tip nodes and at the same time the strength ratio of the plies is constrained within the allowable range, following the MSC/Nastran "first-ply" strength ratio failure concept. Details of the optimization formulation is provided next.

\subsection{Mathematical Optimization Problem Formulation}

The formal expression for the structural optimization of a sandwich composite laminate shell or plate structure is:

$$
\text { Minimize W(x) }
$$

Subject to stress and displacement constraints:

$$
g_{j}(x) \leq 0, \quad j=1, \ldots, N s+N d
$$

where $W$ represents the weight, $g$ denotes the constraints, $N$ s represents the number of stress constraints, $N d$ represents the number of displacement constraints and $x$ represents the independent active design variables within prescribed lower $(L B)$ and upper bounds $(U B)$ as:

$$
\left(x_{i}^{L B} \leq x_{i} \leq x_{i}^{U B}, i=1,2, \ldots, n\right)
$$

where $n$ is the total number of design variables. The nonlinear programming optimization formulation of the composite blade is as follows:

\subsubsection{Objective Function}

The objective function is to minimize the weight of the blade given by:

$$
W=\sum_{j=1}^{m} \rho_{j} A_{j} t_{j}
$$

where $\rho_{j}$ is the material density for each member, $A_{j}$ is the cross-sectional area of the shell element, $t_{j}$ is the thickness of the element and $m$ is the total number of elements, or 3162 elements.

\subsubsection{Constraints}

For the blade, the constraints $g$, are imposed on the strength ratio for each ply group as well as radial displacements on two tip nodes. The two tip nodes are shown in Figure 25. The calculation of the strength ratio depends on the evaluated stress and is implemented in MSC/Nastran using the TSAI-WU failure criteria, given in Equation (8). The strength ratio can be considered as margin of safety and shows how far along the particular ply is to failure. 


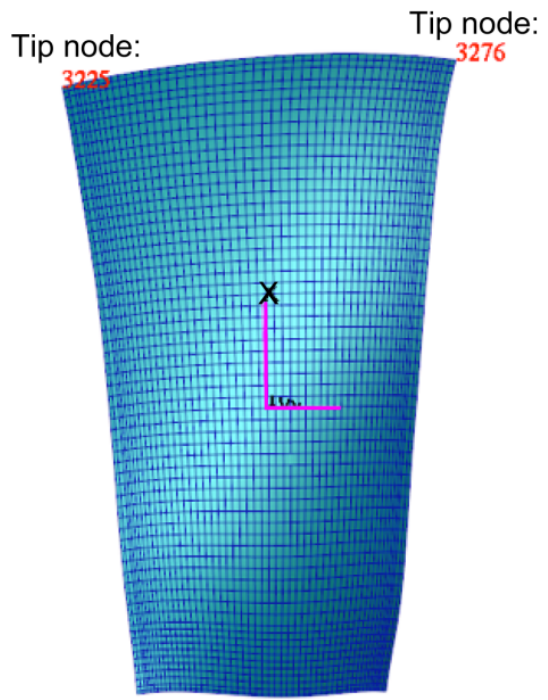

Figure 25.-Node number locations of radial displacements.

\subsubsection{Strength Ratio Constraints}

For the composite blade optimization, the strength ratio constraints are formulated as:

$$
g_{j}=1-\frac{\mathrm{SR}_{j}}{\mathrm{SR}_{0}} \leq 0, \quad j=1, \ldots, N s
$$

where $\mathrm{SR}_{j}$ is the strength ratio parameter calculated as the ratio between failure stress and the actual stress, $\mathrm{SR}_{0}$ is the safety factor and $N s$ is the number of stress constraints. For the blade, the strength ratio for the 15 design groups are considered as the constraints in the optimization problem. The limitation on the strength ratio includes a safety factor (SF) in the range of $(1.5<\mathrm{SF}<3.0)$. The strength ratio constraints taking into account the safety factor are formulated as:

$$
\begin{gathered}
g_{j}=1.5-\frac{\mathrm{SR}_{j}}{\mathrm{SR}_{0}} \leq 0, \quad j=1, \ldots, 15 \\
g_{j}=\frac{\mathrm{SR}_{j}}{\mathrm{SR}_{0}}-3 \leq 0, \quad j=1, \ldots, 15
\end{gathered}
$$

\subsubsection{Radial Displacement Constraints}

The equation which describes the radial displacement at any radial position is the dot product of the displacement vector and the unit vector in the radial direction, given as:

$$
v_{R}=\frac{r \cdot u}{|u|}
$$


where $r$ is the displacement value obtained from static analysis in y-z plane at the tip node and $u$ is the $(y, z)$ coordinate locations of the tip node. For the blade, $x$-axis is the axis of rotation and consequently when $y$ and $z$ are zero we are at the center of the circle. Therefore, the $y$ and $z$ coordinates of a given point also represents the radial direction. The displacement constraints in the optimization computer code are specified as:

$$
g_{j}=\frac{u}{u_{0}}-1 \leq 0, \quad j=1,2
$$

where $u$ is the calculated radial displacement at the tip of the blade, $u_{0}$ is the maximum displacement allowable or $0.5 \mathrm{in}$., taking into consideration the deformed blade tip clearance requirement of less than or equal to $0.5 \mathrm{in}$. The total number of displacement constraints is 2 . For the composite blade, the two radial displacements are calculated at the corner tip nodes, 3225 and 3276 of the leading and trailing edges, as shown in Figure 25.

Coordinate locations and displacement values at tip node 3225 are expressed as:

$$
u=\left\{\begin{array}{l}
y \\
z
\end{array}\right\}=\left\{\begin{array}{l}
-12.1351 \\
71.3424
\end{array}\right\} ; \quad r=\left\{\begin{array}{l}
-7.9256 \\
-1.7210
\end{array}\right\}
$$

where vector $u$ represents the coordinates values and $r$ the displacement values from the static analysis run. The radial displacement at tip node 3225 is calculated as follows:

$$
v_{R}=\frac{r \cdot u}{|u|}=\frac{(-7.9256)(-12.1351)+(-1.7210)(71.3424)}{\sqrt{(12.1351)^{2}+(71.3424)^{2}}}=\frac{-26.6023}{72.3671}=-0.3676 \mathrm{in} .
$$

Coordinate locations and displacement values at tip node 3276 are:

$$
u=\left\{\begin{array}{l}
y \\
z
\end{array}\right\}=\left\{\begin{array}{l}
10.3786 \\
69.7165
\end{array}\right\} ; \quad r=\left\{\begin{array}{c}
-5.6709 \\
1.3826
\end{array}\right\}
$$

where $u$ represents the coordinates values and $r$ the displacement values from the static analysis run. Radial displacement at tip node 3276 is calculated via the expression:

$$
v_{R}=\frac{r \cdot u}{|u|}=\frac{(-5.6709)(10.3786)+(1.3826)(69.7165)}{\sqrt{(10.3786)^{2}+(69.7165)^{2}}}=\frac{37.534}{70.4848}=0.5325 \mathrm{in} .
$$

\subsubsection{Design Variables}

Fifteen design variables are specified in the formulation of the sandwich composite blade. These design variables represent the linking of the 3162 elements into the 15 ply groups. Design variables are defined such that by selecting an initial ply thickness and allowing the thickness of the core plies to vary with a particular fiber orientation for every element, the total laminate thickness can change continuously throughout the blade and at the same time, the shape of the aerodynamic profile remains fixed. Since the honeycomb core ply is constructed for design variables 7 to 15, the first 6 design variables are considered 
passive in the optimization process. Manufacturing constraints or side constraints such as lower and upper bounds on the plies are imposed, limiting the size of the core thickness variables as:

$$
\left(x_{i}^{L B} \leq x_{i} \leq x_{i}^{U B}, i=1,2, \ldots, n\right)
$$

where $x$ represents the design variable, $L B$ and $U B$ are the lower and upper bounds respectively and $n$ is the number of design variables.

In the optimization process, the general formula to update the design variables, $\left(x_{j}\right)$ in a nonlinear programming algorithm at the $k^{\text {th }}$ intermediate iteration is given as:

$$
\{x\}_{k}=\{x\}_{k-1}+\alpha_{k-1}\{d\}_{k-1}
$$

where the step length $\alpha_{k-1}$ is calculated to find the local minimum of the objective or weight in this study along the direction $\{d\}_{k-1}$ in the feasible domain.

\subsection{Optimization Results of the Composite Blade Design}

Optimization algorithms NEWSUMT (Ref. 3) and NLPQ (Ref. 4), both available in OpenMDAO Framework (Ref. 1), are used for obtaining the optimum design of the composite sandwich fan blade.

The minimization algorithm used in NEWSUMT is a Sequence of Unconstrained Minimizations Technique. The major features of NEWSUMT include a modified Newton's method where the second derivatives of the penalty function are approximated by expressions involving only the first derivatives. Another major feature is an extended interior penalty function formulation where it combines the interior and exterior penalty functions. The code is written in Fortran and is very efficient for solving linear and nonlinear constrained or unconstrained minimization problems. This optimizer is included in the OpenMDAO standard library to provide users with a basic gradient-based optimization algorithm.

NLPQ is another gradient-based optimizer available in OpenMDAO although, it is not publicly accessible. NLPQ (NonLinear Programming by Quadratic Langragian) solves nonlinear optimization problems. NLPQ generates a sequence of quadratic programming subproblems obtained by a quadratic approximation of the Lagrangian function and linearization of constraints. This algorithm is also very efficient and in most cases requires fewer function calls than NEWSUMT. However, this algorithm has recently been implemented in the OpenMDAO Framework and the default parameters, such as convergence criteria and step length have been used in the present work, thus requiring greater CPU time than NEWSUMT method. Further development of the OpenMDAO is expected to result in significantly shorter CPU time for the NLPQ optimizer.

In general, structural optimization takes a great deal of computation time because in every iteration a complete finite element analysis is required. The number of iterations, however, can be kept down by a good estimate of the initial values of the design variables. On the other hand, for the sandwich composite blade model, it is nearly impossible to predict a favorable initial design for each layer because of the complexity of the fan blade design and the ply lay-up shapes.

The CPU time in the optimization process for the composite blade design running on a Linux x86_64 workstation at $2.67 \mathrm{GHz}$ was high. NEWSUMT optimizer took 79,799 sec or $22 \mathrm{hr}$ and NLPQ 95,820 sec or $26 \mathrm{hr}$.

\subsection{Static Results of the Optimized Composite Design}

The optimum weight iteration history plot obtained from the two optimization methods is shown in Figure 26. It should be noted that the initial design was not feasible because at least one strength ratio 
constraint was violated, in particular constraint numbers 1 , 7, and 8 , as shown in Table 10 . The optimum weight calculated by NEWSUMT was $27.68 \mathrm{lb}$. The CPU time to convergence was $22 \mathrm{hr}$ with 34 iterations, 998 objective function calls, 408 constraint functions and 284 approximate constraint function calls. The weight is slightly higher than the initial weight of 25.56, but this is reasonable as explained in the next section observing the activity of the response constraints. The convergence from NLPQ optimizer was not achieved at the maximum number of iterations allowed, 100, although the CPU time for NLPQ was $26 \mathrm{hr}$. Figure 26 shows that the optimizer had reached convergence at about iteration number 60 , but due to some other parameter setting, was not able to stop. The weight by NLPQ is $28.07 \mathrm{lb}$, which is also slightly higher that the initial weight of $25.56 \mathrm{lb}$ by 9.75 percent, as shown in Table 8 .

Maximum principal stress and maximum shear stress results with percent differences are given in Table 8. Principal stress values were reduced from the initial design by about 8 percent for both optimization methods. Shear stresses were also reduced by both methods by about 9.5 percent. The magnitude of the displacement was reduced by about 8.8 percent for both NEWSUMT and NLPQ optimizers. Deformation results are depicted in Table 9.

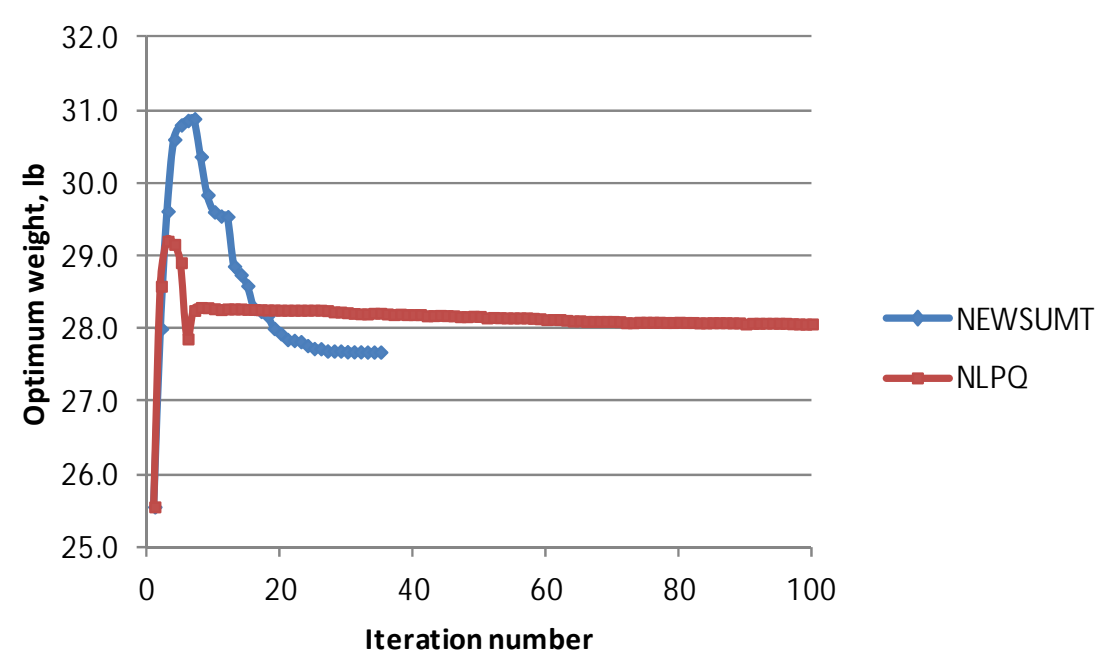

Figure 26.-Optimum weight with number of iterations from NEWSUMT and NLPQ.

TABLE 8.-COMPARISON OF STATIC ANALYSIS RESULTS AND WEIGHT FOR INITIAL AND OPTIMUM DESIGNS

\begin{tabular}{|l|c|c|c|c|c|}
\hline & Initial & $\begin{array}{c}\text { NEWSUMT } \\
\text { optimum }\end{array}$ & $\begin{array}{c}\text { NLPQ } \\
\text { optimum }\end{array}$ & $\begin{array}{c}\text { Percent } \\
\text { difference } \\
\text { NEWSUMT }\end{array}$ & $\begin{array}{c}\text { Percent } \\
\text { difference } \\
\text { NLPQ }\end{array}$ \\
\hline Max principal stress, psi & 117943.0 & 108102.0 & 107921.2 & -8.34 & -8.50 \\
\hline Max shear stress, psi & 59768.47 & 54051.13 & 53960.69 & -9.57 & -9.72 \\
\hline Displacement, resultant, in. & & & & & \\
\hline Displacement, z-direction, in. & 9.38 & 8.56 & 8.55 & -8.74 & -8.85 \\
\hline & 1.40 & 1.27 & 1.28 & -9.29 & -8.57 \\
\hline Weight (lb) & & & & & \\
\hline
\end{tabular}


TABLE 9.-COMPARISON OF TIP DISPLACEMENTS VALUES FOR INITIAL AND OPTIMUM DESIGNS

\begin{tabular}{|c|c|c|c|c|c|c|}
\hline $\begin{array}{c}\text { Constraint } \\
\text { number: } \\
\text { tip node }\end{array}$ & Initial & $\begin{array}{c}\text { NEWSUMT } \\
\text { optimum }\end{array}$ & $\begin{array}{c}\text { NLPQ } \\
\text { optimum }\end{array}$ & $\begin{array}{c}\text { NEWSUMT } \\
\text { percent } \\
\text { difference }\end{array}$ & $\begin{array}{c}\text { NLPQ } \\
\text { percent } \\
\text { difference }\end{array}$ & Remarks \\
\hline $16: 3225$ & -0.374 & -0.340 & -0.341 & -9.26 & -8.84 & \\
\hline $17: 3276$ & 0.549 & 0.500 & 0.500 & -8.98 & -8.98 & Active \\
\hline
\end{tabular}

TABLE 10.-COMPARISON OF STRENGTH RATIO CONSTRAINT

VALUES BETWEEN INITIAL AND OPTIMUM DESIGNS

\begin{tabular}{|c|c|c|c|c|c|c|}
\hline $\begin{array}{c}\text { Constraint } \\
\text { number }\end{array}$ & $\begin{array}{c}\text { Initial } \\
\text { strength ratio }\end{array}$ & $\begin{array}{c}\text { NEWSUMT } \\
\text { optimum } \\
\text { strength ratio }\end{array}$ & $\begin{array}{c}\text { NLPQ } \\
\text { optimum } \\
\text { strength ratio }\end{array}$ & $\begin{array}{c}\text { NEWSUMT } \\
\text { percent } \\
\text { difference }\end{array}$ & $\begin{array}{c}\text { NLPQ percent } \\
\text { difference }\end{array}$ & Remarks \\
\hline 1 & 1.356 & 1.580 & 1.538 & 16.52 & 13.42 & Active \\
\hline 2 & 1.681 & 1.853 & 1.894 & 10.23 & 12.67 & \\
\hline 3 & 1.780 & 2.070 & 1.953 & 16.29 & 9.72 & \\
\hline 4 & 1.874 & 2.293 & 2.091 & 22.36 & 11.58 & \\
\hline 5 & 1.821 & 2.280 & 2.002 & 25.21 & 9.94 & \\
\hline 6 & 1.857 & 2.029 & 1.982 & 9.26 & 6.73 & \\
\hline 7 & 1.216 & 1.508 & 1.500 & 24.01 & 23.36 & Active \\
\hline 8 & 1.422 & 1.788 & 1.666 & 25.74 & 17.16 & \\
\hline 9 & 1.572 & 1.908 & 1.927 & 21.37 & 22.58 & \\
\hline 10 & 1.629 & 1.772 & 1.869 & 8.78 & 14.73 & \\
\hline 11 & 1.621 & 1.979 & 1.809 & 22.09 & 11.60 & \\
\hline 12 & 1.766 & 1.731 & 1.745 & -1.98 & -1.19 & \\
\hline 13 & 1.904 & 1.802 & 1.711 & -5.36 & -10.14 & \\
\hline 14 & 2.169 & 1.931 & 2.314 & -10.97 & 6.69 & \\
\hline 15 & 2.400 & 1.973 & 2.157 & -17.79 & -10.13 & \\
\hline
\end{tabular}

The optimum weight however, increased slightly. The increase in the optimum weight by both optimizers is due to constraint numbers 1,7 , and 8 which were initially violated with strength ratios of $1.356,1.216$, and 1.422 respectively, which are below the minimum allowable of 1.5 (Table 10). The optimization process made these constraints feasible and active by both optimization methods, as shown in Table 10. The optimized strength ratio value for constraint numbers 1,7 , and 8 became 1.580, 1.508, and 1.788 by NEWSUMT and $1.538,1.5$, and 1.666 by NLPQ optimizer. Constraint number 17, which is the radial displacement at tip node 3276, became active by both optimizers. (Active constraint is assumed to be within 0.02 percent of the lower and/or upper bound). Stress plots of these results are shown in Figure 27 and deformation plots in Figure 28.

Failure indices and strength ratio plots from the NEWSUMT optimum design are depicted in Figure 29. The optimum composite blade design does not exhibit any ply failures since the maximum failure index is 0.483 which is less than 1.0 and the minimum strength ratio over the 15 design groups is greater than 1.58 which takes into account the minimum safety factor of 1.5. Strength ratio of less than 1.0 exhibits ply failure. 


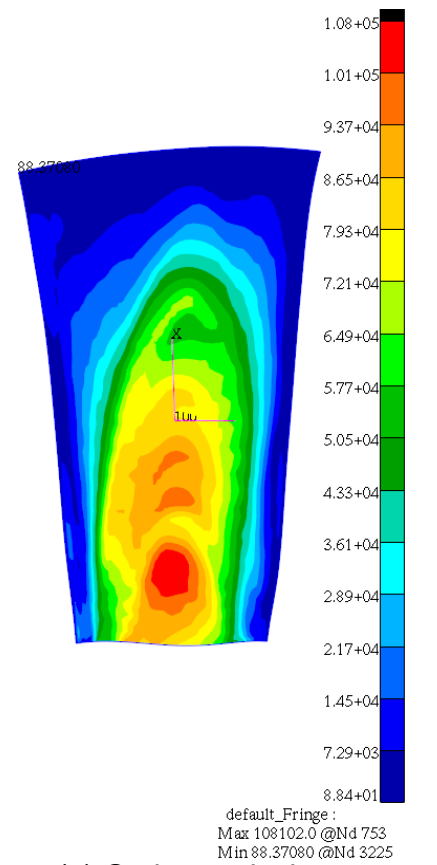

(a) Optimum design:

Max Principal Stress $=108,102 \mathrm{psi}$

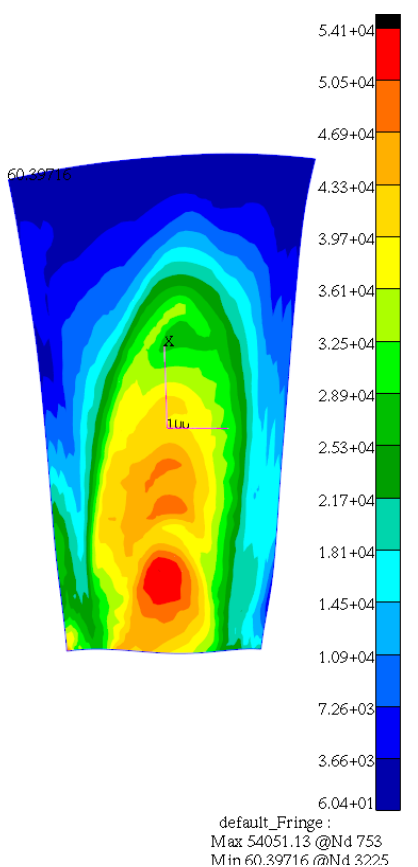

(b) Optimum design:

Max Shear Stress $=54,051 \mathrm{psi}$

Figure 27.-Optimum design of the composite blade results (a) maximum principal stress, (b) maximum shear stress.

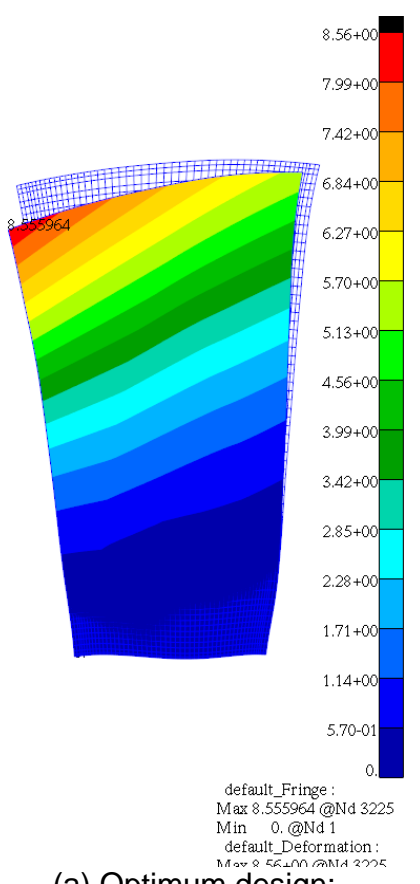

(a) Optimum design:

Displacement Resultant $=8.56$ in .

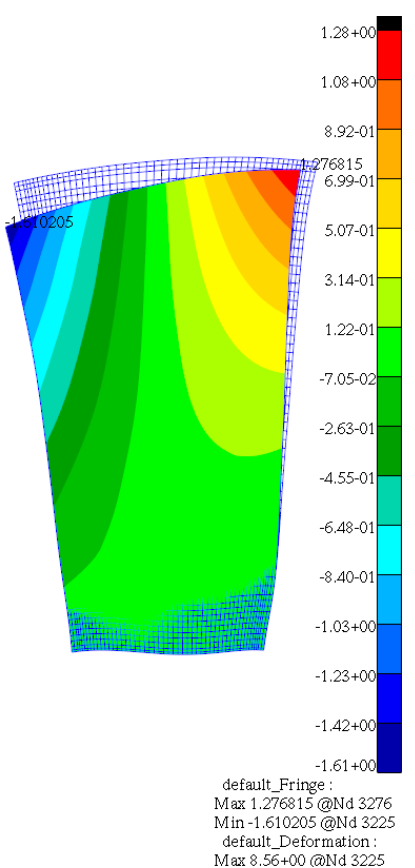

(b) Optimum design:

Displacement z-direction $=1.27$ in.

Figure 28.-Optimum design of the composite blade results (a) displacement resultant, (b) displacement in z-direction. 


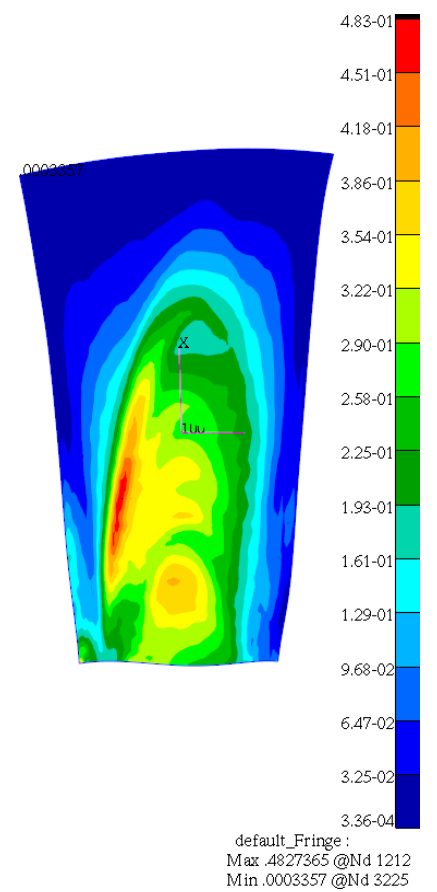

(a) Optimum design: Failure indices $(\mathrm{FI})<0.483$

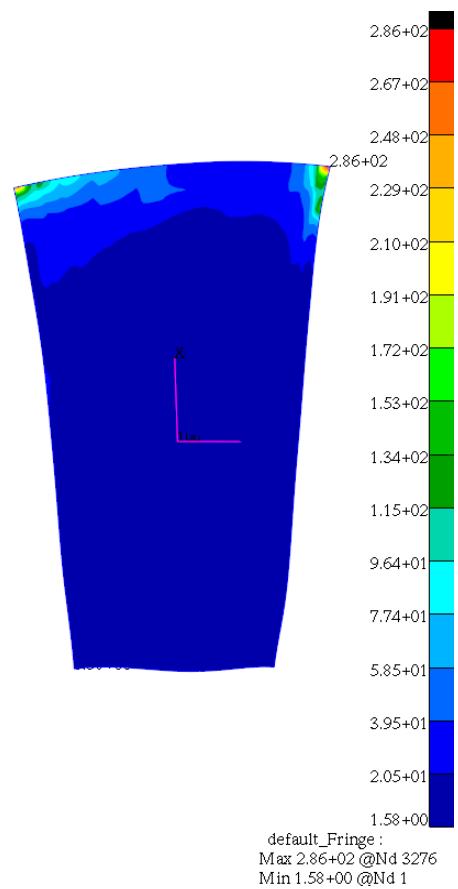

(b) Optimum design: Strength ratios (SR) $>1.58$

Figure 29._Optimum design: (a) failure index, (b) strength ratio.

TABLE 11.-COMPARISON OF INITIAL AND OPTIMUM DESIGNS OF THE COMPOSITE BLADE

\begin{tabular}{|c|c|c|c|c|c|c|c|c|}
\hline \multirow{2}{*}{$\begin{array}{c}\text { Design } \\
\text { variable }\end{array}$} & \multirow{2}{*}{$\begin{array}{c}\text { Initial } \\
\text { number of } \\
\text { plies }\end{array}$} & \multirow{2}{*}{$\begin{array}{l}\text { Initial ply } \\
\text { thickness }\end{array}$} & \multirow{2}{*}{$\begin{array}{l}\text { Initial core } \\
\text { thickness }\end{array}$} & \multirow{2}{*}{$\begin{array}{c}\text { Total } \\
\text { laminate } \\
\text { thickness }\end{array}$} & \multicolumn{2}{|c|}{ NEWSUMT } & \multicolumn{2}{|c|}{ NLPQ } \\
\hline & & & & & $\begin{array}{l}\text { Optimum } \\
\text { ply } \\
\text { thickness }\end{array}$ & $\begin{array}{c}\text { Optimum } \\
\text { core } \\
\text { thickness }\end{array}$ & $\begin{array}{l}\text { Optimum } \\
\text { ply } \\
\text { thickness }\end{array}$ & $\begin{array}{l}\text { Optimum } \\
\text { core } \\
\text { thickness }\end{array}$ \\
\hline 1 & 4 & 0.025 & 0.000 & 0.1 & 0.025 & 0.000 & 0.025 & 0.000 \\
\hline 2 & 8 & 0.025 & 0.000 & 0.2 & 0.025 & 0.000 & 0.025 & 0.000 \\
\hline 3 & 12 & 0.025 & 0.000 & 0.3 & 0.025 & 0.000 & 0.025 & 0.000 \\
\hline 4 & 16 & 0.025 & 0.000 & 0.4 & 0.025 & 0.000 & 0.025 & 0.000 \\
\hline 5 & 20 & 0.025 & 0.000 & 0.5 & 0.025 & 0.000 & 0.025 & 0.000 \\
\hline 6 & 24 & 0.025 & 0.000 & 0.6 & 0.025 & 0.000 & 0.025 & 0.000 \\
\hline 7 & 8 & 0.025 & 0.500 & 0.7 & 0.033 & 0.434 & 0.038 & 0.395 \\
\hline 8 & 12 & 0.025 & 0.500 & 0.8 & 0.034 & 0.388 & 0.032 & 0.415 \\
\hline 9 & 16 & 0.025 & 0.500 & 0.9 & 0.033 & 0.374 & 0.035 & 0.345 \\
\hline 10 & 20 & 0.025 & 0.500 & 1 & 0.029 & 0.424 & 0.032 & 0.358 \\
\hline 11 & 24 & 0.025 & 0.500 & 1.1 & 0.045 & 0.015 & 0.030 & 0.386 \\
\hline 12 & 28 & 0.025 & 0.500 & 1.2 & 0.024 & 0.529 & 0.024 & 0.534 \\
\hline 13 & 32 & 0.025 & 0.500 & 1.3 & 0.022 & 0.601 & 0.021 & 0.617 \\
\hline 14 & 36 & 0.025 & 0.500 & 1.4 & 0.019 & 0.711 & 0.038 & 0.015 \\
\hline 15 & 40 & 0.025 & 0.500 & 1.5 & 0.017 & 0.826 & 0.021 & 0.664 \\
\hline
\end{tabular}

The optimum design by both NEWSUMT and NLPQ optimization methods along with a comparison with the initial design of the composite blade, are shown in Table 11. For the first six design groups, ply thickness was passive in the optimization process (i.e., not allowed to vary). The honeycomb core thickness was updated for design variables 7 thought 15 as shown in Table 11. The lower and upper bounds of the design variables were set at 0.001 and 1.0 in., respectively. For NEWSUMT the minimum core thickness varied between 0.015 in. for design group 11 and 0.826 in. for design group 15 . The ply thickness in column 6 for NEWSUMT and column 8 for NLPQ both in Table 11 is calculated as follows: 
Optimum ply thickness $=($ total laminate thickness - optimum core thickness $) /$ initial number of plies

In the optimization results, the total laminate thickness for each design group remains at the same value as the initial laminate thickness thus maintaining the aerodynamic and geometric parameters and verified as follows:

Total laminate thickness $=$ initial number of plies*(optimum ply thickness $)+$ optimum core thickness

\subsection{Dynamic Analysis Results of the Optimized Composite Design}

Dynamic analysis results of the optimized design of the composite blade were calculated using MSC/Nastran SOL 103 analysis solver (Ref. 2). Results of the first six natural modes from the MSC/Nastran dynamic calculations and comparison with the initial frequency of the composite design are summarized in Table 12. Similar to the initial composite design results, all six modes are evenly distributed in the frequency domain. Eigenvalue plots of the first six natural modes are depicted in Figure 30(a) to (c) and Figure 31(a) to (c). The modes depicted in the figures can be divided into bending modes $\left(1^{\text {st }}, 2^{\text {nd }}, 4^{\text {th }}\right.$, and $6^{\text {th }}$ modes $)$ and torsion modes $\left(3^{\text {rd }}\right.$ and $5^{\text {th }}$ modes $)$.

TABLE 12.-COMPARISON OF NATURAL FREQUENCIES (HZ) FOR THE INITIAL AND OPTIMIZED COMPOSITE DESIGN

\begin{tabular}{|l|c|c|c|c|c|}
\hline Mode number & $\begin{array}{c}\text { Initial } \\
\text { frequency }\end{array}$ & $\begin{array}{c}\text { Optimum } \\
\text { frequency } \\
\text { NEWSUMT }\end{array}$ & $\begin{array}{c}\text { Optimum } \\
\text { frequency } \\
\text { NLPQ }\end{array}$ & $\begin{array}{c}\text { Percent } \\
\text { difference } \\
\text { NEWSUMT }\end{array}$ & $\begin{array}{c}\text { Percent } \\
\text { difference } \\
\text { NLPQ }\end{array}$ \\
\hline Mode 1 & 19.472 & 19.915 & 19.773 & 2.28 & 1.55 \\
\hline Mode 2 & 58.792 & 63.075 & 60.745 & 7.29 & 3.32 \\
\hline Mode 3 & 110.320 & 115.372 & 114.745 & 4.58 & 4.01 \\
\hline Mode 4 & 150.936 & 158.179 & 153.801 & 4.80 & 1.90 \\
\hline Mode 5 & 248.470 & 251.893 & 251.541 & 1.38 & 1.24 \\
\hline Mode 6 & 263.912 & 268.871 & 270.126 & 1.88 & 2.35 \\
\hline
\end{tabular}

$\therefore$ Default, Mode 1:Freq. $=19.915$, Eigenvectors, Translati

: Default, Mode 2:Freq. $=63.075$, Eigenvectors, Translatic Default, Mode 3:Freq. $=115.37$, Eigenvectors, Translational,

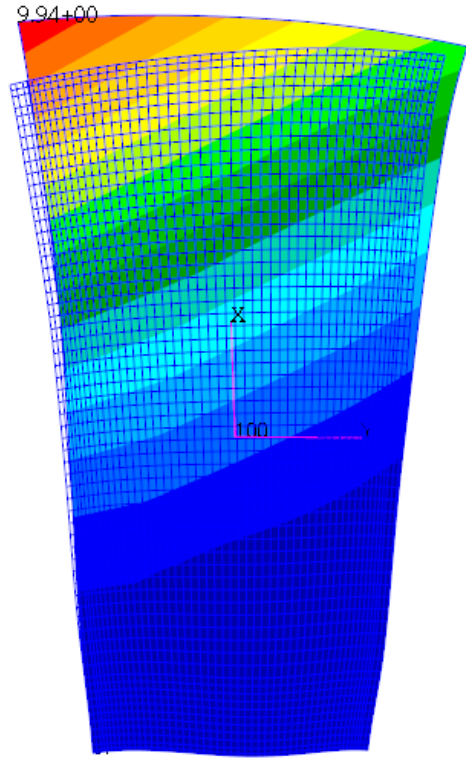

(a) Optimum design

Mode 1: Frequency $=19.915 \mathrm{~Hz}$

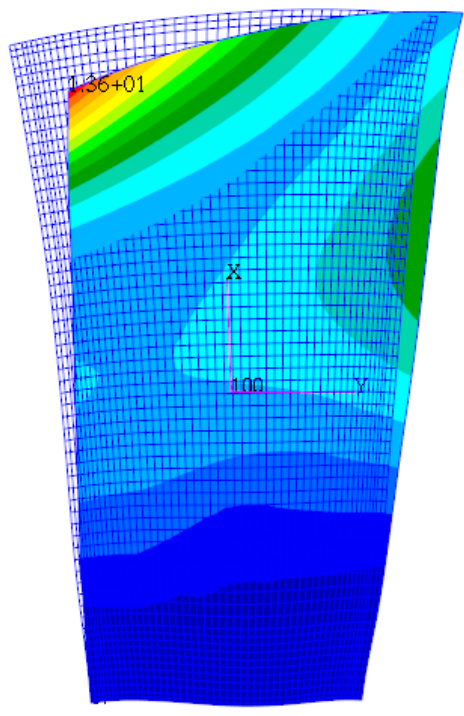

(b) Optimum design Mode 2: Frequency $=63.075 \mathrm{~Hz}$

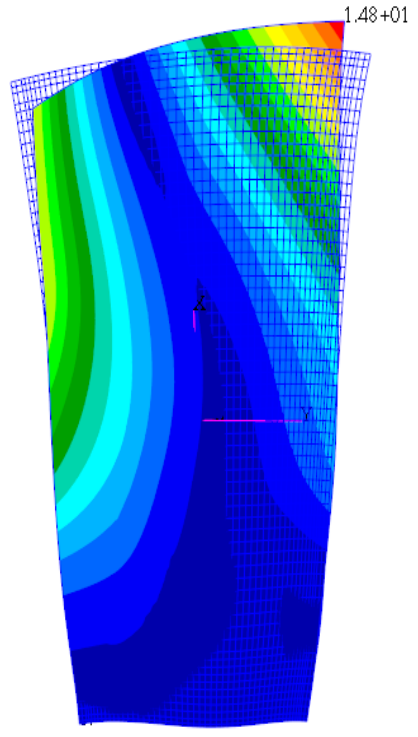

(c) Optimum design Mode 3: Frequency $=115.37 \mathrm{~Hz}$

Figure 30.—Mode shapes for the optimum design of the composite blade (a) mode 1, (b) mode 2, (c) mode 3. 


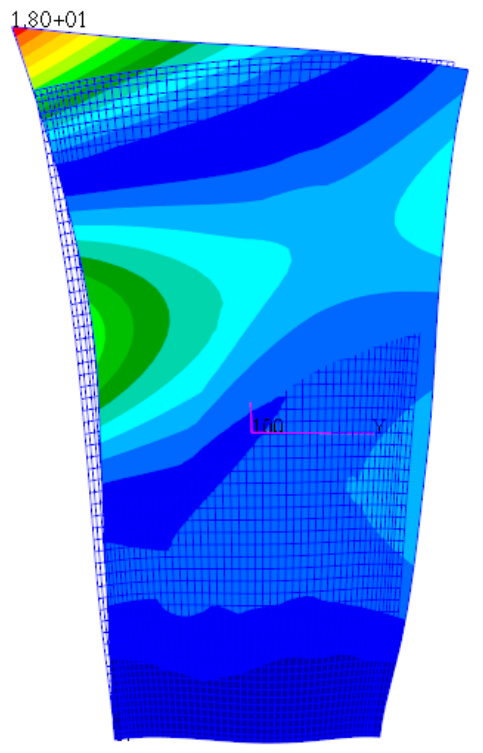

(a) Optimum design

Mode 4: Frequency $=158.179 \mathrm{~Hz}$

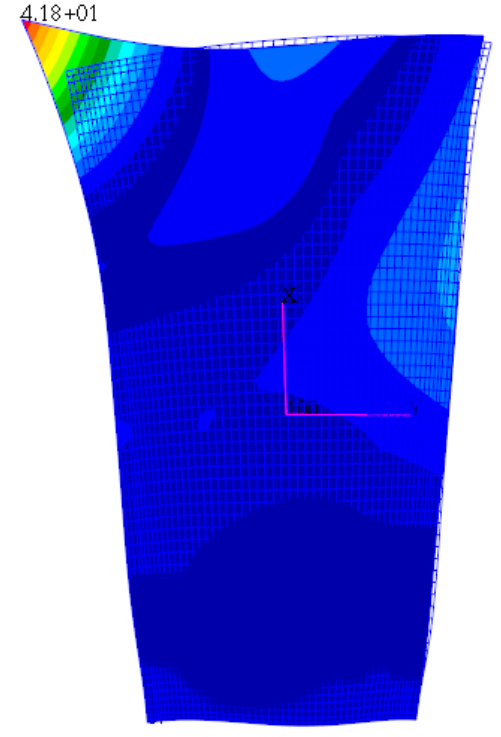

(b) Optimum design Mode 5: Frequency $=251.893 \mathrm{~Hz}$

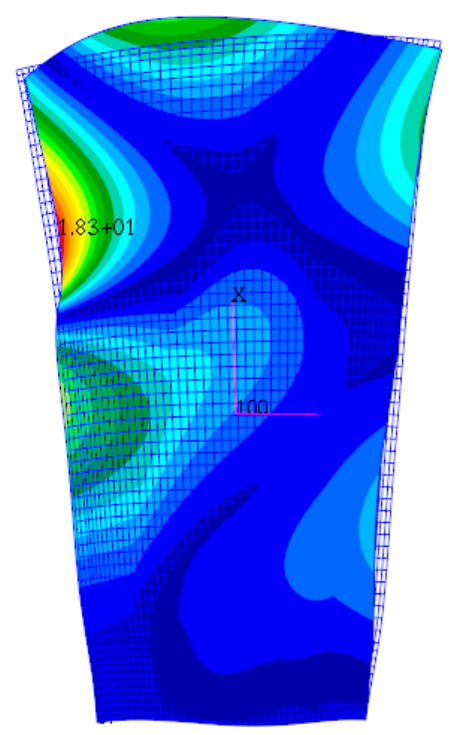

(c) Optimum design Mode 6: Frequency $=268.871 \mathrm{~Hz}$

Figure 31.-Mode shapes for the optimum design of the composite blade (a) mode 4, (b) mode 5, (c) mode 6.

\subsection{Discrete Optimization to Obtain Number of Plies}

Discrete optimization is performed to obtain the optimum number of plies. Once the optimum design is obtained from the optimizer, discrete optimization and final static analysis is performed to obtain the minimum number of plies and the optimum weight. Table 13 depicts the number of plies back-calculated from the NEWSUMT optimum design. Design variables (1 to 6) remain passive. The calculation is approximated by rounding up the real numbers to integers as shown in Column 4 of Table 13. The ply lay-up is adjusted to fit the specified ply lay-up, which is in increments of 4 plies, as shown earlier for the symmetric lay-up specification in Table 5. The core thickness of the blade (last column in Table 13) and the optimum number of plies $\left(3^{\text {rd }}\right.$ column in Table 13) are back-calculated as follows:

Core thickness $=$ Total laminate thickness $-($ optimum number of plies*0.025)

Optimum number of plies $=($ Optimum ply thickness $) *($ Initial number of plies $) / 0.025$, where 0.025 in the assumed initial ply thickness.

The number of plies for NLPQ is back-calculated following the same process as NEWSUMT. Results at the final iteration are considered for this method since convergence was not fully achieved. The number of plies back-calculated from the NLPQ last iteration, considered as optimum, are given in Table 14. The core thickness and optimum number of plies are calculated as presented above for the NEWSUMT design. 
TABLE 13.-NUMBER OF PLIES BACK-CALCULATED FROM NEWSUMT OPTIMUM DESIGN

\begin{tabular}{|c|c|c|c|c|c|}
\hline Design variable & $\begin{array}{c}\text { Initial number } \\
\text { of plies }\end{array}$ & $\begin{array}{c}\text { Optimum number } \\
\text { of plies }\end{array}$ & $\begin{array}{c}\text { Round optimum } \\
\text { number of plies }\end{array}$ & $\begin{array}{c}\text { Adjust for } \\
\text { symmetric } \\
\text { ply lay-up }\end{array}$ & $\begin{array}{c}\text { Updated } \\
\text { half core thickness } \\
\text { (symmetric) }\end{array}$ \\
\hline 1 & 4 & 4 & 4 & 2 & 0 \\
\hline 2 & 8 & 8 & 8 & 4 & 0 \\
\hline 3 & 12 & 12 & 12 & 6 & 0 \\
\hline 4 & 16 & 16 & 16 & 10 & 0 \\
\hline 5 & 20 & 20 & 20 & 12 & 0 \\
\hline 6 & 24 & 24 & 24 & 6 & 0.200 \\
\hline 7 & 8 & 10.624 & 11 & 16 & 0.200 \\
\hline 8 & 12 & 16.478 & 21 & 12 & 0.200 \\
\hline 9 & 16 & 21.041 & 23 & 22 & 0.200 \\
\hline 10 & 20 & 23.049 & 43 & 14 & 0.000 \\
\hline 11 & 24 & 43.397 & 27 & 14 & 0.250 \\
\hline 12 & 28 & 26.829 & 28 & 14 & 0.300 \\
\hline 14 & 32 & 27.976 & 28 & 14 & 0.350 \\
\hline 15 & 36 & 27.560 & 27 & & 0.400 \\
\hline
\end{tabular}

TABLE 14.-NUMBER OF PLIES BACK-CALCULATED FROM NLPQ OPTIMUM DESIGN

\begin{tabular}{|c|c|c|c|c|c|}
\hline Design variable & $\begin{array}{c}\text { Initial number } \\
\text { of plies }\end{array}$ & $\begin{array}{c}\text { Optimum number } \\
\text { of plies }\end{array}$ & $\begin{array}{c}\text { Round optimum } \\
\text { number of plies }\end{array}$ & $\begin{array}{c}\text { Adjust for } \\
\text { symmetric } \\
\text { ply lay-up }\end{array}$ & $\begin{array}{c}\text { Updated } \\
\text { half core thickness } \\
\text { (symmetric) }\end{array}$ \\
\hline 1 & 4 & 4 & 4 & 2 & 0 \\
\hline 2 & 8 & 8 & 8 & 4 & 0 \\
\hline 3 & 12 & 12 & 12 & 6 & 0 \\
\hline 4 & 16 & 16 & 16 & 10 & 0 \\
\hline 5 & 20 & 20 & 20 & 12 & 0 \\
\hline 6 & 24 & 24 & 24 & 6 & 0.200 \\
\hline 7 & 8 & 10.624 & 11 & 10 & 0.200 \\
\hline 8 & 12 & 16.478 & 16 & 22 & 0.200 \\
\hline 9 & 16 & 21.041 & 21 & 12 & 0.200 \\
\hline 10 & 20 & 23.049 & 23 & 14 & 0.000 \\
\hline 11 & 24 & 43.397 & 43 & 27 & 0.250 \\
\hline 12 & 28 & 26.829 & 28 & 14 & 0.300 \\
\hline 14 & 32 & 27.976 & 28 & 14 & 0.350 \\
\hline 15 & 36 & 27.560 & 27 & & 0.400 \\
\hline
\end{tabular}

\subsection{Final Analysis Results and Discussion of the Optimized Composite Blade}

Final static and dynamic analyses is required in the final step of the sandwich composite blade design process to calculate/verify the final weight, ply strength ratios, deformations and mode shapes using the optimum ply lay-up sequence, number of plies and corresponding core thicknesses.

In this final step, MSC/Nastran database PCOMP entries are updated with the new number of plies and core thickness and final static (SOL 101) and dynamic (SOL 103) analyses are executed. The integer number of plies and core thickness from the NEWSUMT design, as given in Table 13 columns 5 and 6 , and the design obtained from NLPQ optimizer, as given in Table 14, columns 5 and 6, were considered for the final analysis of the sandwich composite blade, in two separate runs. 
The initial ply thickness for the all design variables remained fixed at $0.025 \mathrm{in}$. The core thicknesses of design variables 7 to 15 and the number of plies for these variables, as given in the last column of Tables 13 and 14 were entered in the PCOMP cards in the MSC/Nastran database for each of the runs. The final number of plies and core thicknesses for each design variable group is shown in Table 15. From Table 15 we observe the following:

- For design variable 7, the number of plies was increased to 12 from 8 for both NEWSUMT and NLPQ optimizers and the core thickness was reduced from the initial 0.5 to 0.4 in.

- For design variable 8, the number of plies was increased to 16 from 12 with both optimizers while the core thickness was reduced from the initial 0.5 to 0.4 in.

- For design variable 9, the number of plies was increased to 20 from 16 with both optimizers while the core thickness was reduced from the initial 0.5 to 0.4 in.

- For design variable 10, the number of plies was increased to 24 from 20 with both optimizers while the core thickness was reduced from the initial 0.5 to 0.4 in.

- For design variable 11, the number of plies was increased to 44 from 24 with NEWSUMT optimization process while the core thickness was reduced from the initial 0.5 to 0.0 in. Therefore, no core thickness is required in the final analysis run for design variable 11 but the number of plies was increased from 24 to 44 . With the NLPQ optimum design the number of plies was increased to 28 from the initial 24 and the core thickness was reduced to 0.4 from the initial 0.5 in.

- For design variable 12, the number of plies and core thickness remained unchanged at 28 plies with core thickness of 0.5 in. for both optimizers.

- For design variable 13, the number of plies was reduced to 28 from 32 while the core thickness increased to 0.6 in. from the initial 0.5 in., with both optimizers.

- For design variable 14, the number of plies was reduced to 28 from 36 with NEWSUMT optimizer with increased core thickness to 0.7 in. from the initial $0.5 \mathrm{in}$. With the NLPQ optimum design the number of plies were increased to 56 and no core ply.

- For design variable 15, the number of plies was reduced to 28 from 40 with NEWSUMT optimizer while the core thickness increased to $0.8 \mathrm{in}$. from the initial $0.5 \mathrm{in}$. For NLPQ the number of plies was reduced to 32 with an increase in the core thickness to 0.7 in.

TABLE 15.-FINAL NUMBER OF PLIES AND CORE THICKNESSES COMPARED WITH INITIAL DESIGN

\begin{tabular}{|c|c|c|c|c|c|c|}
\hline \multirow{2}{*}{ Design variable: } & \multicolumn{2}{|c|}{ Initial } & \multicolumn{2}{c|}{ NEWSUMT design } & \multicolumn{2}{c|}{ NLPQ design } \\
\cline { 2 - 7 } & $\begin{array}{c}\text { Number of } \\
\text { plies }\end{array}$ & Core thickness & $\begin{array}{c}\text { Number of } \\
\text { plies }\end{array}$ & $\begin{array}{c}\text { Core } \\
\text { thickness }\end{array}$ & $\begin{array}{c}\text { Number of } \\
\text { plies }\end{array}$ & $\begin{array}{c}\text { Core } \\
\text { thickness }\end{array}$ \\
\hline 1 & 4 & 0.0 & 4 & 0.0 & 4 & 0.0 \\
\hline 2 & 8 & 0.0 & 8 & 0.0 & 8 & 0.0 \\
\hline 3 & 12 & 0.0 & 12 & 0.0 & 12 & 0.0 \\
\hline 4 & 16 & 0.0 & 16 & 0.0 & 16 & 0.0 \\
\hline 5 & 20 & 0.0 & 20 & 0.0 & 20 & 0.0 \\
\hline 6 & 24 & 0.0 & 24 & 0.0 & 24 & 0.0 \\
\hline 7 & 8 & 0.5 & 12 & 0.4 & 12 & 0.4 \\
\hline 8 & 12 & 0.5 & 16 & 0.4 & 16 & 0.4 \\
\hline 9 & 16 & 0.5 & 20 & 0.4 & 20 & 0.4 \\
\hline 10 & 20 & 0.5 & 24 & 0.4 & 24 & 0.4 \\
\hline 11 & 24 & 0.5 & 44 & 0.0 & 28 & 0.4 \\
\hline 12 & 28 & 0.5 & 28 & 0.5 & 28 & 0.5 \\
\hline 13 & 32 & 0.5 & 28 & 0.6 & 28 & 0.6 \\
\hline 14 & 36 & 0.5 & 28 & 0.7 & 56 & 0.0 \\
\hline
\end{tabular}




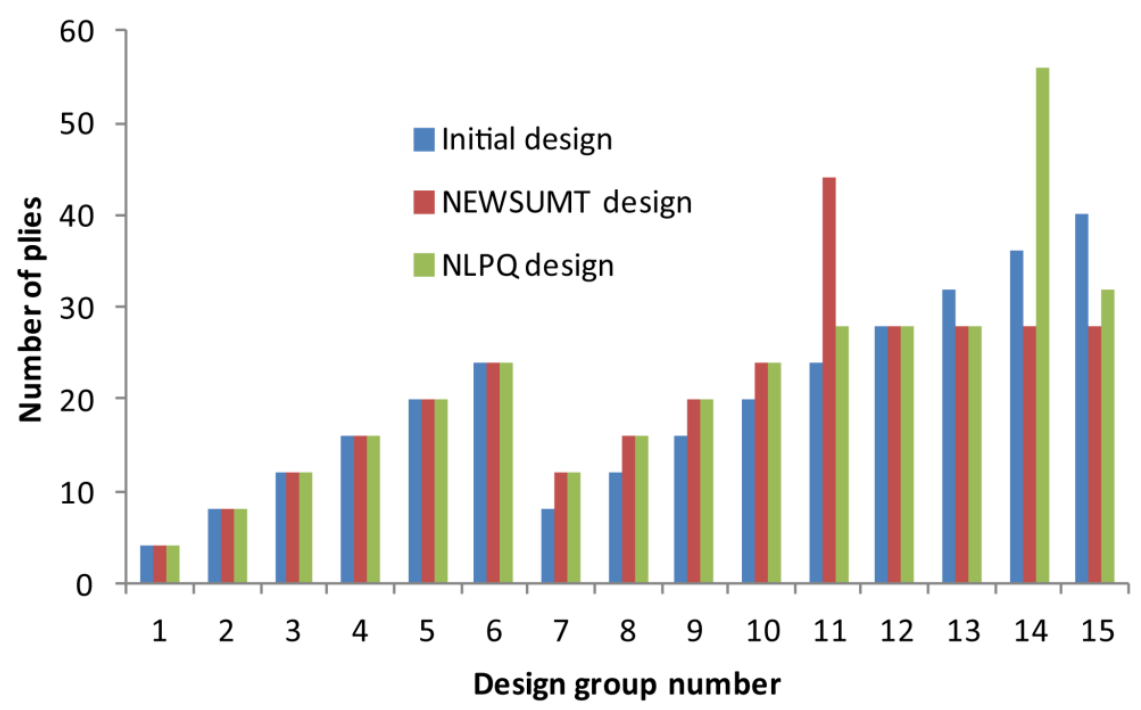

Figure 32.-Number of plies in final analysis for each design group (excluding core ply).

The number of plies in the final analysis for each design group and comparison with the initial design is plotted in Figure 32.

The final symmetric ply lay-up with the NEWSUMT optimizer for each design group, denoted with an (F), is shown in Table 16 along with comparison with the initial ply lay-up (I). Ply symmetry is denoted with a subscript ([ ] $\mathrm{s})$. In final analysis, for design group 7, four additional plies were required, shown as 90/0 in red, considering symmetry (Table 16). Similarly, for design groups 8,9 and 10, four additional plies were required in final analysis. Design group 11 required 20 additional plies with no core ply. The lay-up sequence for the additional plies that produced the best design for this design group was the $[90 / 0 / 0 / 0 / 0 / 0 / 0 / 0 / 0 / 0]$ degree angles. This is because at $[90 / 45 /-45]$ degree angles, the ply stiffness and strength are much more like the matrix properties than the fiber properties, whereas, at $0^{\circ}$ in the fiber direction, the properties are fiber dominated (Ref. 8). The number of ply shapes or designs was reduced to 8 in the final analysis from the initial 10, as shown in the last row of Table 16. A comparison of the initial and final ply lay-up shapes is provided in the next section.

\subsection{Comparison of Initial and Final Ply Build-Up Shapes}

The blade was designed initially with 10 ply lay-up shapes, as shown in Figures 17 to 19. The final optimization process with the NEWSUMT optimum design reduced the 10 ply lay-up shapes to 8 , as shown in Table 16 and Figures 33 to 38. A side-by-side comparison of the initial ply shape and final ply shape, shown in these figures as follows:

- The optimum design of ply shape 3 , includes the four additional plies in design group 7 , as shown in Figure 33.

- The optimum ply shape 4 includes the four additional plies for design group 8, shown in Figure 34.

- Optimum ply shape 5 includes the four additional plies for design group 9, shown in Figure 35.

- Optimum ply shape 6 includes the four additional plies for design group 10, shown in Figure 36.

- Optimum ply shape 7 includes ten additional plies for design group 11, shown in Figure 37.

- New ply shape 8 includes the eight-zero degree angles [0/0/0/0/0/0/0/0] for design group 11, shown in Figure 38 . 
The initial ply shape layups $(8,9$, and 10$)$ of design groups $(13,14$, and 15$)$ were eliminated from the final optimization, as shown crossed off in red in Table 16.

TABLE 16.-FINAL ANALYSIS (F) SYMMETRIC PLY LAYUP FROM NEWSUMT DESIGN, AND COMPARISON WITH INITIAL (I), CORE PLY DENOTED WITH AN ASTERISK*

\begin{tabular}{|c|c|}
\hline Group number & Optimum Ply Layup with NEWSUMT Optimizer \\
\hline $1(\mathrm{I})$ & {$[0 / 90]_{\mathrm{s}}$} \\
\hline $1(\mathrm{~F})$ & {$[0 / 90]_{\mathrm{s}}$} \\
\hline $2(\mathrm{I})$ & {$[0 / 90 / 45 /-45]_{\mathrm{s}}$} \\
\hline $2(\mathrm{~F})$ & {$[0 / 90 / 45 /-45]_{\mathrm{s}}$} \\
\hline 3 (I) & {$[0 / 90 / 45 /-45 / 90 / 0]_{\mathrm{s}}$} \\
\hline $3(\mathrm{~F})$ & {$[0 / 90 / 45 /-45 / 90 / 0]_{\mathrm{s}}$} \\
\hline $4(\mathrm{I})$ & {$[0 / 90 / 45 /-45 / 90 / 0 /-45 / 45]_{\mathrm{s}}$} \\
\hline $4(\mathrm{~F})$ & {$[0 / 90 / 45 /-45 / 90 / 0 /-45 / 45]_{\mathrm{s}}$} \\
\hline 5 (I) & {$[0 / 90 / 45 /-45 / 90 / 0 /-45 / 45 / 0 / 90]_{\mathrm{s}}$} \\
\hline $5(\mathrm{~F})$ & {$[0 / 90 / 45 /-45 / 90 / 0 /-45 / 45 / 0 / 90]_{\mathrm{s}}$} \\
\hline $6(\mathrm{I})$ & {$[0 / 90 / 45 /-45 / 90 / 0 /-45 / 45 / 0 / 90 / 45 /-45]_{\mathrm{s}}$} \\
\hline $6(\mathrm{~F})$ & {$[0 / 90 / 45 /-45 / 90 / 0 /-45 / 45 / 0 / 90 / 45 /-45]_{\mathrm{s}}$} \\
\hline 7 (I) & {$[0 / 90 / 45 /-45 / *]_{\mathrm{s}}$} \\
\hline $7(\mathrm{~F})$ & {$[0 / 90 / 45 /-45 / 90 / 0 / *]_{\mathrm{s}}$} \\
\hline 8 (I) & {$[0 / 90 / 45 /-45 / 90 / 0 / *]_{\mathrm{s}}$} \\
\hline $8(\mathrm{~F})$ & {$[0 / 90 / 45 /-45 / 90 / 0 /-45 / 45 / *]_{\mathrm{s}}$} \\
\hline 9 (I) & {$[0 / 90 / 45 /-45 / 90 / 0 /-45 / 45 / *]_{\mathrm{s}}$} \\
\hline $9(\mathrm{~F})$ & {$[0 / 90 / 45 /-45 / 90 / 0 /-45 / 45 / 0 / 90 / *]_{\mathrm{s}}$} \\
\hline $10(\mathrm{I})$ & {$[0 / 90 / 45 /-45 / 90 / 0 /-45 / 45 / 0 / 90 / *]_{\mathrm{s}}$} \\
\hline $10(\mathrm{~F})$ & {$[0 / 90 / 45 /-45 / 90 / 0 /-45 / 45 / 0 / 90 / 45 /-45 / *]_{\mathrm{s}}$} \\
\hline $11(\mathrm{I})$ & {$[0 / 90 / 45 /-45 / 90 / 0 /-45 / 45 / 0 / 90 / 45 /-45 / *]_{\mathrm{s}}$} \\
\hline $11(\mathrm{~F})$ & {$[0 / 90 / 45 /-45 / 90 / 0 /-45 / 45 / 0 / 90 / 45 /-45 / 90 / 0 / 0 / 0 / 0 / 0 / 0 / 0 / 0 / 0 *]_{\mathrm{s}}$} \\
\hline $12(\mathrm{I})$ & {$[0 / 90 / 45 /-45 / 90 / 0 /-45 / 45 / 0 / 90 / 45 /-45 / 90 / 0 / *]_{\mathrm{s}}$} \\
\hline $12(\mathrm{~F})$ & {$[0 / 90 / 45 /-45 / 90 / 0 /-45 / 45 / 0 / 90 / 45 /-45 / 90 / 0 / *]_{\mathrm{s}}$} \\
\hline $13(\mathrm{I})$ & {$[0 / 90 / 45 /-45 / 90 / 0 /-45 / 45 / 0 / 90 / 45 /-45 / 90 / 0 /-45 / 45 * *]_{\mathrm{s}}$} \\
\hline $13(\mathrm{~F})$ & {$[0 / 90 / 45 /-45 / 90 / 0 /-45 / 45 / 0 / 90 / 45 /-45 / 90 / 0 / *]_{\mathrm{s}}$} \\
\hline 14 (I) & {$[0 / 90 / 45 /-45 / 90 / 0 /-45 / 45 / 0 / 90 / 45 /-45 / 90 / 0 /-45 / 45 / 0 / 90 / *]_{\mathrm{s}}$} \\
\hline $14(\mathrm{~F})$ & {$[0 / 90 / 45 /-45 / 90 / 0 /-45 / 45 / 0 / 90 / 45 /-45 / 90 / 0 / *]_{\mathrm{s}}$} \\
\hline 15 (I) & {$[0 / 90 / 45 /-45 / 90 / 0 /-45 / 45 / 0 / 90 / 45 /-45 / 90 / 0 /-45 / 45 / 0 / 90 / 45 /=45 / *]_{\mathrm{s}}$} \\
\hline $15(\mathrm{~F})$ & {$[0 / 90 / 45 /-45 / 90 / 0 /-45 / 45 / 0 / 90 / 45 /-45 / 90 / 0 / *]_{\mathrm{s}}$} \\
\hline Ply shapes: & $\begin{array}{lllllll}1 & 2 & 3 & 4 & 5 & 6 & 7\end{array}$ \\
\hline
\end{tabular}




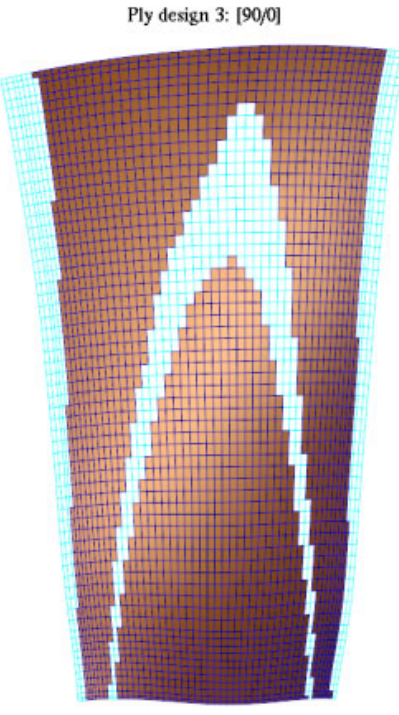

(a) Initial ply shape 3 : [90/0]

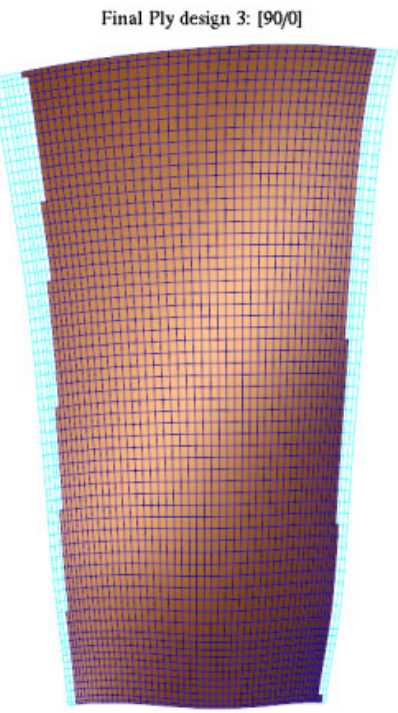

(b) Final ply shape 3: [90/0]

Figure 33.-Comparison of ply shapes: (a) initial ply shape 3, (b) final ply shape 3.

Ply design 4: [-45/45]

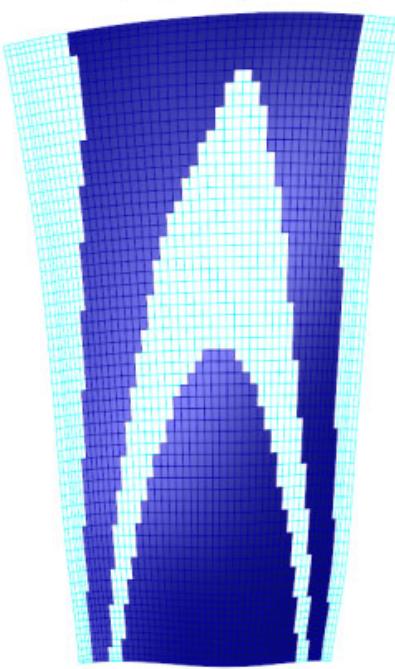

(a) Initial ply design 4: [-45/45]
Final Ply design 4: [-45/45]

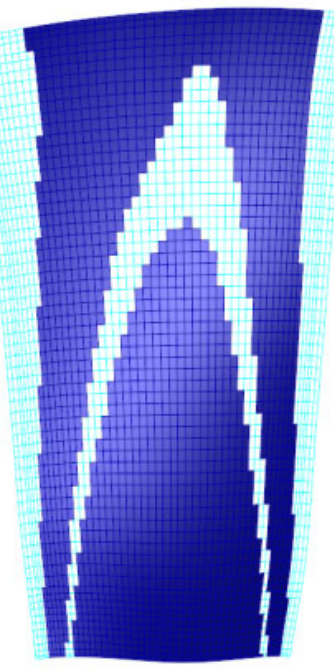

(b) Final ply design 4: [-45/45]

Figure 34.-Comparison of ply shapes: (a) initial ply shape 4, (b) final ply shape 4. 


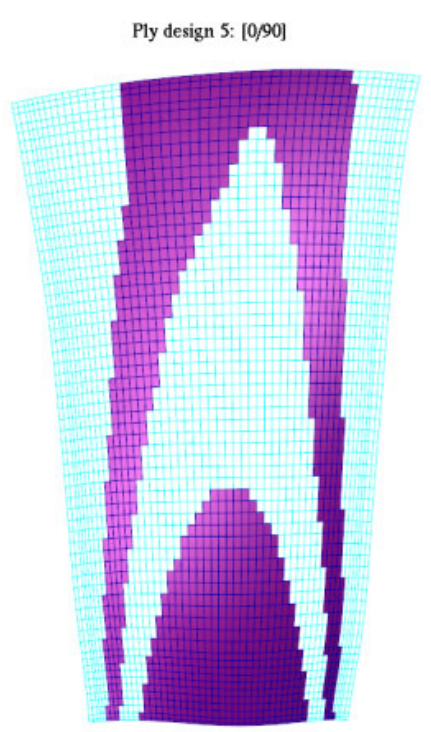

(a) Initial ply design 5 : [0/90]

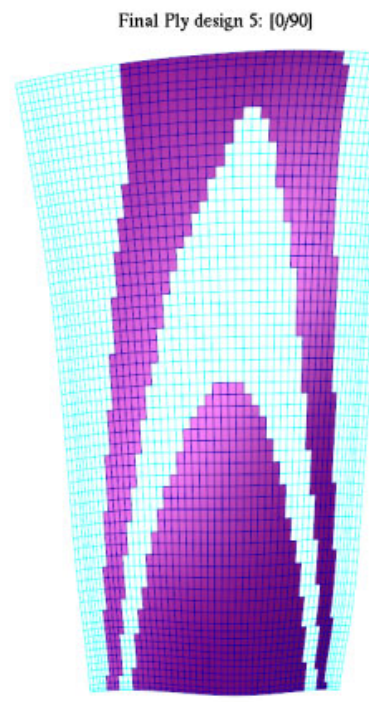

(b) Final ply design 5 : [0/90]

Figure 35.-Comparison of ply shapes: (a) initial ply shape 5 , (b) final ply shape 5.

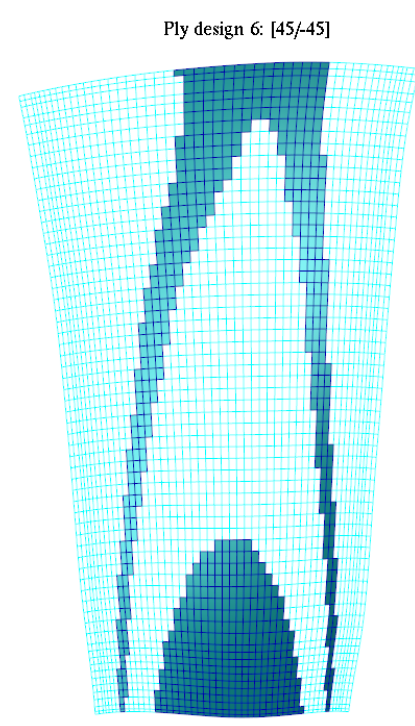

(a) Initial ply design 6: [45/-45]

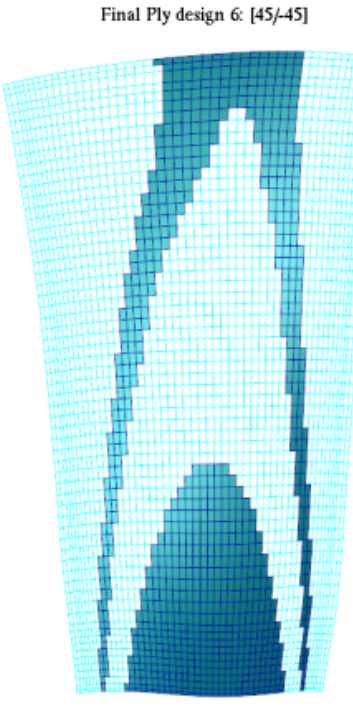

(b) Final ply design 6 : [45/-45]

Figure 36.-Comparison of ply shapes: (a) initial ply shape 6, (b) final ply shape 6 . 


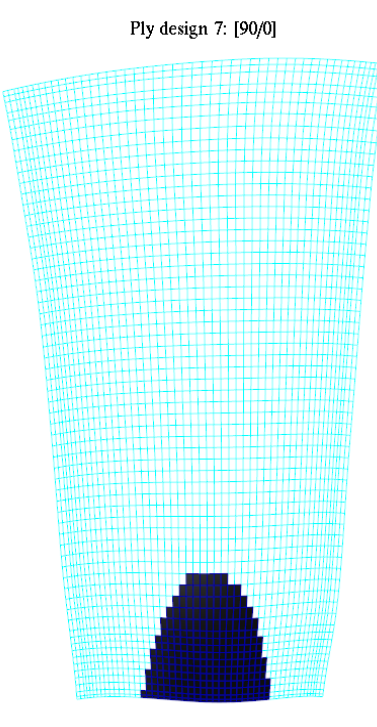

(a) Initial ply design 7 : [90/0]

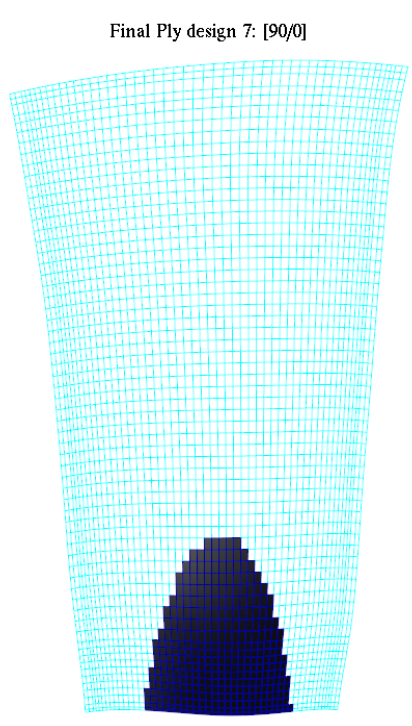

(b) Final ply design 7 : [90/0]

Figure 37.-Comparison of ply shapes: (a) initial ply shape 7, (b) final ply shape 7.

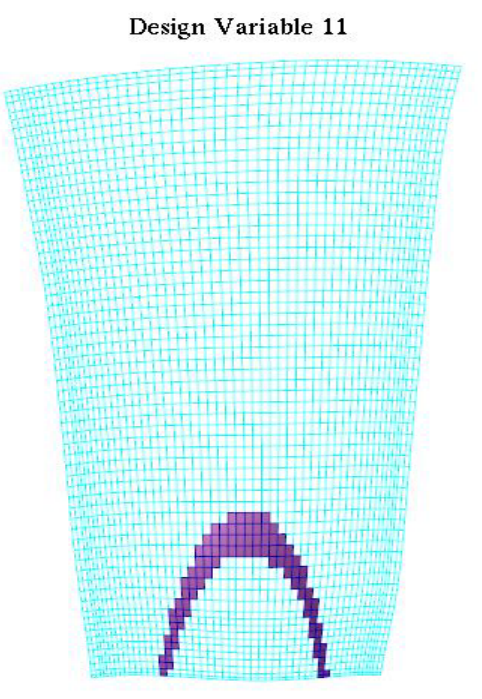

Ply shape 8 : [0/0/0/0/0/0/0/0]

Figure 38.-New ply shape 8. 


\subsection{Final Static Analysis Results}

A final static analysis was executed of the updated MSC/Nastran database and the results are shown in Table 18. Comparing with the initial design the final weight was increased from 25.56 to $27.94 \mathrm{lb}$ with NEWSUMT and to $27.84 \mathrm{lb}$ with NLPQ. The initial design was not feasible because at least one strength ratio constraint did not meet the design criteria, as shown in Table 10. The maximum principal stress and maximum shear stress results with percent differences are given in Table 17. Both maximum principal stress and max shear stresses were reduced in the final analysis by both NESUMT and NLPQ optimum designs. The percent difference for NEWSUMT was 8 percent for maximum principal stress and 9.22 percent for maximum shear stress. The differences for NLPQ were 9.78 percent reduction and 10.98 percent for maximum principal stress and maximum shear stress, respectively. The displacement magnitude was reduced in the final analysis, 10.55 percent by the NEWSUMT design and 8.57 percent by the NLPQ design. The final stress and deformation plots are depicted in Figures 39 and 40.

Radial tip displacements were also reduced by both optimizers at tip nodes 3225 and 3276, as shown in Table 18. The percent reduction was 10.5 percent with NEWSUMT for both tip nodes and about 9 percent with NLPQ.

Final analysis results of strength ratio and comparison with the initial ratios is shown in Table 19. Percent difference with NEWSUM ranged from 2.6 percent reduction to 43.2 percent increase. The final analysis from the NEWSUMT optimum design shows all strength ratio values to be in the feasible domain, i.e., greater than or equal to 1.5 and less than, or equal to 3.0, which account for the safety factor. The final analysis using the NLPQ optimum design however produced a slightly infeasible constraint, namely constraint number 7. The strength ratio for constraint number 7, as shown in Table 19, was 1.387 for NLPQ which is less than the allowable of 1.5 but since the ratio is greater than 1.0, it passes the ply failure TSAI-WU test criteria. This non feasibility is because NLPQ failed to converge at the maximum allowable iterations.

Final analysis results for failure indices and strength ratio from both NEWSUMT and NLPQ optimum designs are depicted in Figure 41. The final sandwich composite blade analysis does not exhibit any ply failures since the maximum failure index is 0.479 , which is less than 1.0 , and the minimum strength ratio over all 15 design groups is greater than 1.60 which takes into account the minimum safety factor of 1.5 .

TABLE 17.-FINAL ANALYSIS STATIC ANALYSIS RESULTS AND COMPARISON WITH INITIAL DESIGN

\begin{tabular}{|l|c|c|c|c|c|}
\hline & $\begin{array}{c}\text { Initial } \\
\text { analysis }\end{array}$ & $\begin{array}{c}\text { Final analysis } \\
\text { NEWSUMT }\end{array}$ & $\begin{array}{c}\text { Final analysis } \\
\text { NLPQ }\end{array}$ & $\begin{array}{c}\text { Percent } \\
\text { difference } \\
\text { NEWSUMT }\end{array}$ & $\begin{array}{c}\text { Percent } \\
\text { difference } \\
\text { NLPQ }\end{array}$ \\
\hline Max principal stress, psi & 117,943 & $108,510.9$ & $106,406.4$ & -8.00 & -9.78 \\
\hline Max shear stress, psi & $59,768.47$ & $54,255.52$ & $53,205.51$ & -9.22 & -10.98 \\
\hline Displacement, resultant, in. & 9.38 & 8.39 & 8.51 & -10.55 & -9.28 \\
\hline Displacement, z-direction, in. & 1.4 & 1.26 & 1.28 & -10.00 & -8.57 \\
\hline Weight (lb) & 25.56 & 27.94 & 27.84 & 9.33 & 8.93 \\
\hline
\end{tabular}

TABLE 18.-FINAL ANALYSIS RESULTS OF RADIAL DISPLACEMENTS VALUES AND COMPARISON WITH INITIAL

\begin{tabular}{|l|c|c|c|c|c|}
\hline $\begin{array}{c}\text { Constraint number: } \\
\text { tip node }\end{array}$ & Initial & $\begin{array}{c}\text { Final } \\
\text { analysis } \\
\text { NEWSUMT }\end{array}$ & $\begin{array}{c}\text { Final } \\
\text { analysis } \\
\text { NLPQ }\end{array}$ & $\begin{array}{c}\text { Percent } \\
\text { difference } \\
\text { NEWSUMT }\end{array}$ & $\begin{array}{c}\text { Percent } \\
\text { difference } \\
\text { NLPQ }\end{array}$ \\
\hline $16: 3225$ & -0.374 & -0.334 & -0.341 & -10.569 & -8.97 \\
\hline $17: 3276$ & 0.549 & 0.491 & 0.498 & -10.589 & -9.30 \\
\hline
\end{tabular}




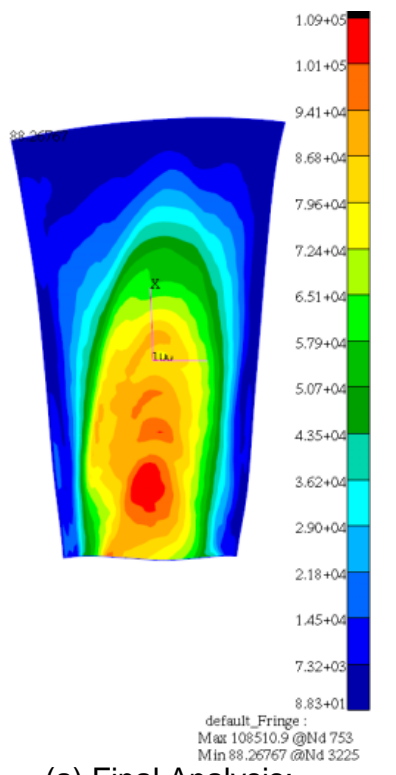

(a) Final Analysis:

Max Principal Stress $=108510$ psi

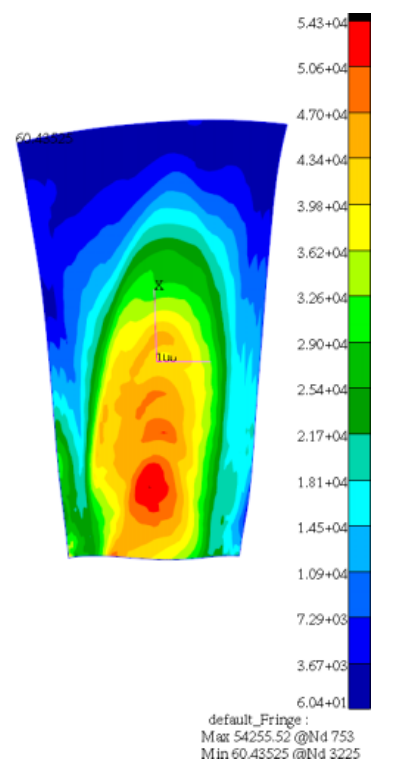

(b) Final Analysis:

Max Shear Stress $=54255$ psi

Figure 39.-Final analysis of the composite blade results (a) Maximum principal stress, (b) maximum shear stress.

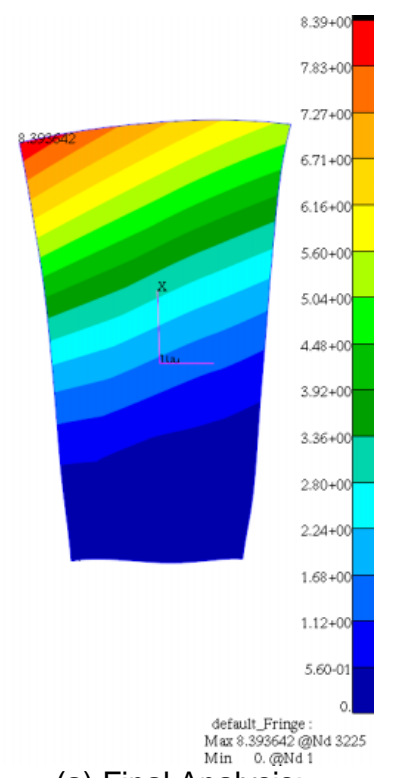

(a) Final Analysis:

Displacement resultant $=8.39$ in .

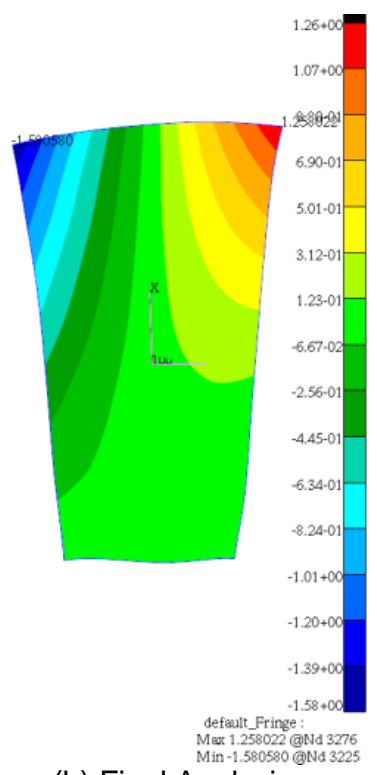

(b) Final Analysis:

Displacement z-direction $=1.26$ in .

Figure 40.-Final analysis of the composite blade results (a) Displacement resultant, (b) displacement in z-direction. 
TABLE 19.-FINAL ANALYSIS RESULTS OF STRENGTH RATIO

VALUES AND COMPARISON WITH INITIAL

\begin{tabular}{|c|c|c|c|c|c|}
\hline $\begin{array}{c}\text { Constraint } \\
\text { number }\end{array}$ & $\begin{array}{c}\text { Initial strength } \\
\text { ratio }\end{array}$ & $\begin{array}{c}\text { Final analysis } \\
\text { NEWSUMT }\end{array}$ & $\begin{array}{c}\text { Final analysis } \\
\text { NLPQ }\end{array}$ & $\begin{array}{c}\text { Percent } \\
\text { difference } \\
\text { NEWSUMT }\end{array}$ & $\begin{array}{c}\text { Percent } \\
\text { difference } \\
\text { NLPQ }\end{array}$ \\
\hline 1 & 1.356 & 1.943 & 1.589 & 43.257 & 17.17 \\
\hline 2 & 1.681 & 2.192 & 1.952 & 30.414 & 16.11 \\
\hline 3 & 1.780 & 2.386 & 2.011 & 34.062 & 12.98 \\
\hline 4 & 1.874 & 2.630 & 2.153 & 40.363 & 14.87 \\
\hline 5 & 1.821 & 2.816 & 2.055 & 54.662 & 12.83 \\
\hline 6 & 1.857 & 2.071 & 1.959 & 11.522 & 5.51 \\
\hline 7 & 1.216 & 1.528 & 1.387 & 25.676 & 14.08 \\
\hline 8 & 1.422 & 1.947 & 1.845 & 36.898 & 29.78 \\
\hline 9 & 1.572 & 1.902 & 1.814 & 21.004 & 15.37 \\
\hline 10 & 1.629 & 1.760 & 1.732 & 8.025 & 6.33 \\
\hline 11 & 1.621 & 1.504 & 1.821 & -7.242 & 12.32 \\
\hline 12 & 1.766 & 1.720 & 1.792 & -2.607 & 1.47 \\
\hline 13 & 1.904 & 1.819 & 1.829 & -4.468 & -3.94 \\
\hline 14 & 2.169 & 1.950 & 2.141 & -10.090 & -1.30 \\
\hline 15 & 2.400 & 2.073 & 2.069 & -13.623 & -13.80 \\
\hline
\end{tabular}

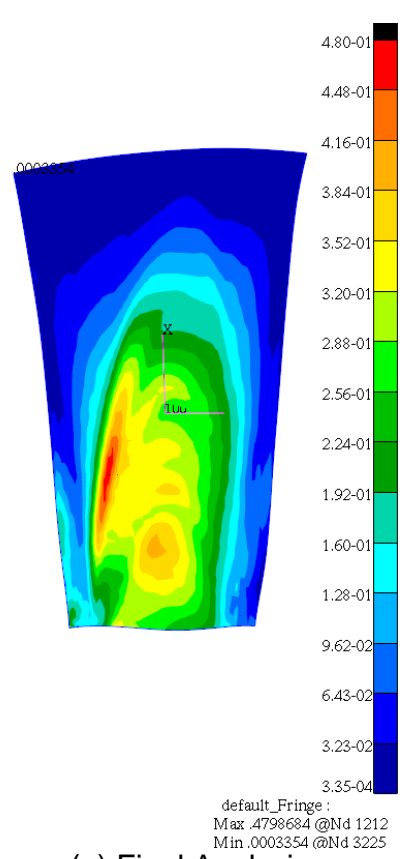

(a) Final Analysis:

Failure indices $(\mathrm{FI})<0.479$

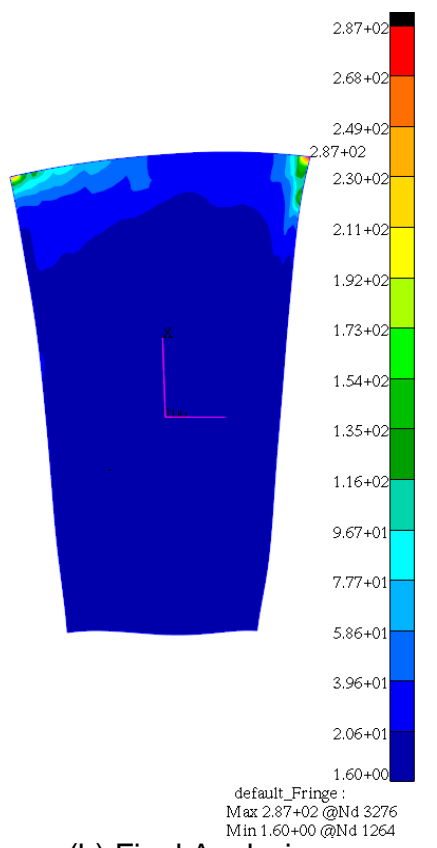

(b) Final Analysis:

Strength Ratio (SR) $>1.60$

Figure 41.-Final analysis: (a) Failure index and (b) strength ratio.

\subsection{Final Dynamic Analysis Results}

Dynamic analysis results of the final design of the sandwich composite blade were calculated using MSC/Nastran SOL 103 analysis solver. Results for the first six natural modes from the MSC/Nastran dynamic calculations and comparison with the initial frequency of the composite design are summarized in Table 20. Both optimizers produced slightly higher frequencies than the initial design, but this is expected since there was a small increase in the final weight.

Eigenvalue plots of the first six natural modes are depicted in Figures 42 and 43. As with the earlier mode shapes modes $\left(1^{\text {st }}, 2^{\text {nd }}, 4^{\text {th }}\right.$, and $6^{\text {th }}$ modes $)$ are bending modes and modes $\left(3^{\text {rd }}\right.$ and $\left.5^{\text {th }}\right)$ are torsion modes. 
TABLE 20.-COMPARISON OF NATURAL FREQUENCIES (HZ) FOR THE INITIAL

AND THE FINAL COMPOSITE BLADE

\begin{tabular}{|l|c|c|c|c|c|}
\hline Mode number & $\begin{array}{c}\text { Initial } \\
\text { frequency }\end{array}$ & $\begin{array}{c}\text { Final analysis } \\
\text { NEWSUMT }\end{array}$ & $\begin{array}{c}\text { Final analysis } \\
\text { NLPQ }\end{array}$ & $\begin{array}{c}\text { Percent } \\
\text { difference } \\
\text { NEWSUMT }\end{array}$ & $\begin{array}{c}\text { Percent } \\
\text { difference } \\
\text { NLPQ }\end{array}$ \\
\hline Mode 1 & 19.472 & 20.034 & 19.811 & 2.89 & 1.74 \\
\hline Mode 2 & 58.792 & 65.086 & 61.277 & 10.71 & 4.23 \\
\hline Mode 3 & 110.320 & 116.106 & 114.538 & 5.24 & 3.82 \\
\hline Mode 4 & 150.936 & 164.183 & 155.518 & 8.78 & 3.04 \\
\hline Mode 5 & 248.470 & 254.159 & 251.691 & 2.29 & 1.30 \\
\hline Mode 6 & 263.912 & 273.790 & 271.258 & 3.74 & 2.78 \\
\hline
\end{tabular}

Default, Mode 1:Freq. $=20.034$, Eigenvectors, Translationa Default, Mode 2:Freq. $=65.086$, Eigenvectors, Translational,

Default, Mode 3:Freq. $=116.11$, Eigenvectors, Translational

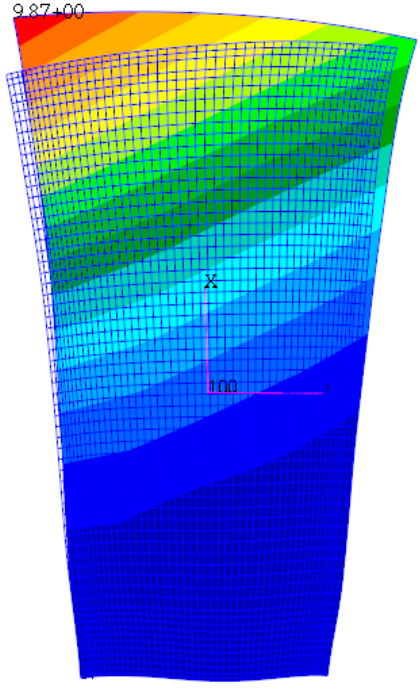

(a) Final Analysis

Mode 1: Frequency $=20.034 \mathrm{~Hz}$

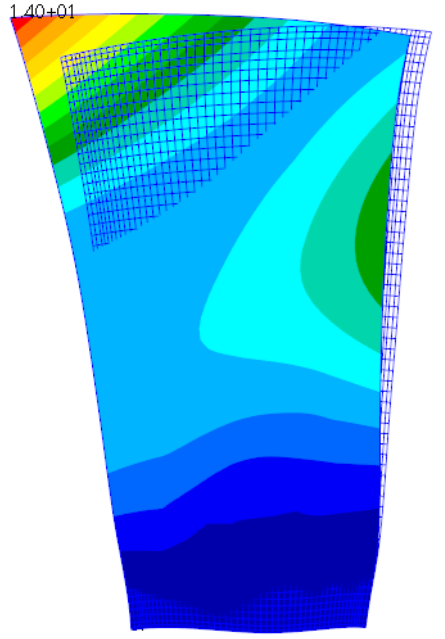

(b) Final Analysis

Mode 2: Frequency $=65.086 \mathrm{~Hz}$

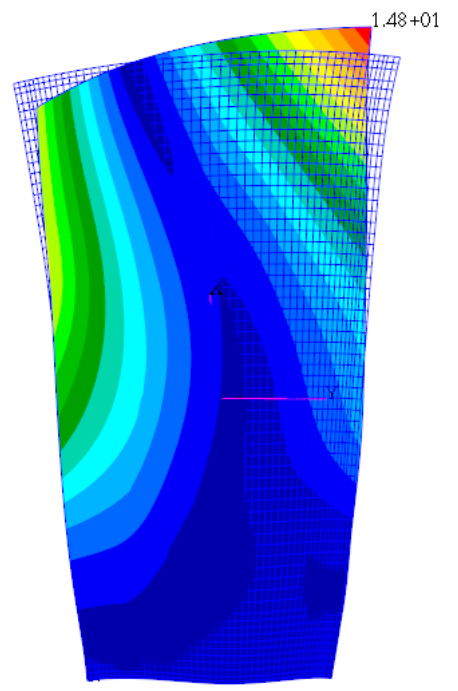

(c) Final Analysis

Figure 42.-Mode shapes for the final analysis of the composite blade (a) mode 1, (b) mode 2, (c) mode 3.

: Default, Mode 4:Freq.=164.18, Eigenvectors, Translational, Default, Mode 5:Freq.=254.16, Eigenvectors, Translational, Default, Mode 6:Freq. $=273.79$, Eigenvectors, Translational,

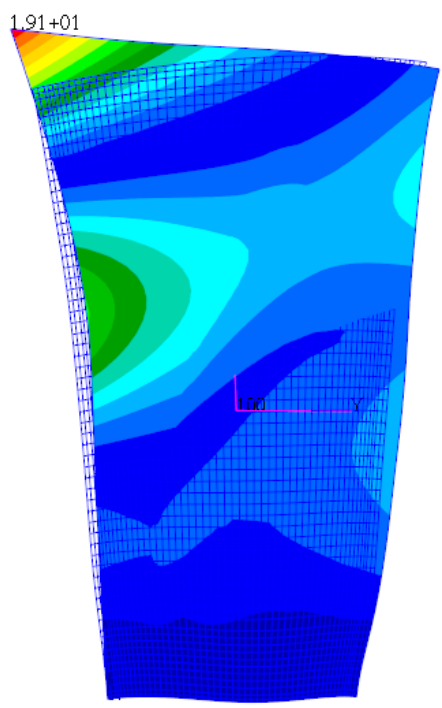

(a) Final Analysis

Mode 4: Frequency $=164.18 \mathrm{~Hz}$

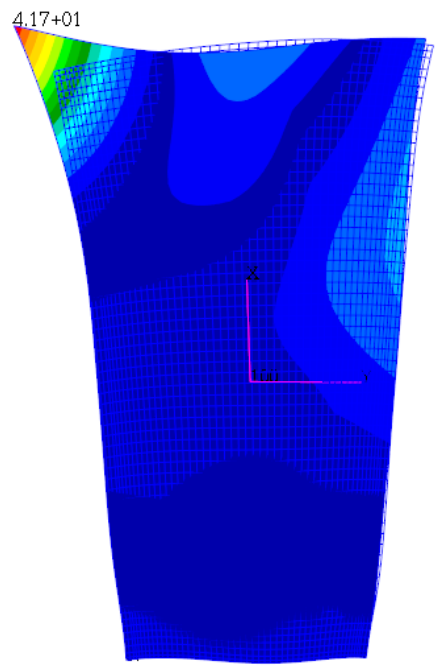

(b) Final Analysis Mode 5: Frequency $=254.16 \mathrm{~Hz}$

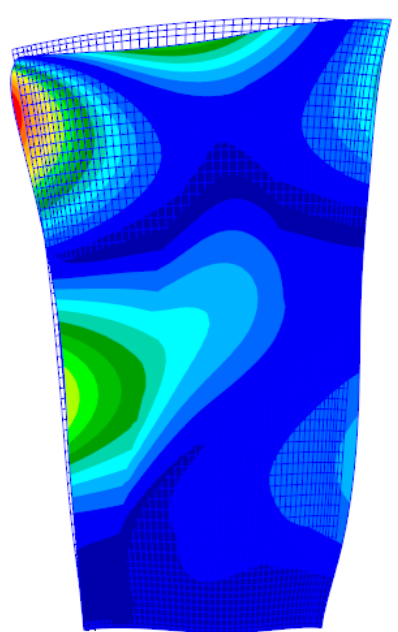

(c) Final Analysis Mode 6: Frequency $=273.79 \mathrm{~Hz}$

Figure 43.-Mode shapes for the final analysis of the composite blade (a) mode 4, (b) mode 5, (c) mode 6. 


\subsection{Conclusions}

An optimized design for a turbofan engine blade sized for a large aircraft engine was developed from a given baseline solid metallic model to a sandwich composite fan blade. The optimized composite blade design meets the aerodynamic and geometric considerations throughout the design process while the solution ensured that the final design was efficient and conformed to constraints imposed on radial displacement limitations and ply failure. The result was a lighter blade design, with mass savings of 72 percent compared to the metallic blade, when the combined pressure and centrifugal loads were considered. The maximum stresses and radial displacement for the final optimized composite blade were at much higher values than the metallic blade but still within their allowable limits. It was shown that the deformation behavior can be greatly influenced by the fiber orientation. It was also shown that the final design did not exhibit any ply failures considering an additional safety factor of 1.5 in the design process. Analyses and optimization was performed utilizing the OpenMDAO Framework, developed at NASA Glenn Research Center, which allows flexibility in case any modifications are required. The study performed in this paper highlights the continuing development of an optimization process for composite material lay-ups. Further research and development will continue, considering the application of an Integer programming algorithm to further refine the optimization process. Ply angle orientation may be optimized in addition to, or instead of, ply thickness depending on manufacturing considerations.

\section{References}

1. OpenMDAO Documentation, http://openmdao.org

2. MSC/NASTRAN 2005 Quick Reference Guide, Vol. 1 and 2, MacNeal-Schwendler Software Corporation, (2004).

3. Miura, H.; and Schmit, L.A., Jr.: NEWSUMT: A FORTRAN Program for Inequality Constrained Function Minimization, Users' Guide. NASA CR-159070, 1979.

4. Schittkowski, K.: NLPQL: A Fortran Subroutine for Solving Constrained Nonlinear Programming Problems. Annals of Operations Research, Vol. 5, 1986, pp. 485-500.

5. MSC/Patran 2010, MacNeal-Schwendler Software Corporation.

6. Christos C. Chamis, ASTM Committee D-30 on High Modulus Fibers and Their Composites, Test Methods and Design Allowables for Fibrous Composites, Issue 1003, 1989.

7. Patnaik, S.N, Pai S.S. and Coroneos R.M., Reliability-Based Design Optimization of a Composite Airframe Component, NASA/TM-2009-215501.

8. Jones, R.M. Mechanics of Composite Materials, $2^{\text {nd }}$ ed., 1999, ISBN: 1-56032-712-X. 


\begin{tabular}{|c|c|c|c|c|c|}
\hline \multicolumn{5}{|c|}{ REPORT DOCUMENTATION PAGE } & $\begin{array}{l}\text { Form Approved } \\
\text { OMB No. 0704-0188 }\end{array}$ \\
\hline \multicolumn{6}{|c|}{ 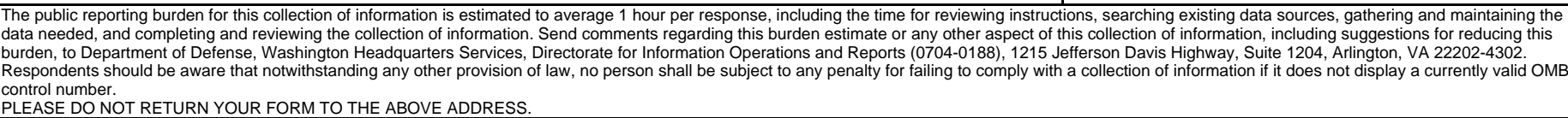 } \\
\hline \multicolumn{2}{|c|}{$\begin{array}{l}\text { 1. REPORT DATE (DD-MM-YYYY) } \\
01-08-2012\end{array}$} & \multicolumn{3}{|c|}{$\begin{array}{l}\text { 2. REPORT TYPE } \\
\text { Technical Memorandum }\end{array}$} & 3. DATES COVERED (From - To) \\
\hline \multirow{3}{*}{\multicolumn{5}{|c|}{$\begin{array}{l}\text { 4. TITLE AND SUBTITLE } \\
\text { Structural Analysis and Optimization of a Composite Fan Blade for Future Aircraft Engine }\end{array}$}} & 5a. CONTRACT NUMBER \\
\hline & & & & & 5b. GRANT NUMBER \\
\hline & & & & & 5c. PROGRAM ELEMENT NUMBER \\
\hline \multirow{3}{*}{\multicolumn{5}{|c|}{$\begin{array}{l}\text { 6. AUTHOR(S) } \\
\text { Coroneos, Rula, M. }\end{array}$}} & 5d. PROJECT NUMBER \\
\hline & & & & & 5e. TASK NUMBER \\
\hline & & & & & $\begin{array}{l}\text { 5f. WORK UNIT NUMBER } \\
\text { WBS 561581.02.08.03.42.01 }\end{array}$ \\
\hline \multicolumn{5}{|c|}{$\begin{array}{l}\text { 7. PERFORMING ORGANIZATION NAME(S) AND ADDRESS(ES) } \\
\text { National Aeronautics and Space Administration } \\
\text { John H. Glenn Research Center at Lewis Field } \\
\text { Cleveland, Ohio 44135-3191 }\end{array}$} & $\begin{array}{l}\text { 8. PERFORMING ORGANIZATION } \\
\text { REPORT NUMBER } \\
\text { E-18234 }\end{array}$ \\
\hline \multirow{2}{*}{\multicolumn{5}{|c|}{$\begin{array}{l}\text { 9. SPONSORING/MONITORING AGENCY NAME(S) AND ADDRESS(ES) } \\
\text { National Aeronautics and Space Administration } \\
\text { Washington, DC 20546-0001 }\end{array}$}} & $\begin{array}{l}\text { 10. SPONSORING/MONITOR'S } \\
\text { ACRONYM(S) } \\
\text { NASA }\end{array}$ \\
\hline & & & & & $\begin{array}{l}\text { 11. SPONSORING/MONITORING } \\
\text { REPORT NUMBER } \\
\text { NASA/TM-2012-217632 }\end{array}$ \\
\hline \multicolumn{6}{|c|}{$\begin{array}{l}\text { 12. DISTRIBUTION/AVAILABILITY STATEMENT } \\
\text { Unclassified-Unlimited } \\
\text { Subject Category: } 39 \\
\text { Available electronically at http://www.sti.nasa.gov } \\
\text { This publication is available from the NASA Center for AeroSpace Information, 443-757-5802 }\end{array}$} \\
\hline \multicolumn{6}{|c|}{ 13. SUPPLEMENTARY NOTES } \\
\hline \multicolumn{6}{|c|}{$\begin{array}{l}\text { 14. ABSTRACT } \\
\text { This report addresses the structural analysis and optimization of a composite fan blade sized for a large aircraft engine. An existing baseline } \\
\text { solid metallic fan blade was used as a starting point to develop a hybrid honeycomb sandwich construction with a polymer matrix composite } \\
\text { face sheet and honeycomb aluminum core replacing the original baseline solid metallic fan model made of titanium. The focus of this work } \\
\text { is to design the sandwich composite blade with the optimum number of plies for the face sheet that will withstand the combined pressure } \\
\text { and centrifugal loads while the constraints are satisfied and the baseline aerodynamic and geometric parameters are maintained. To satisfy } \\
\text { the requirements, a sandwich construction for the blade is proposed with composite face sheets and a weak core made of honeycomb } \\
\text { aluminum material. For aerodynamic considerations, the thickness of the core is optimized whereas the overall blade thickness is held fixed } \\
\text { so as to not alter the original airfoil geometry. Weight is taken as the objective function to be minimized by varying the core thickness of the } \\
\text { blade within specified upper and lower bounds. Constraints are imposed on radial displacement limitations and ply failure strength. From } \\
\text { the optimum design, the minimum number of plies, which will not fail, is back-calculated. The ply lay-up of the blade is adjusted from the } \\
\text { calculated number of plies and final structural analysis is performed. Analyses were carried out by utilizing the OpenMDAO Framework, } \\
\text { developed at NASA Glenn Research Center combining optimization with structural assessment. }\end{array}$} \\
\hline \multicolumn{6}{|c|}{$\begin{array}{l}\text { 15. SUBJECT TERMS } \\
\text { Composite; Ply failure; Nonlinear optimization; Static analysis; Dynamic analysis }\end{array}$} \\
\hline \multicolumn{3}{|c|}{ 16. SECURITY CLASSIFICATION OF: } & $\begin{array}{l}\text { 17. LIMITATION OF } \\
\text { ABSTRACT }\end{array}$ & $\begin{array}{l}\text { 18. NUMBER } \\
\text { OF }\end{array}$ & $\begin{array}{l}\text { 19a. NAME OF RESPONSIBLE PERSON } \\
\text { STI Help Desk (email:help@sti.nasa.gov) }\end{array}$ \\
\hline $\begin{array}{l}\text { a. REPORT } \\
\text { U }\end{array}$ & $\begin{array}{l}\text { b. ABSTRACT } \\
\text { U }\end{array}$ & $\begin{array}{l}\text { c. THIS } \\
\text { PAGE } \\
\text { U }\end{array}$ & UU & $\begin{array}{l}\text { PAGES } \\
50\end{array}$ & $\begin{array}{l}\text { 19b. TELEPHONE NUMBER (include area code) } \\
443-757-5802\end{array}$ \\
\hline
\end{tabular}


